\title{
User's Manual for the Data Analysis System for Monitoring the Fuel Oil Spill at the Sandia National Laboratories Installation in Livermore, California
}

Decision and Information Sciences Division

Argonne National Laboratory

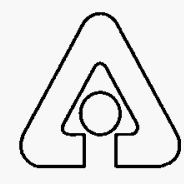

Operated by The University of Chicago, under Contract W-31-109-Eng-38, for the United States Department of Energy 


\section{User's Manual for the Data Analysis System for Monitoring the Fuel Oil Spill at the Sandia National Laboratories Installation in Livermore, California}

by M.A. Widing and C.C. Leser

Decision and Information Sciences Division

and Environmental Research Division

Argonne National Laboratory, 9700 South Cass Avenue, Argonne, Illinois 60439

April 1995

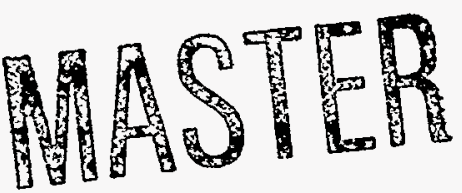

Work sponsored by Sandia National Laboratories, California 


\section{DISCLAIMER}

This report was prepared as an account of work sponsored by an agency of the United States Government. Neither the United States Government nor any agency thereof, nor any of their employees, make any warranty, express or implied, or assumes any legal liability or responsibility for the accuracy, completeness, or usefulness of any information, apparatus, product, or process disclosed, or represents that its use would not infringe privately owned rights. Reference herein to any specific commercial product, process, or service by trade name, trademark, manufacturer, or otherwise does not necessarily constitute or imply its endorsement, recommendation, or favoring by the United States Government or any agency thereof. The views and opinions of authors expressed herein do not necessarily state or reflect those of the United States Government or any agency thereof. 


\section{DISCLAIMER}

\section{Portions of this document may be illegible in electronic image products. Images are produced from the best available original document.}




\section{CONTENTS}

ABSTRACT $\ldots \ldots \ldots \ldots \ldots \ldots \ldots \ldots \ldots \ldots \ldots \ldots \ldots \ldots \ldots \ldots \ldots \ldots \ldots \ldots \ldots \ldots \ldots$

1 INTRODUCTION $\ldots \ldots \ldots \ldots \ldots \ldots \ldots \ldots \ldots \ldots \ldots \ldots \ldots \ldots \ldots \ldots \ldots \ldots \ldots$

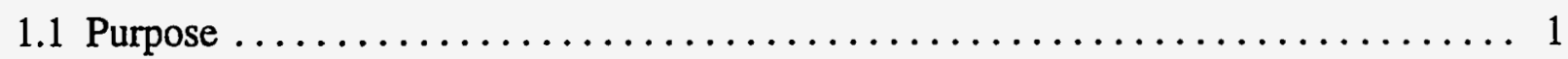

1.2 Overview of the Data Acquisition and Management System $\ldots \ldots \ldots \ldots \ldots \ldots \ldots$

1.3 Data Analysis Subsystem . . . . . . . . . . . . . . . . . . . . . . . . . 2

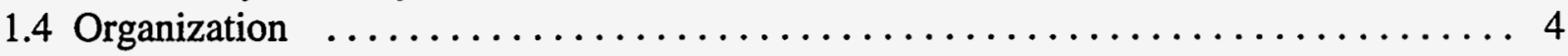

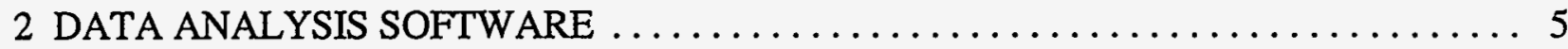

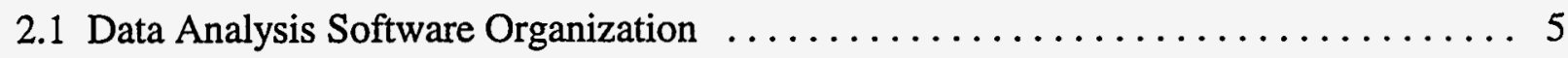

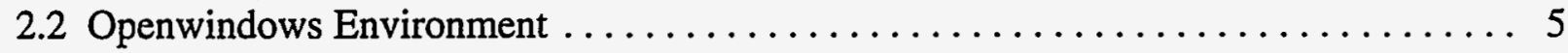

3 SENSOR DATA QUERY TOOL $\ldots \ldots \ldots \ldots \ldots \ldots \ldots \ldots \ldots \ldots \ldots \ldots \ldots \ldots \ldots$

3.1 Sensor Data Query Tool Overview $\ldots \ldots \ldots \ldots \ldots \ldots \ldots \ldots \ldots \ldots \ldots \ldots$

3.2 Query Tool Window $\ldots \ldots \ldots \ldots \ldots \ldots \ldots \ldots \ldots \ldots \ldots \ldots \ldots \ldots \ldots \ldots \ldots \ldots$

3.3 Data Directory Window $\ldots \ldots \ldots \ldots \ldots \ldots \ldots \ldots \ldots \ldots \ldots \ldots \ldots \ldots \ldots \ldots \ldots \ldots \ldots \ldots$

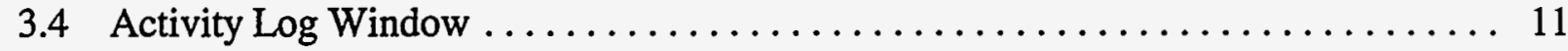

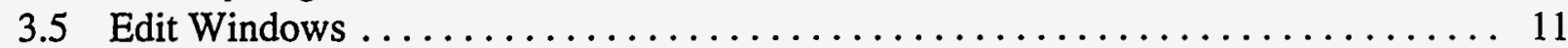

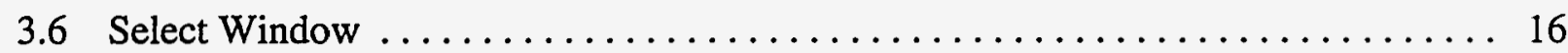

3.7 Temperature \& Pressure ASCII Output Window .................... 17

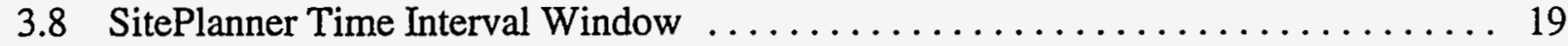

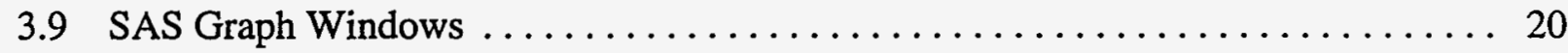

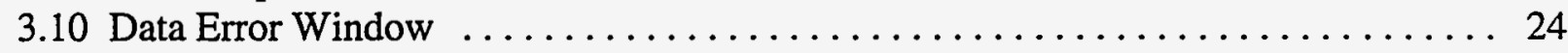

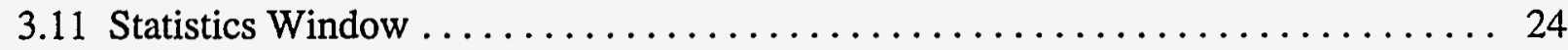

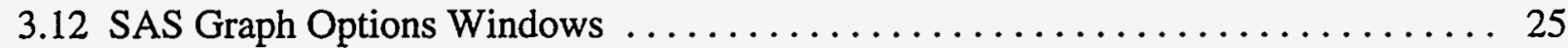

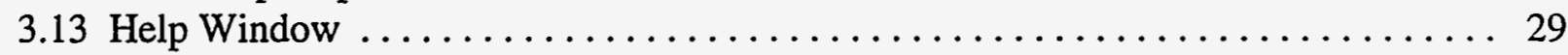

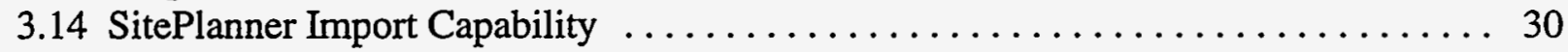

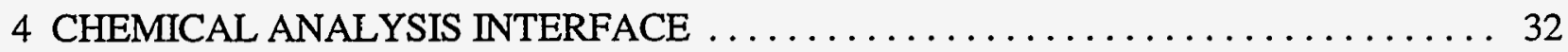

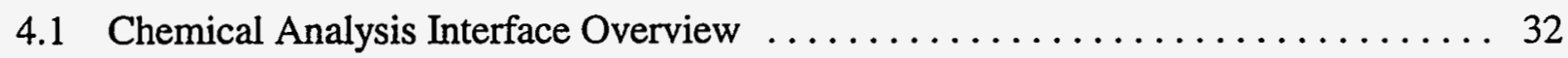

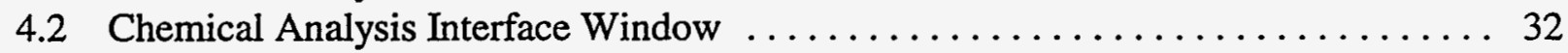

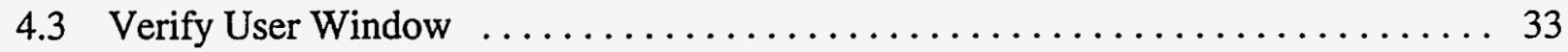

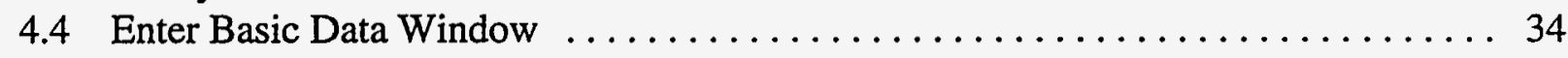

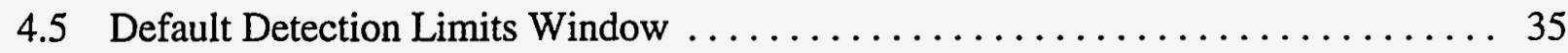

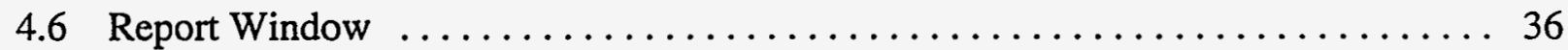

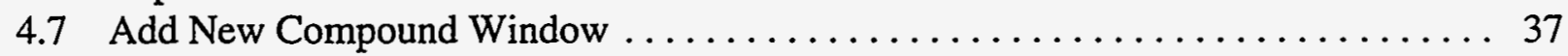

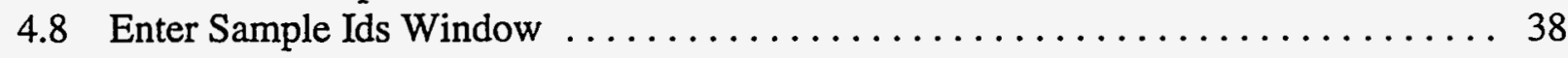

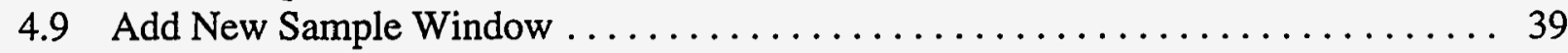

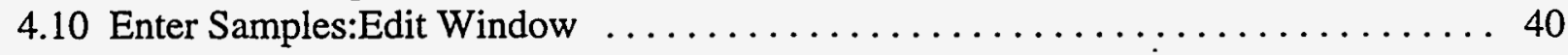




\section{CONTENTS (Cont.)}

\section{CHEMICAL ANALYSIS INTERFACE (.Cont.)}

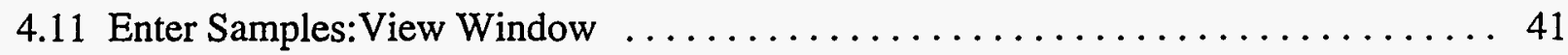

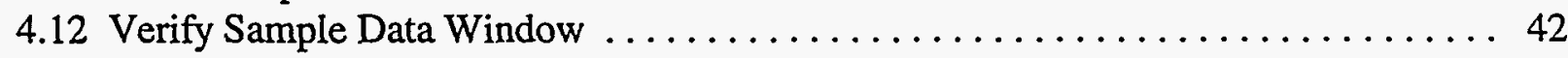

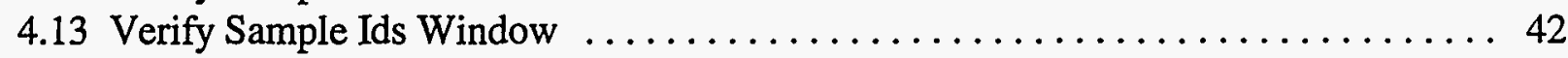

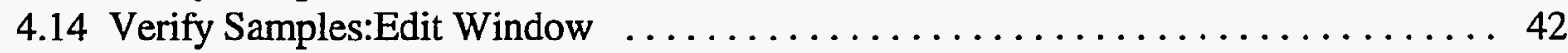

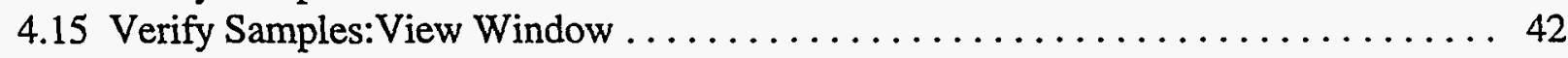

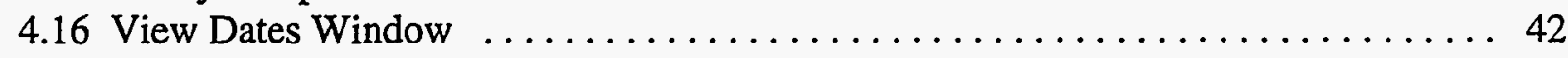

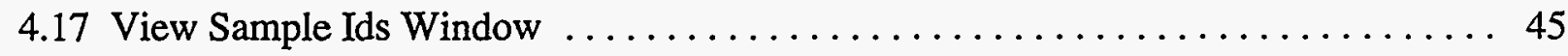

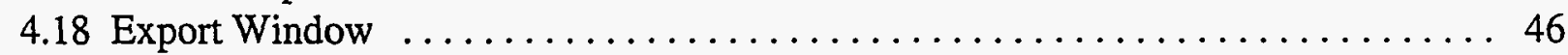

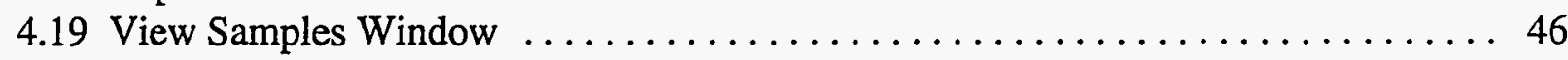

4.20 View One Sample on Multiple Dates Window $\ldots \ldots \ldots \ldots \ldots \ldots \ldots \ldots \ldots 47$

4.21 View Sample at Dates Window ............................. 48

4.22 View Multiple Samples on One Date Window $\ldots \ldots \ldots \ldots \ldots \ldots \ldots \ldots . \ldots \ldots$

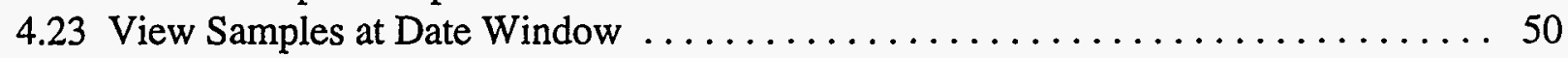

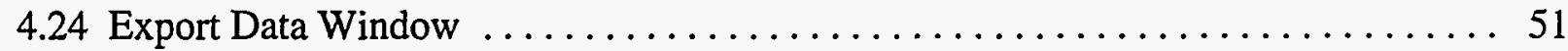

4.25 Sample Export Session ................................. 52

5 DATA DISTRIBUTION $\ldots \ldots \ldots \ldots \ldots \ldots \ldots \ldots \ldots \ldots \ldots \ldots \ldots \ldots \ldots \ldots \ldots \ldots \ldots \ldots \ldots$

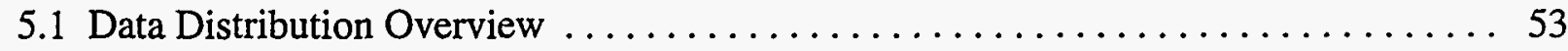

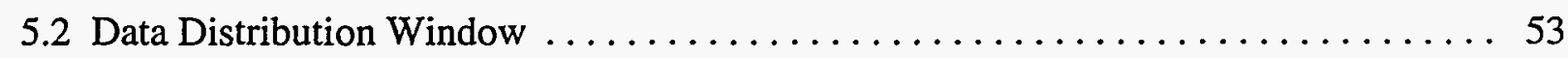

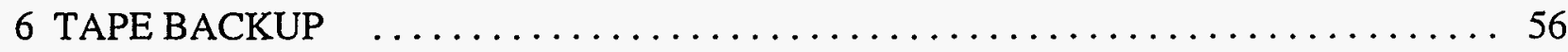

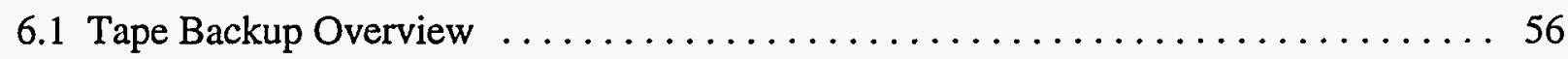

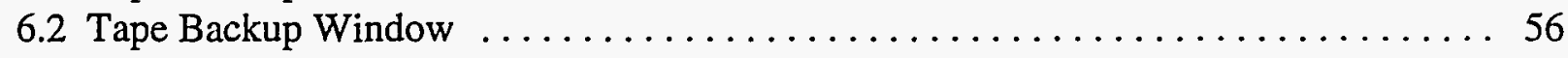

APPENDIX A: Chemical Compound List $\ldots \ldots \ldots \ldots \ldots \ldots \ldots \ldots \ldots \ldots \ldots$

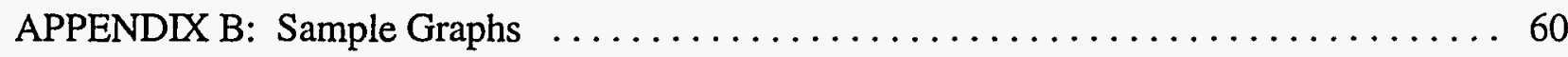

\section{TABLE}

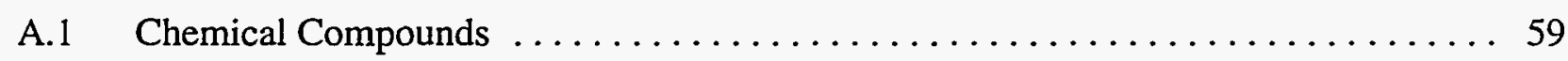




\section{FIGURES}

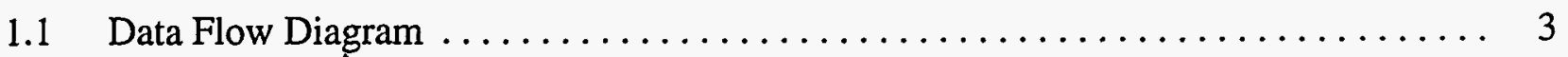

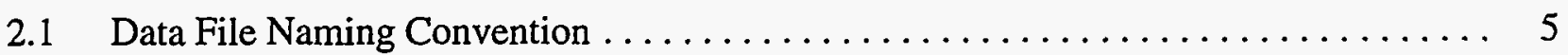

2.2 Sample Data Analysis Screen $\ldots \ldots \ldots \ldots \ldots \ldots \ldots \ldots \ldots \ldots \ldots \ldots \ldots \ldots$

3.1 Sensor Query Tool Main Window $\ldots \ldots \ldots \ldots \ldots \ldots \ldots \ldots \ldots \ldots \ldots$

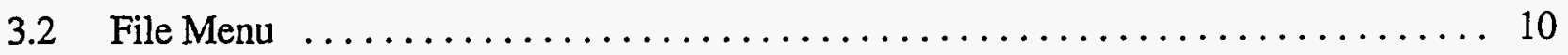

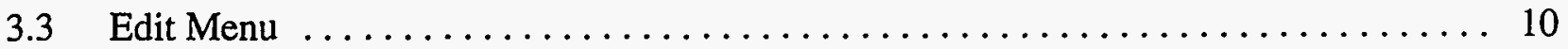

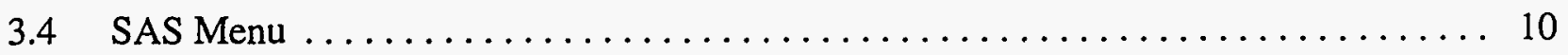

3.5 Data Directory Window $\ldots \ldots \ldots \ldots \ldots \ldots \ldots \ldots \ldots \ldots \ldots \ldots \ldots \ldots \ldots \ldots \ldots$

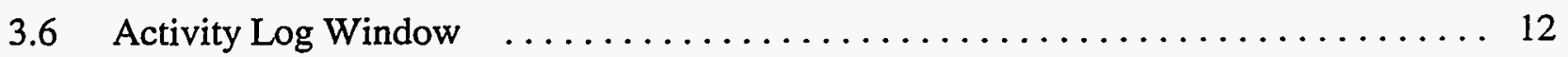

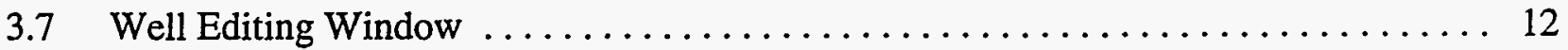

$3.8 \quad$ Station Editing Window $\ldots \ldots \ldots \ldots \ldots \ldots \ldots \ldots \ldots \ldots \ldots \ldots \ldots \ldots \ldots \ldots \ldots \ldots \ldots$

3.9 Temperature Editing Window $\ldots \ldots \ldots \ldots \ldots \ldots \ldots \ldots \ldots \ldots \ldots \ldots \ldots \ldots \ldots \ldots \ldots$

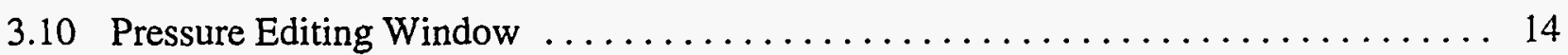

3.11 Tensiometer Editing Window $\ldots \ldots \ldots \ldots \ldots \ldots \ldots \ldots \ldots \ldots \ldots \ldots \ldots \ldots \ldots \ldots$

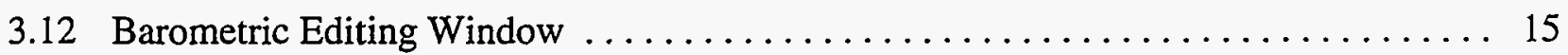

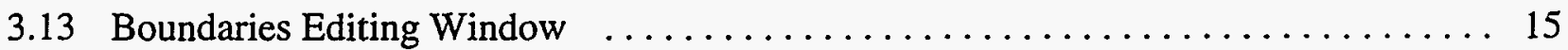

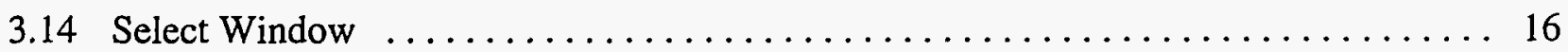

3.15 Temperature \& Pressure ASCII Output Window $\ldots \ldots \ldots \ldots \ldots \ldots \ldots \ldots . \ldots \ldots$

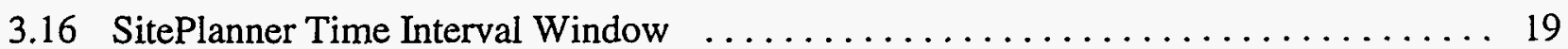

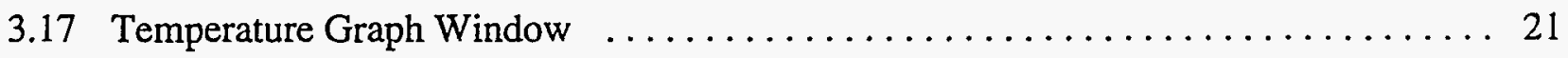

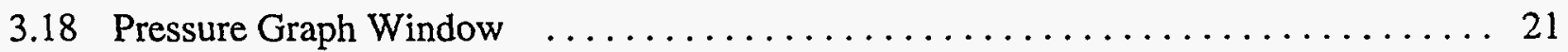

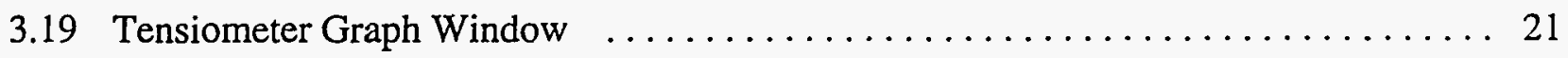




\section{FIGURES (Cont.)}

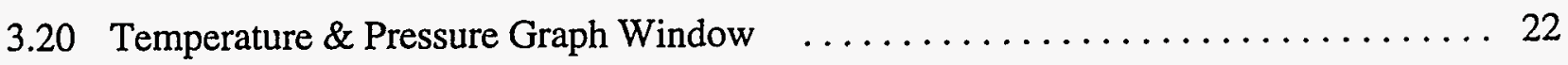

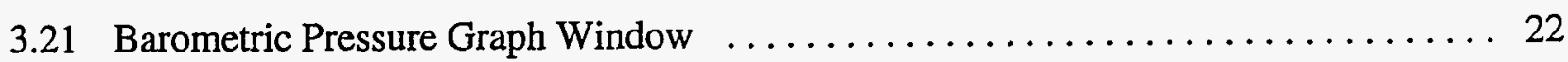

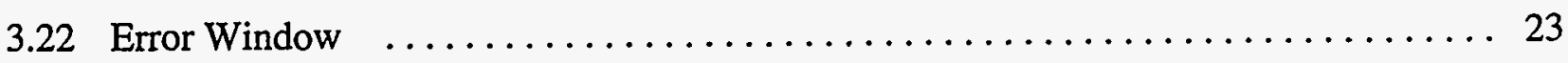

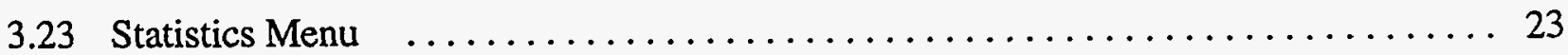

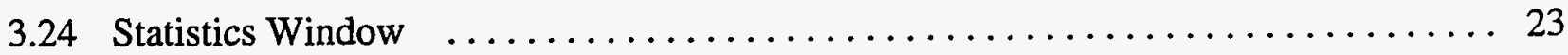

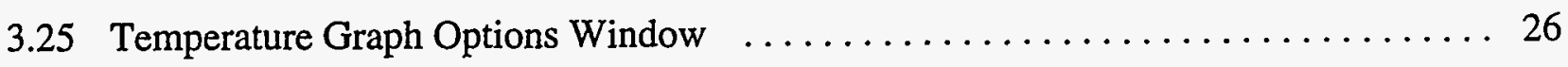

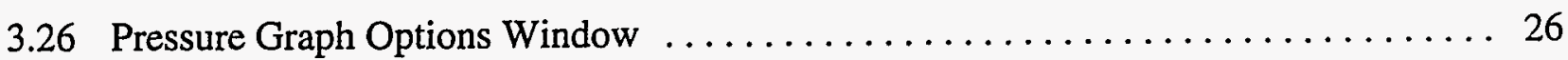

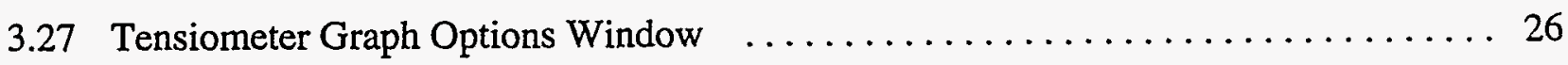

3.28 Temperature \& Pressure Graph Options Window $\ldots \ldots \ldots \ldots \ldots \ldots \ldots \ldots \ldots$

3.29 Barometric Pressure Graph Options Window $\ldots \ldots \ldots \ldots \ldots \ldots \ldots \ldots \ldots \ldots$

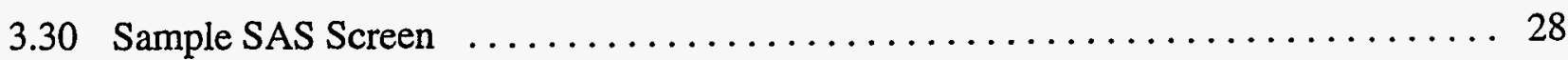

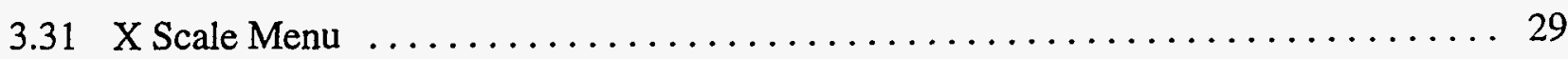

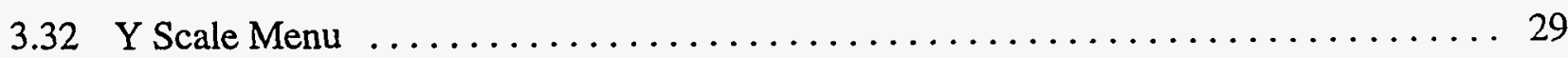

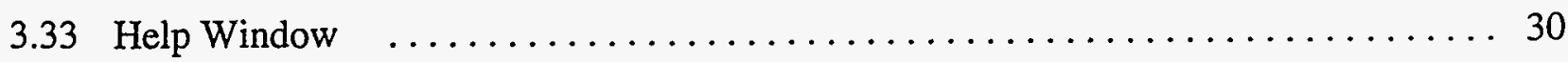

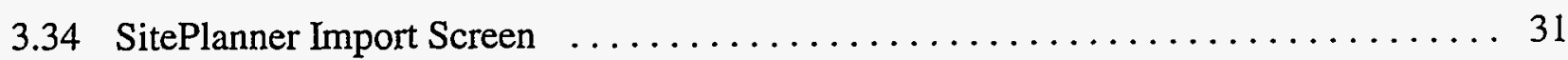

4.1 Chemical Analysis Interface Window $\ldots \ldots \ldots \ldots \ldots \ldots \ldots \ldots \ldots \ldots \ldots \ldots \ldots$

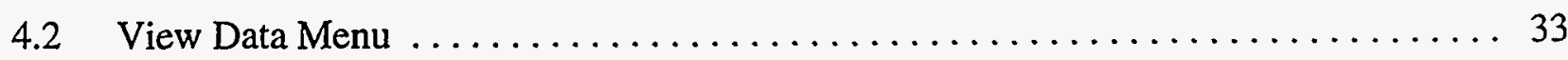

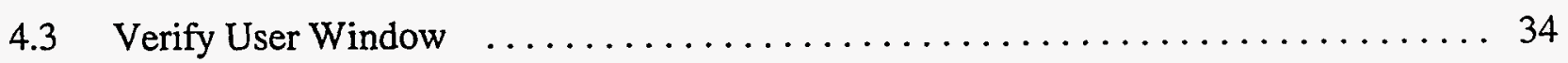

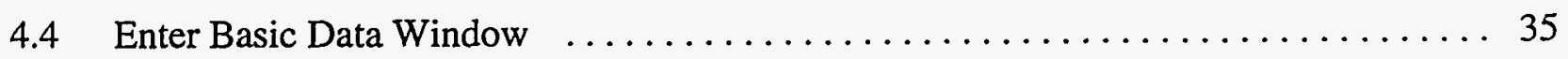

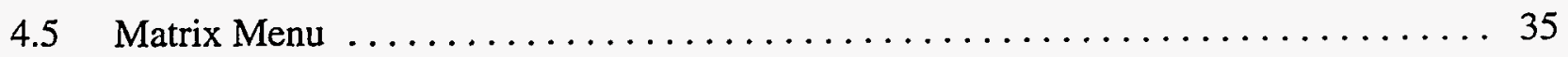




\section{FIGURES (Cont.)}

4.6 Default Detection Limits Window $\ldots \ldots \ldots \ldots \ldots \ldots \ldots \ldots \ldots \ldots \ldots \ldots \ldots \ldots \ldots \ldots \ldots \ldots$

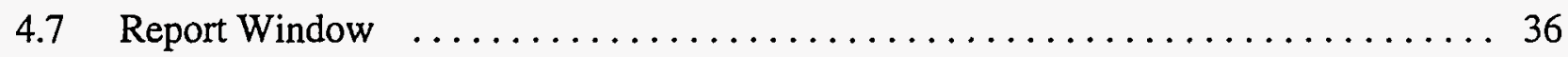

4.8 Add New Compound Window $\ldots \ldots \ldots \ldots \ldots \ldots \ldots \ldots \ldots \ldots \ldots \ldots \ldots \ldots \ldots \ldots \ldots \ldots \ldots$

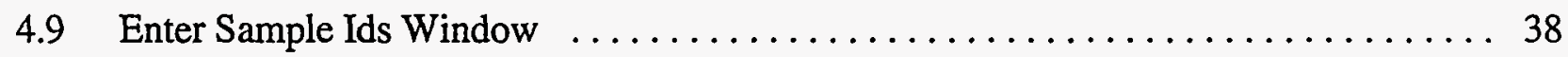

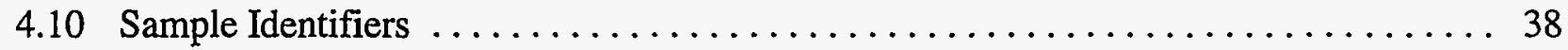

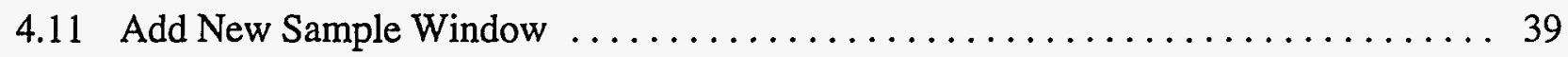

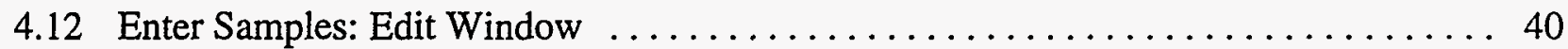

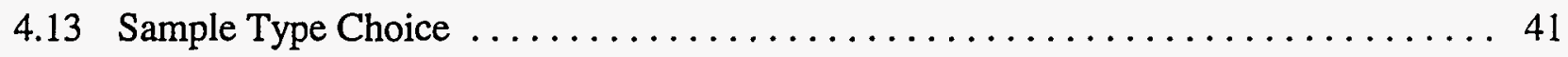

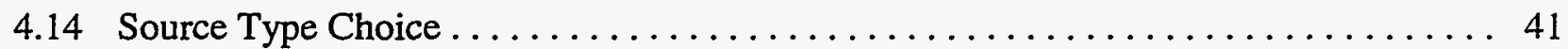

4.15 Enter Samples: View Window $\ldots \ldots \ldots \ldots \ldots \ldots \ldots \ldots \ldots \ldots \ldots \ldots \ldots \ldots \ldots \ldots \ldots \ldots$

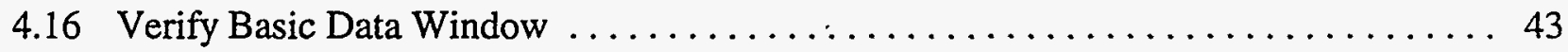

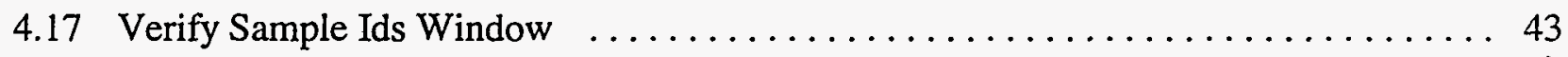

4.18 Verify Samples: Edit Window $\ldots \ldots \ldots \ldots \ldots \ldots \ldots \ldots \ldots \ldots \ldots \ldots \ldots \ldots \ldots \ldots \ldots \ldots$

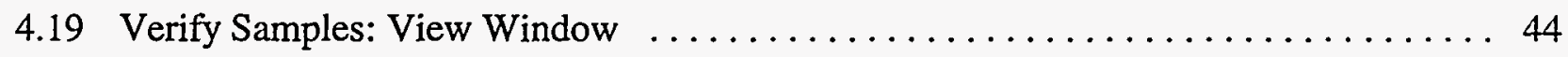

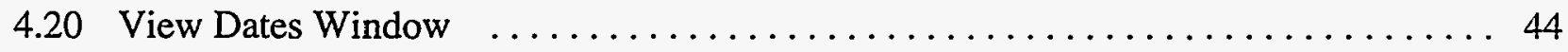

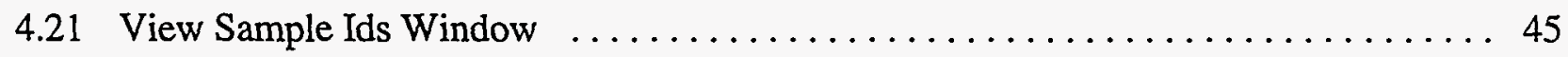

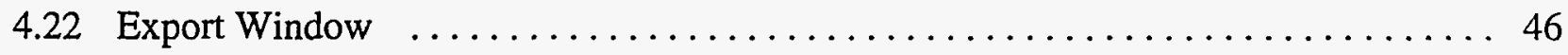

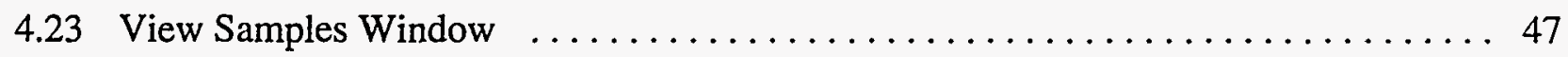

4.24 View One Sample on Multiple Dates Window $\ldots \ldots \ldots \ldots \ldots \ldots \ldots \ldots \ldots$

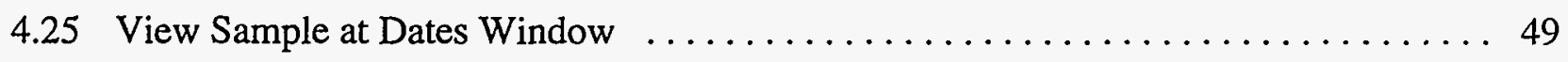




\section{FIGURES (Cont.)}

4.26 View Multiple Samples on One Date Window $\ldots \ldots \ldots \ldots \ldots \ldots \ldots \ldots$

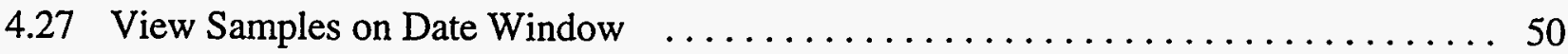

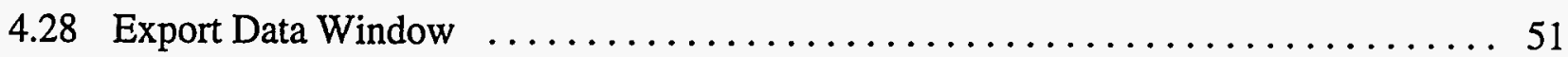

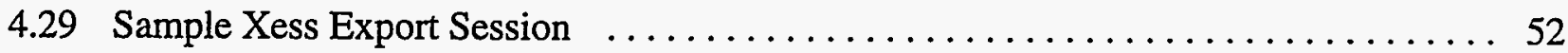

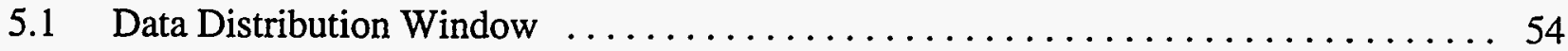

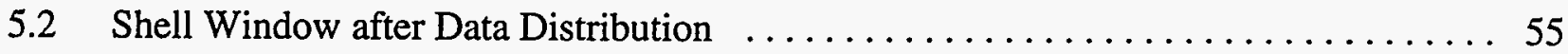

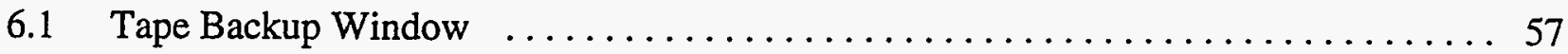

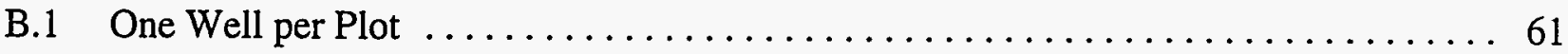

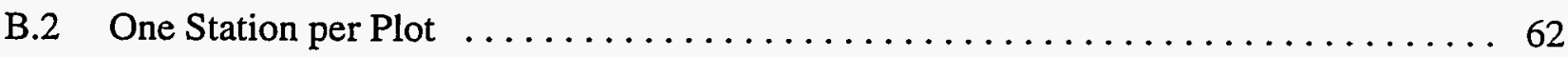

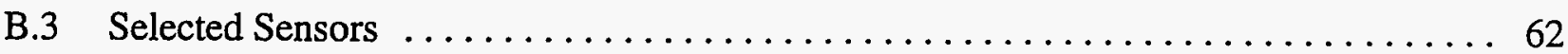

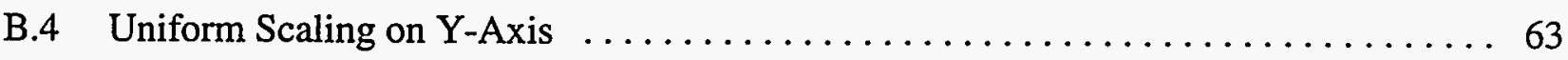

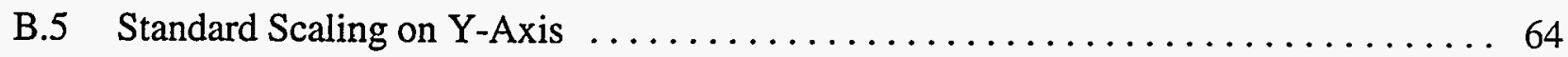

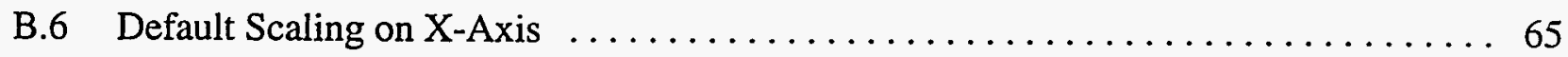

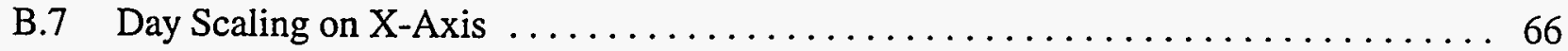

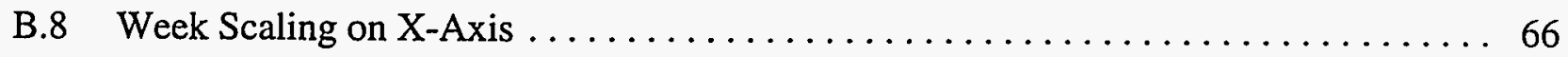

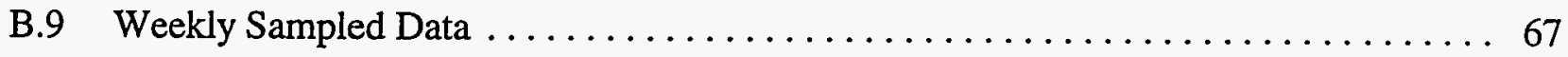

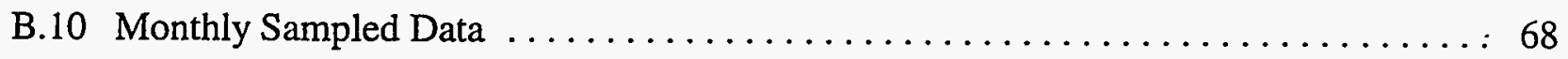

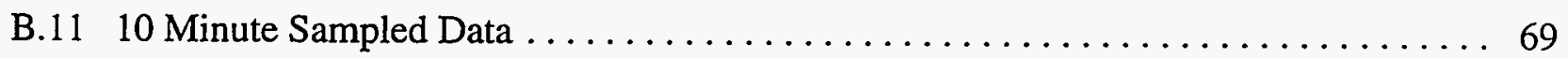

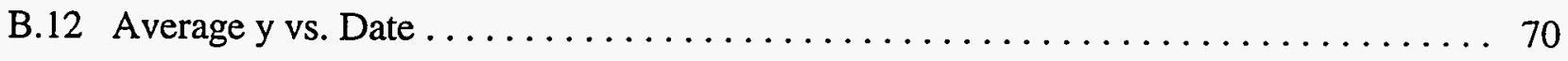




\title{
USER'S MANUAL FOR THE DATA ANALYSIS SYSTEM FOR MONITORING THE FUEL OIL SPILL AT THE SANDIA NATIONAL LABORATORIES INSTALLATION IN LIVERMORE, CALIFORNIA
}

\author{
by
}

M.A. Widing and C.C. Leser

\begin{abstract}
This report describes the use of the data analysis software developed by Argonne National Laboratory (ANL) and installed at the fuel oil spill site at Sandia National Laboratories. This software provides various programs for analyzing the data from physical and chemical sensors. This manual provides basic information on the design and use of these user interfaces. Analysts use these interfaces to evaluate the site data. Four software programs included in the data analysis software suite provide the following capabilities: physical data analysis, chemical data entry, chemical data analysis, and data management.
\end{abstract}

\section{INTRODUCTION}

\subsection{PURPOSE}

This manual describes the design and use of the data analysis system that assists analysts in entering and evaluating the physical and chemical data at the fuel oil spill site at the Sandia National Laboratories (SNL) installation in Livermore, California. It is intended to be used as a reference guide to the site coordinators at the SNL site. Specific problems not covered in this document or associated literature should be addressed to the computer support personnel at Argonne National Laboratory (ANL) for resolution.

\subsection{OVERVIEW OF THE DATA ACQUISITION AND MANAGEMENT SYSTEM}

As part of an ongoing bioremediation study, ANL developed a data acquisition and management system to support data collection and analysis from downhole sensors at a fuel oil spill site. The overall design, quality assurance practices, and testing procedures used in this effort are described in the following documents:

- Remedial Action Plan for the Fuel Oil Spill at Sandia National Laboratories, Livermore, Argonne National Laboratory, Argonne, Ill. (July 1992). 
- Draft Report: Work Plan for the Fuel Oil Spill at Sandia National Laboratories, Livermore, Argonne National Laboratory, Argonne, Ill. (June 4, 1993).

- Quality Assurance Plan for the Data Acquisition and Management System for Monitoring the Fuel Oil Spill at the Sandia National Laboratories Installation in Livermore, California, ANL/ER-DIS/TM-4, Argonne National Laboratory, Argonne, Ill. (April 1995).

- Test Plan for the Data Acquisition and Management System for Monitoring the Fuel Oil Spill at the Sandia National Laboratories Installation in Livermore, California, ANL/ER-DIS/TM-1, Argonne National Laboratory, Argonne, Ill. (April 1995).

As detailed in the aforementioned documents, three subsystems were developed to support data management at the site: (1) a monitoring and logging subsystem, (2) a data acquisition subsystem, and (3) a data analysis subsystem. This manual addresses the software suite provided in the data analysis subsystem.

\subsection{DATA ANALYSIS SUBSYSTEM}

As shown in Figure 1.1, the data analysis subsystem plays an integral role in the coordination of physical and chemical sensor data in the data management system. Three subunits of the monitoring system collect data from 51 pressure sensors installed downhole, 50 temperature probes installed downhole, and 7 tensiometers installed in shallow boreholes throughout the pilot study area. The data acquisition subsystem reads these data values and transfers them to the data analysis subsystem.

The data analysis subsystem consists of a Sun SPARCstation computer that runs the UNIX operating system with the $X$ Windows windowing environment. To interface with this hardware, a software suite was formed by using commercial software and custom interfaces created with ANLdeveloped application development libraries. The commercial software includes FrameMaker, SitePlanner, Statistical Analysis Software (SAS), and Xess. Specific details on these programs are not given in this manual.

This manual documents the user interfaces of the four custom software programs used in the data analysis system. The Sensor Data Query Tool assists the user in subsampling physical data from the electronic sensors and formatting them for input into commercial packages. The Chemical Analysis Interface assists the user in entering and verifying chemical analysis. The Data Distribution Program creates "tar" files of data sets for distribution and archiving. The Tape Backup System assists the user in formating new tapes and setting parameters used in creating automated backups. 
Physical Samples

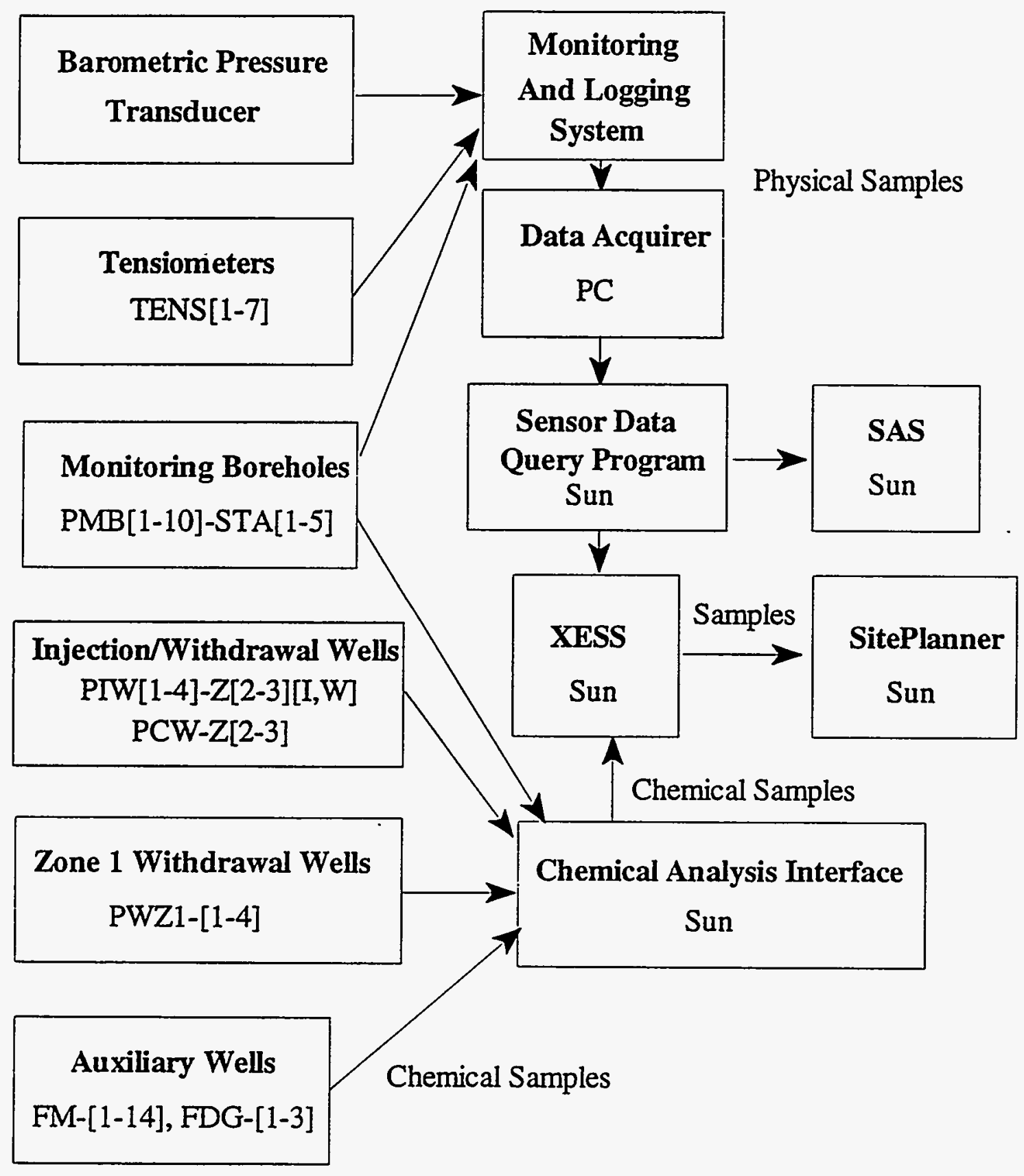

FIGURE 1.1 Data Flow Diagram 


\subsection{ORGANIZATION}

The remainder of this manual is organized as follows. Section 2 provides background information on the data analysis software system, including a brief description of the use of the OpenWindows environment. Directory structure and commercial software use are also discussed in this section. Section 3 discusses the Sensor Data Query Tool and how to subsample data, create graphs, and export the data to commercial packages. Section 4 discusses the Chemical Analysis Interface and how to enter chemical analysis data. Finally, Sections 5 and 6, respectively, discuss the two small utilities provided on the system: the Data Distribution Program and the Tape Backup System. 


\section{DATA ANALYSIS SOFTWARE}

\subsection{DATA ANALYSIS SOFTWARE ORGANIZATION}

The data analysis system resides on a Sun workstation under the UNIX operating system that uses the X Windows windowing enviroment. Although the primary focus of this manual is the data analysis workstation installed at the fuel oil spill site, the data analysis software may also be installed at other locations. Consequently, the instructions are as generic as possible. Users of the data analysis software are responsible for structuring, maintaining, and making backups of their own working directory areas. The data analysis software maintains only the common data directory. Users are responsible for maintaining any data files they create for their own analysis.

After reading physical data values from the monitoring subsystem, the data acquisition subsystem copies these files to the "/haw0/data" directory on the data analysis workstation. This directory contains the data from the temperature, pressure, and tensiometer subunits. Files are named according to the convention shown in Figure 2.1. Julian days are used to represent the date in the file names. Julian day conversion tables can be found in the appendix of Widing and Leser (1995).

\subsection{OPENWINDOWS ENVIRONMENT}

This document does not discuss the UNLX operating system. It is assumed that users have a basic understanding of UNIX. For detailed information on UNIX, Sun workstations, and $\mathrm{X}$ Windows, consult the documentation delivered with the Sun workstation or one of the many Unix primers available.

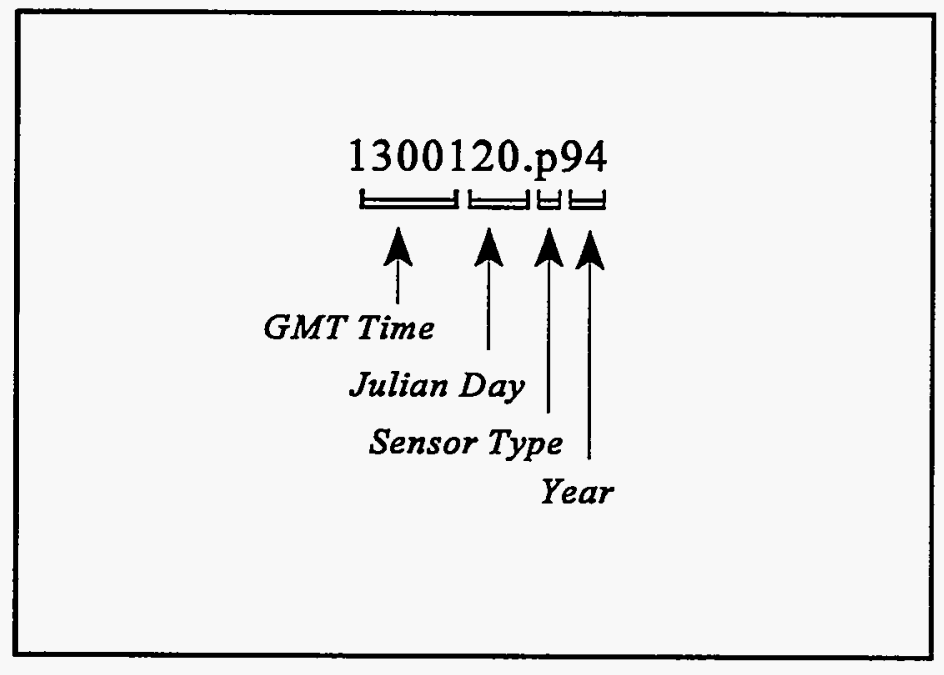

FIGURE 2.1 Data File Naming Convention 
OpenWindows is an X Windows windowing manager commonly used on Sun workstations. It is available on the Sun computer named "hawk" at the fuel oil spill site. The figures in this manual show the appearance of the software with this window manager. To start applications under OpenWindows, the program name must be typed in a text window called a "shell." Under OpenWindows, the text entry focus follows the movement of the mouse cursor. Therefore, the mouse cursor must be located above a window before text can be typed into it. After entering the OpenWindows environment, move the cursor over a shell window and change to the correct subdirectory by using the "cd" command. This action establishes the working directory for programs run subsequently. The proper working directory for each program is discussed in the section for that program. Figure 2.2 illustrates a sample data analysis screen.

All of the applications in the data analysis suite were developed by using the same application development library for consistency. The following text editing standards are used in all ANL-developed software in both the data acquisition and data analysis software suites:

Enter Press the Enter key to move from one text field to the next. In a table, this key moves you down to the next row in that column.

Shift-Enter Press the Shift key in combination with the Enter key to move to the previous item. In a table, this action moves you to the previous row in that column.

Tab

Press the Tab key to move to the next column in a table.

Shift-Tab Press the Shift key in combination with the Tab key to move to the previous column in a table.

Delete Press the Delete key to clear out one character in a text field.

Shift-Delete Press the Shift key in combination with the Delete key to clear out all of the characters in a text field in a table.

Esc

Press the Esc key to revert a text field value back to the last entered value.

The Sun workstation has a mouse device with three buttons. In the OpenWindows environment, some activities that require use of the left mouse button include selecting choices, pressing buttons, and moving windows. The right mouse button is used for displaying menus and choosing options for them. The middle mouse button is seldom used in OpenWindows. All of the programs developed by ANL for the data analysis program use this style of mouse interaction. Two of the commercial packages, SAS and Xess, are Motif applications and use the mouse differently. Consult the reference guides for these programs for a detailed explanation of the mouse use in these programs. 


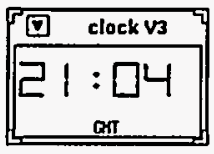

\begin{tabular}{|c|c|c|c|c|c|}
\hline 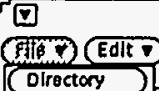 & Soloct & $\operatorname{tac}$ & $\begin{array}{l}\text { Analys Is Subsy } \\
\text { SCII SIteplann }\end{array}$ & $\overline{\text { SAS }}$ & $\begin{array}{l}\text { ery Tool } \\
7 \text { HelD }\end{array}$ \\
\hline $\log$ & Probes & & Pross ure Trat & & Tens \\
\hline Close & $E$ & [ & PHB1-STA1 & $\theta$ & TENSI \\
\hline PMB1-STA2 & 5 & [ & PMB1-STA2 & $\theta$ & [] TENS2 \\
\hline 口 РM8I-STA3 & & & ] РMB1-STA3 & & $\square$ TENSЗ \\
\hline [1] PMBI-STAA & & & ] РМВI-STA4 & & 口 TENSA \\
\hline$\square$ РМВI-5ТАБ & & & ᄀ РМВ1-5TA5 & & D TENS5 \\
\hline PME2-STAI & & & ] РHB2-STA1 & & $\square$ TENSG \\
\hline 口 PMQ2-STA2 & & & ] PHQ2-5TA2 & & 口 TENS7 \\
\hline$\square$ РМВ2-STA3 & & & Р РМв2-STA3 & & \\
\hline 口 РМв2-SТА4 & & & ] РMB:2-STAA & & \\
\hline$\square$ PM82-STA5 & & & ] PMQ2-STA5 & & \\
\hline م__nes_cras & & & I_ 0 venzerat & & \\
\hline
\end{tabular}

5. shalltool -/bin/csh

santber: cd user

sanibalx quary

Setting SEHSOR_OIRECTCRY to be /proj/san2/aio/viding/sandia/data/fos data

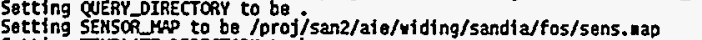

Sotting TERPLATE DIRECTORY to bo .

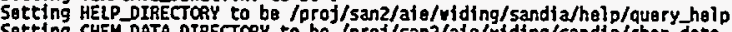
Satting CHEHHELP_DIRECTCRY to be /proj/san2/ate/viding/sandia/help/ches_help

Solect AII (ClearAiI)

Solect AII (Claar AII)

SelectAII Cloar AII

Reading in the sensor files ...

Reading dif rectory...

parsing fllenazes.

Sorting files ...

Year:1994 Day:258 Tine:1003

Fil leNane: 1643258 .p94

Year:1994 Day:300 Tíes:

conpleted reading in the sensor files.
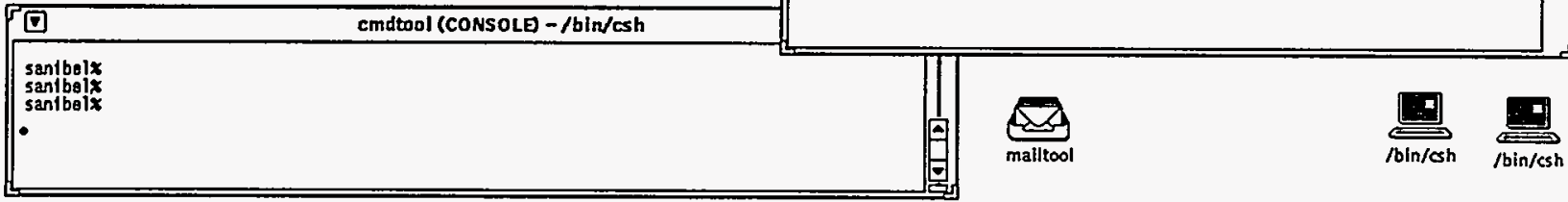

FIGURE 2.2 Sample Data Analysis Screen 


\section{SENSOR DATA QUERY TOOL}

\subsection{SENSOR DATA QUERY TOOL OVERVIEW}

The Sensor Data Query Tool (Query Tool) assists you in subsampling physical data for analysis through the commercial products Xess, SitePlanner, and SAS. To use this program, enter OpenWindows and change to your working directory. For reference, this directory is called "user" in this manual. This directory should contain the following files:

Parameters This file contains parameters specifying the directory locations of files used by the program.

sens.map This file contains information on the sensors, such as identification values and well associations. This file name can be changed as it is specified in the file "Parameters".

bounds.dat This file contains the minimum and maximum allowable sensor values.

The program will create other files in the user directory during execution. For faster execution, you may create a data directory with a subset of data files in your personal directory. For example, create a directory named "fos_1095" and copy all data for October 1995. Specify the new directory in the "Parameters" file so that the Query Tool can find the appropriate data at run time.

To run the Query Tool, enter the following command in the same shell window:

\section{query}

As shown in Figure 2.2, various messages appear in the originating shell window, including the number of data files found and the beginning and ending dates. If you use a directory with a large number of data files, you can specify a subset of dates on the command line as follows:

\section{query 12/1/94 1/1/95}

If the program does not start correctly, examine the messages printed in the shell window to see if a required file is missing. The current version of the Query Tool resides in the directory $\sim$ widing/bin. Symbolic links have been created between each user's directory/bin and this source area. Any new version of the program will be installed in this directory, along with previous versions.

\subsection{QUERY TOOL WINDOW}

The main window of the Query Tool is shown in Figure 3.1. A menu bar at the top of the window provides access to the subwindows in the program. The three tables in the window show 


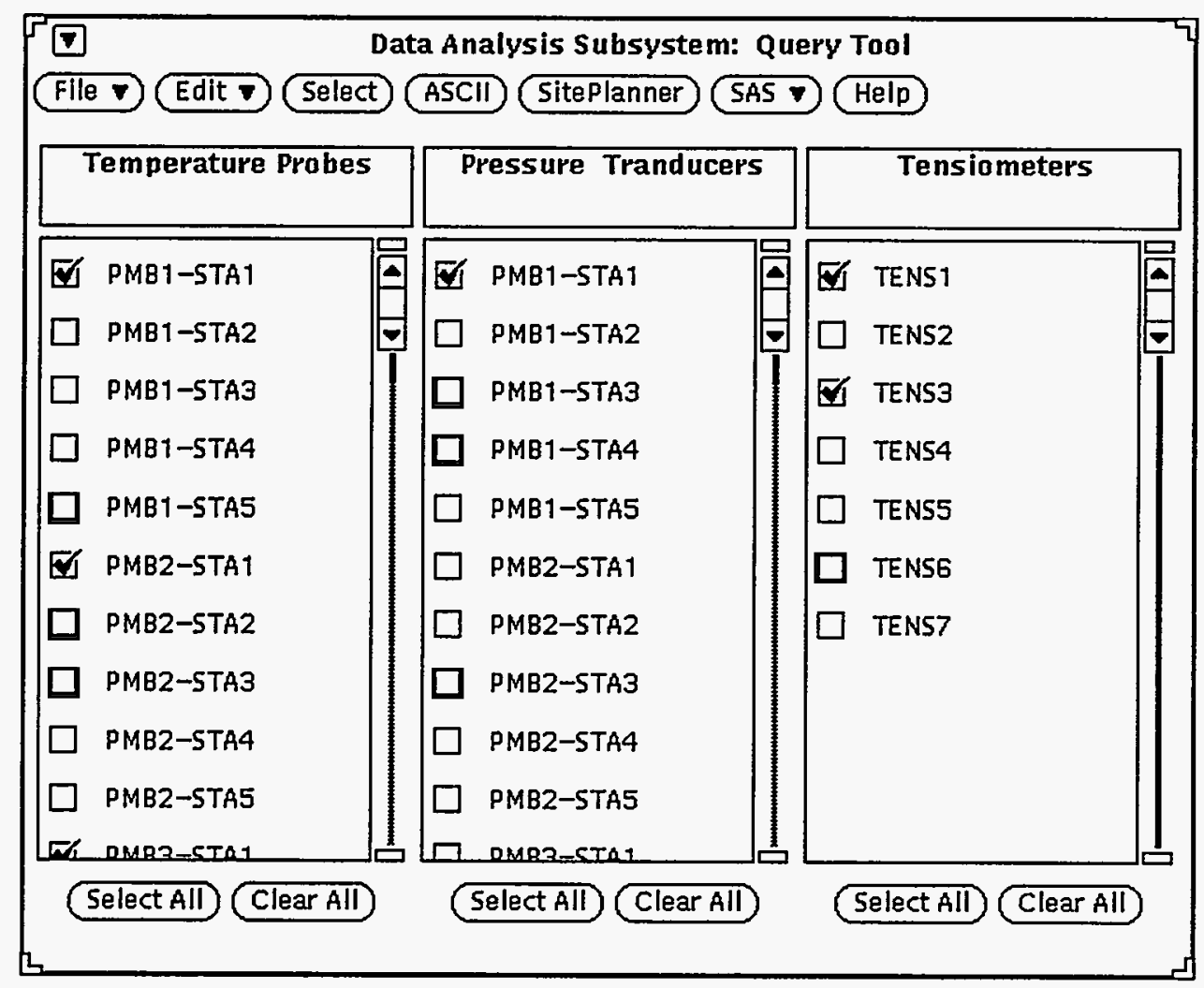

\section{FIGURE 3.1 Sensor Query Tool Main Window}

the identification values of the electronic sensors. Each table corresponds to one subunit: temperature, pressure, or tensiometer. The choice boxes indicate which sensors you have selected.

The menubar options perform the following actions.

File

Edit

Select

ASCII

SitePlanner
Select this option to display the menu for performing file actions (Figure 3.2).

Select this option to display the menu for editing data values (Figure 3.3). A window is displayed to edit the data corresponding to the option selected in the menu (Section 3.5).

Select this option to display a window for selecting a subset of temperature and pressure sensors on the basis of their well and station associations (Section 3.6).

Select this option to display a window for creating an ASCII file with temperature and pressure data (Section 3.7).

Select this option to display a window for creating an Xess file with sensor data for input into SitePlanner (Section 3.8). 


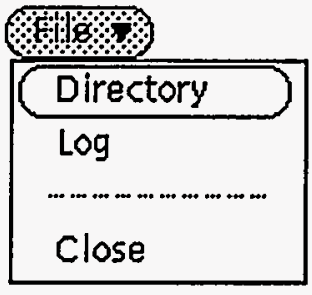

FIGURE 3.2 File Menu

\begin{tabular}{|l|}
\multicolumn{1}{c|}{ Well } \\
\hline Station \\
Temperature \\
Pressure \\
Tensiometer \\
Barometric Pressure \\
Boundaries \\
\hline
\end{tabular}

FIGURE 3.3 Edit Menu

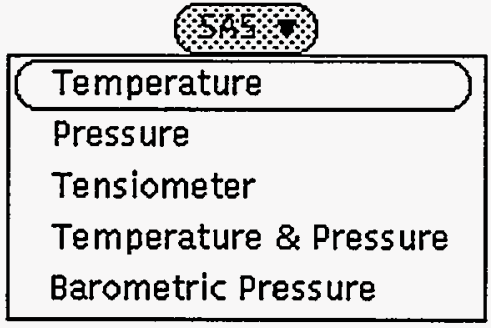

FIGURE 3.4 SAS Menu

SAS

Select this option to display the menu shown in Figure 3.4 for creating sensor data sets for SAS (Section 3.12).

Help Select this option to bring up the Help window on the Query Tool.

The options in the File menu perform the following actions:

Directory Select this option to show the Data Directory window to load a new data set (Section 3.3).

$\log$

Select this option to show the Activity Log window with status information (Section 3.4).

Close

Select this option to quit the Query Tool.

The sensors listed in the tables in the main window can be selected in several ways. The choice next to the option can be selected by clicking on it with the left mouse button. The Select All and Clear All buttons will select and deselect all choices in the corresponding table. The choices can also be selected through the Select window (Section 3.6).

\subsection{DATA DIRECTORY WINDOW}

The Data Directory window is shown in Figure 3.5. By typing in the full name of a data directory in the Directory Name text field, you specify a new set of data file names. If you mark Append choice, the program adds this set of file names to the existing set of names in memory.

The buttons on this window perform the following actions:

Quit

Help

Load
Press this button to exit this window.

Press this button to bring up the Help window for the Data Directory window.

Press this button to load in the names of the data files in the directory. 


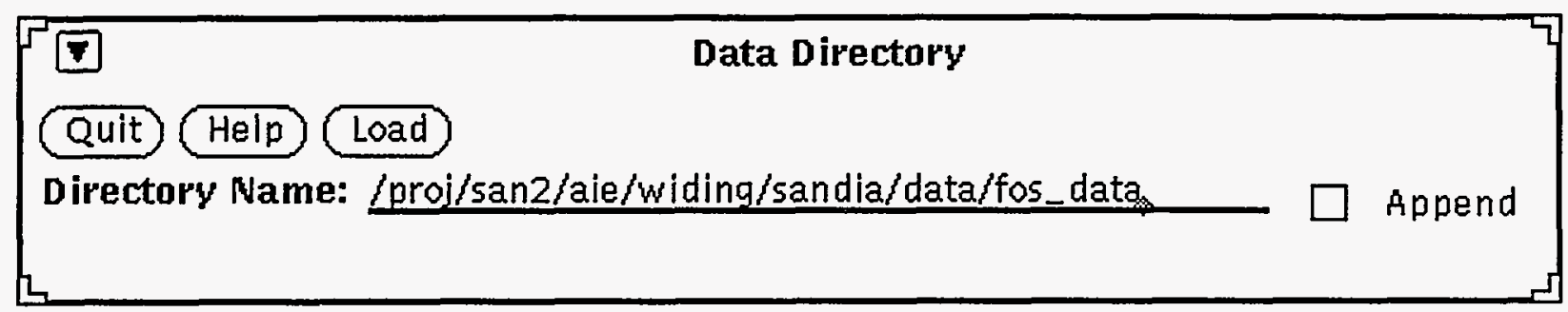

FIGURE 3.5 Data Directory Window

\subsection{ACTIVITY LOG WINDOW}

The Activity Log window allows you to create a log, as shown in Figure 3.6. The text region displays the log file, which can be edited to record notes on the current Query Tool session. The Autosave option automatically saves the log to the "log.txt" file in the working directory after each message is added by the Query Tool.

The buttons on this window perform the following actions:

Quit Press this button to exit this window.

Help Press this button to bring up the Help window for the Activity Log window.

Add Time Press this button to add a message to the log with the current time.

Save Press this button to save the log to the "log.txt" file.

Print $\quad$ Press this button to print the log file.

Clear Press this button to clear the log.

\subsection{EDIT WINDOWS}

A different Edit window is displayed for each of the items shown in the Edit menu. These windows are very similar, as shown in Figures 3.7 through 3.13. All of the windows contain a table of data that can be edited. The buttons in these windows perform the following actions:

Quit

Help

Save
Press this button to exit this window.

Press this button to bring up the Help window for the Edit window.

Press this button to save the data. For the Boundaries option, the "bounds.dat" file is created. For all other options, the file specified in the SENSOR_MAP variable ("sens.map") in the "Parameters" file is created. 


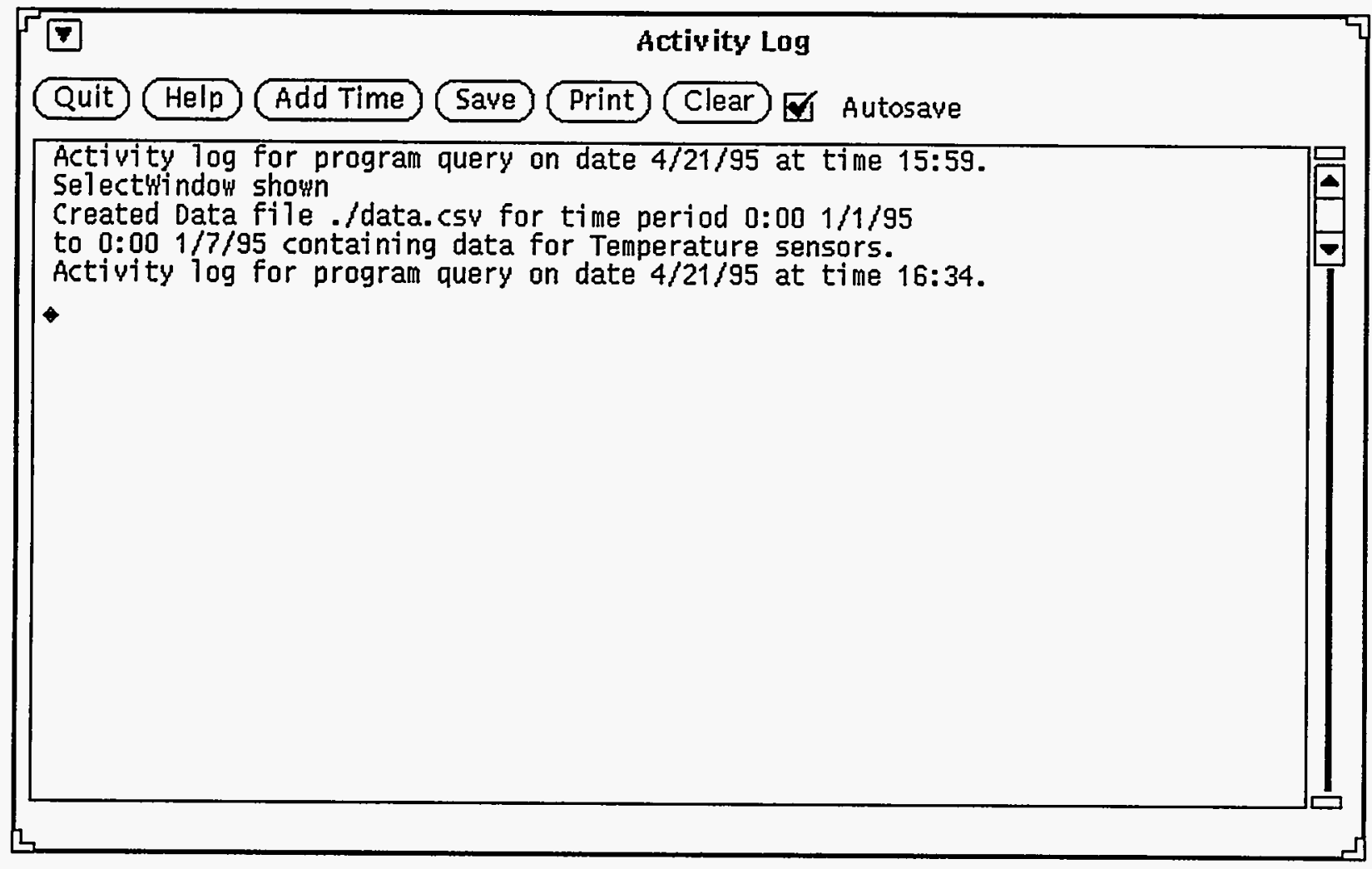

FIGURE 3.6 Activity Log Window

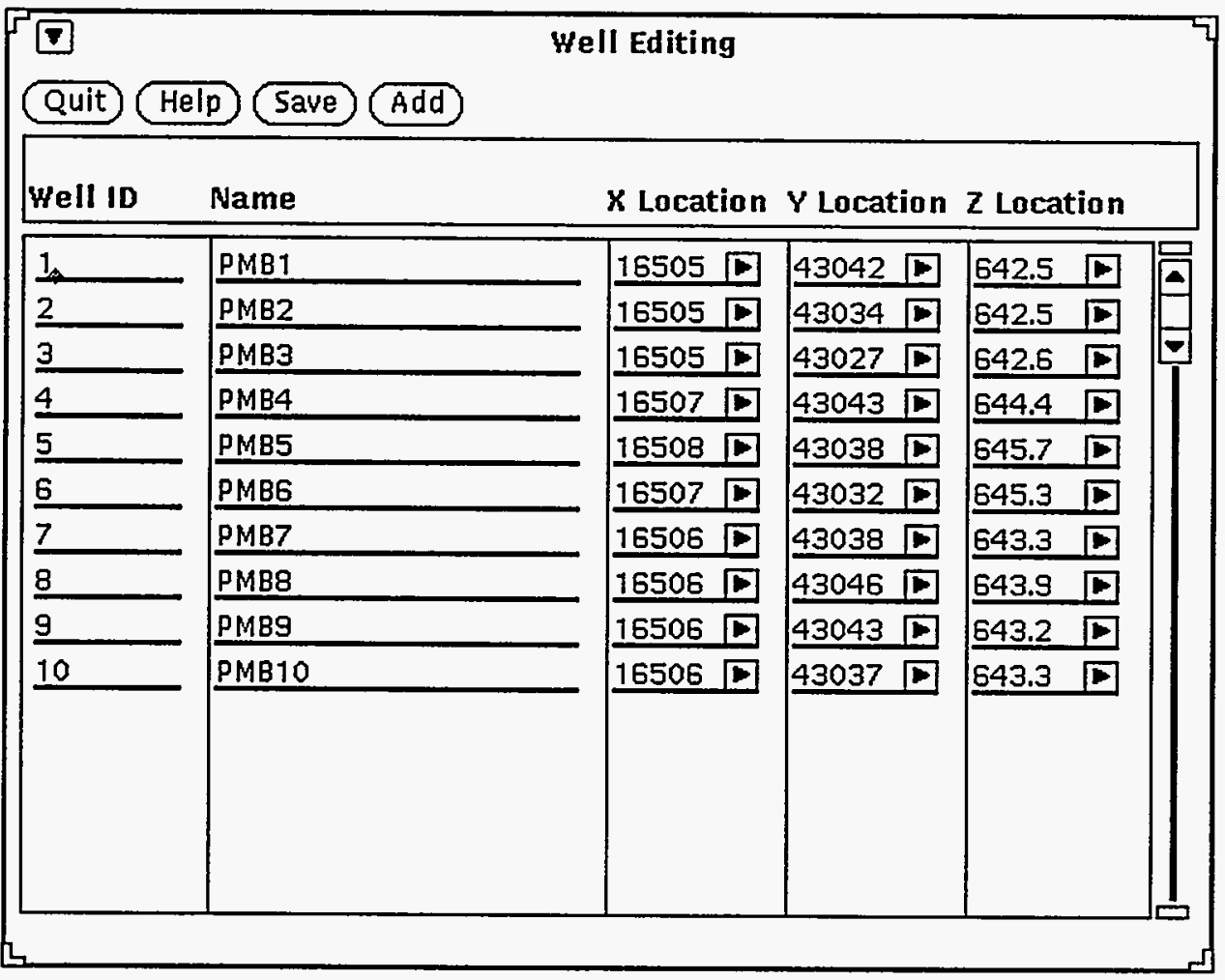

FIGURE 3.7 Well Editing Window 


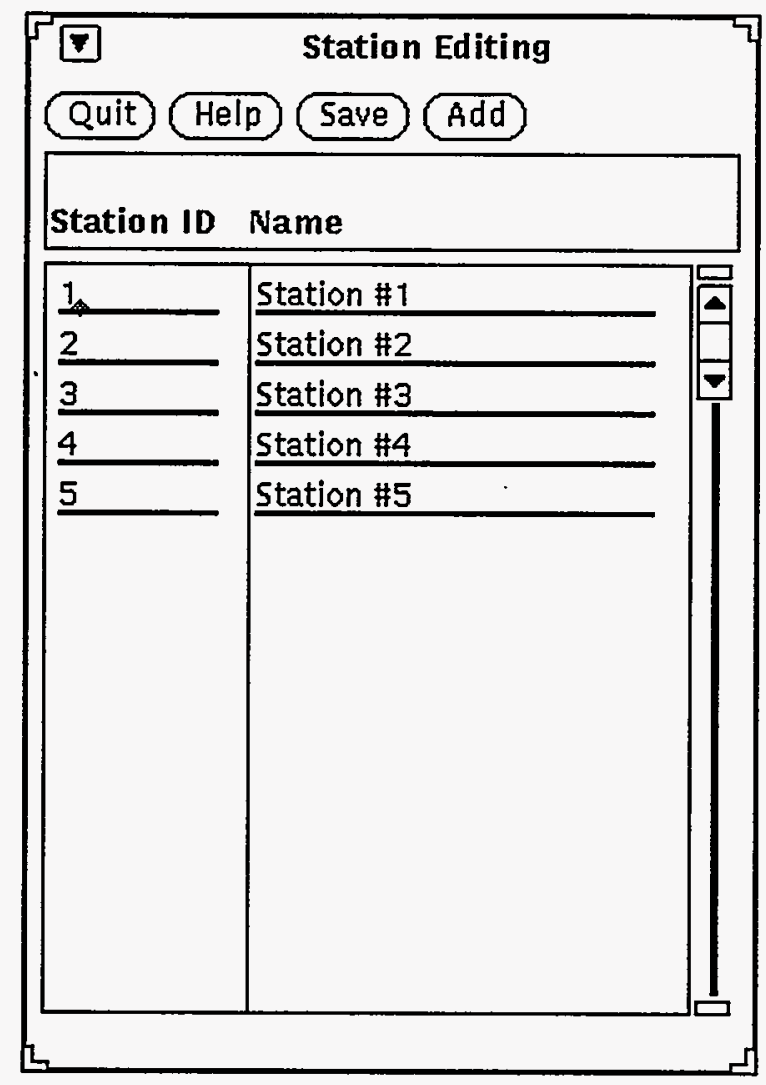

FIGURE 3.8 Station Editing Window

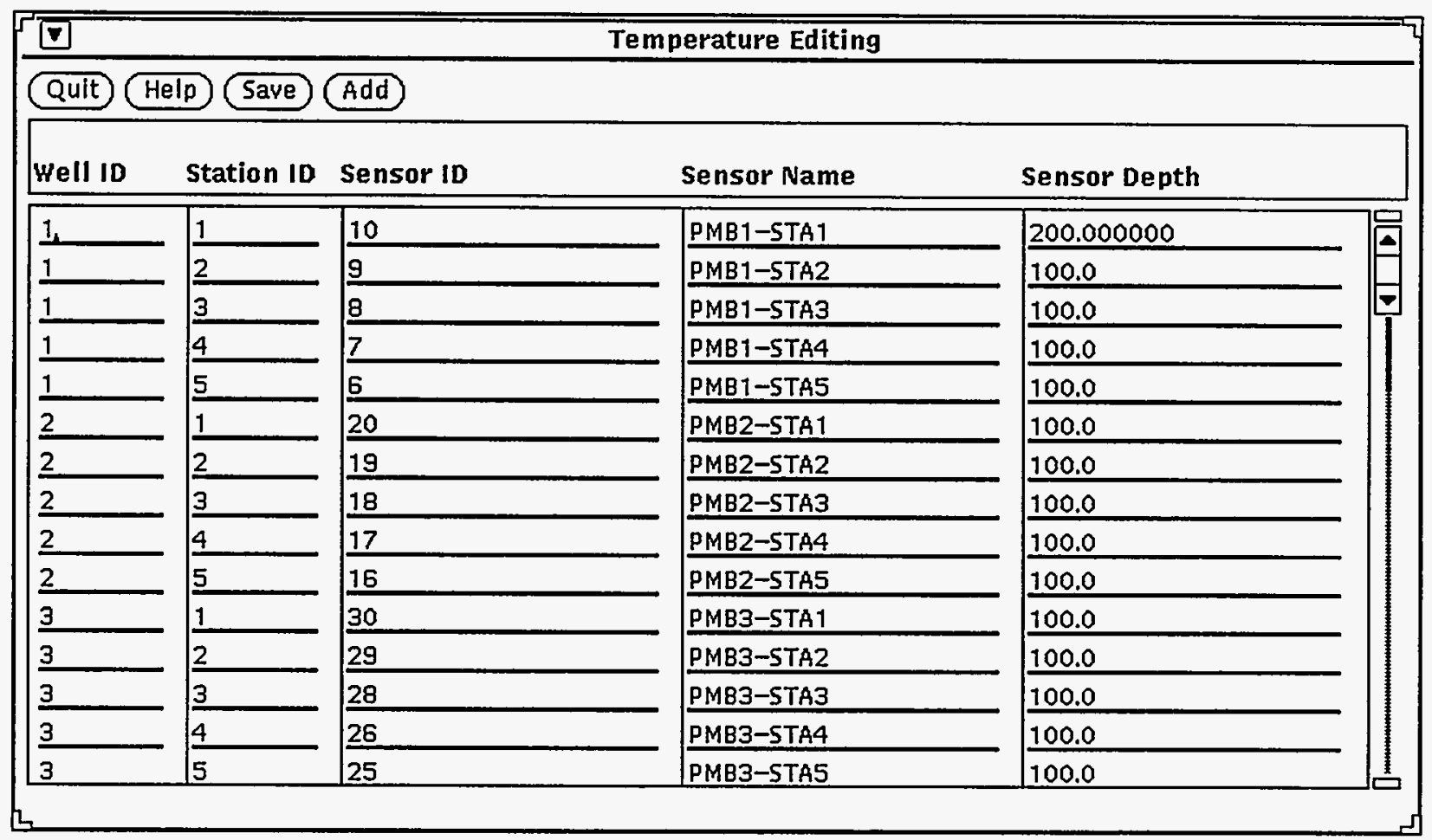




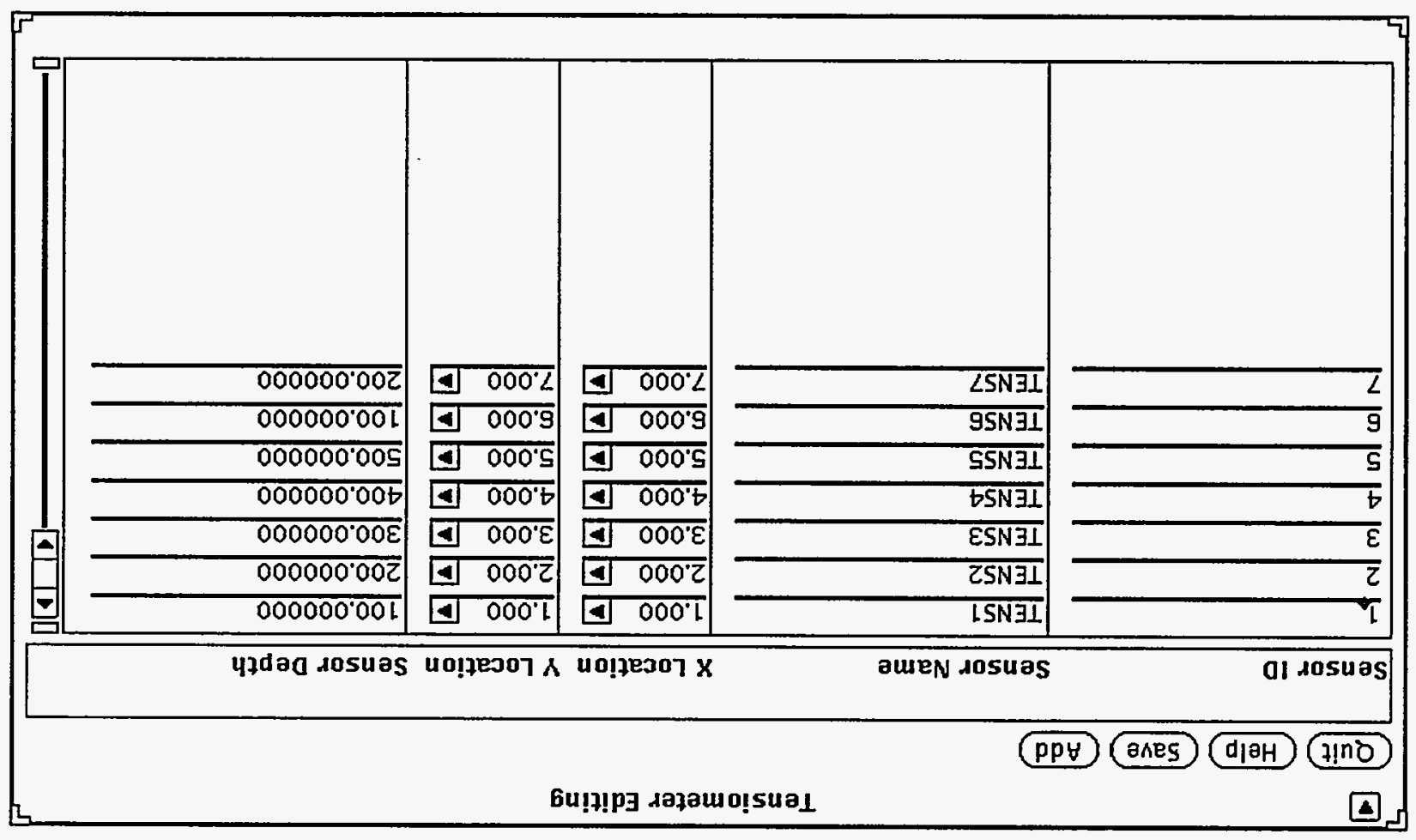

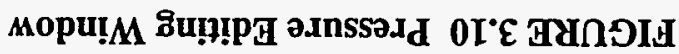

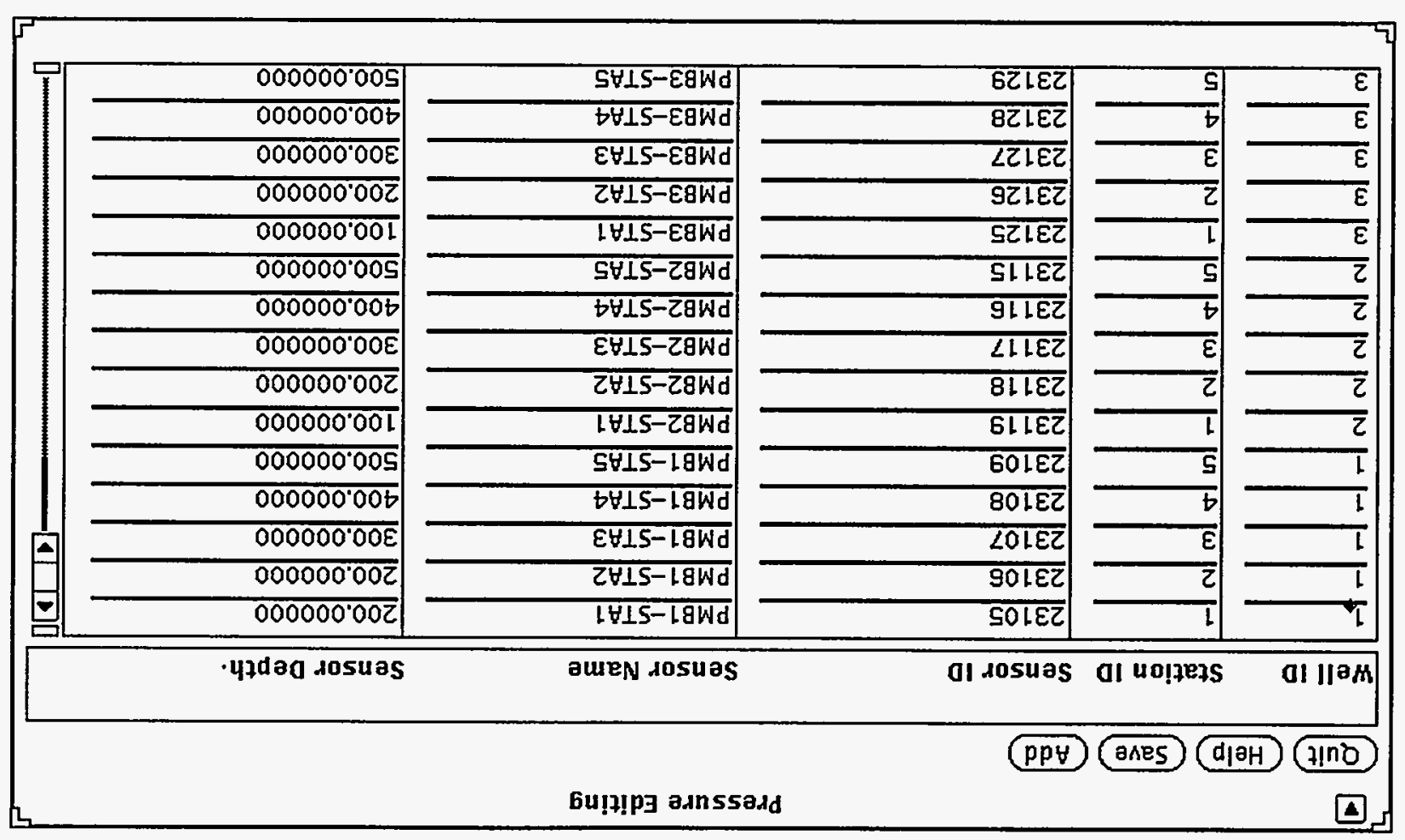




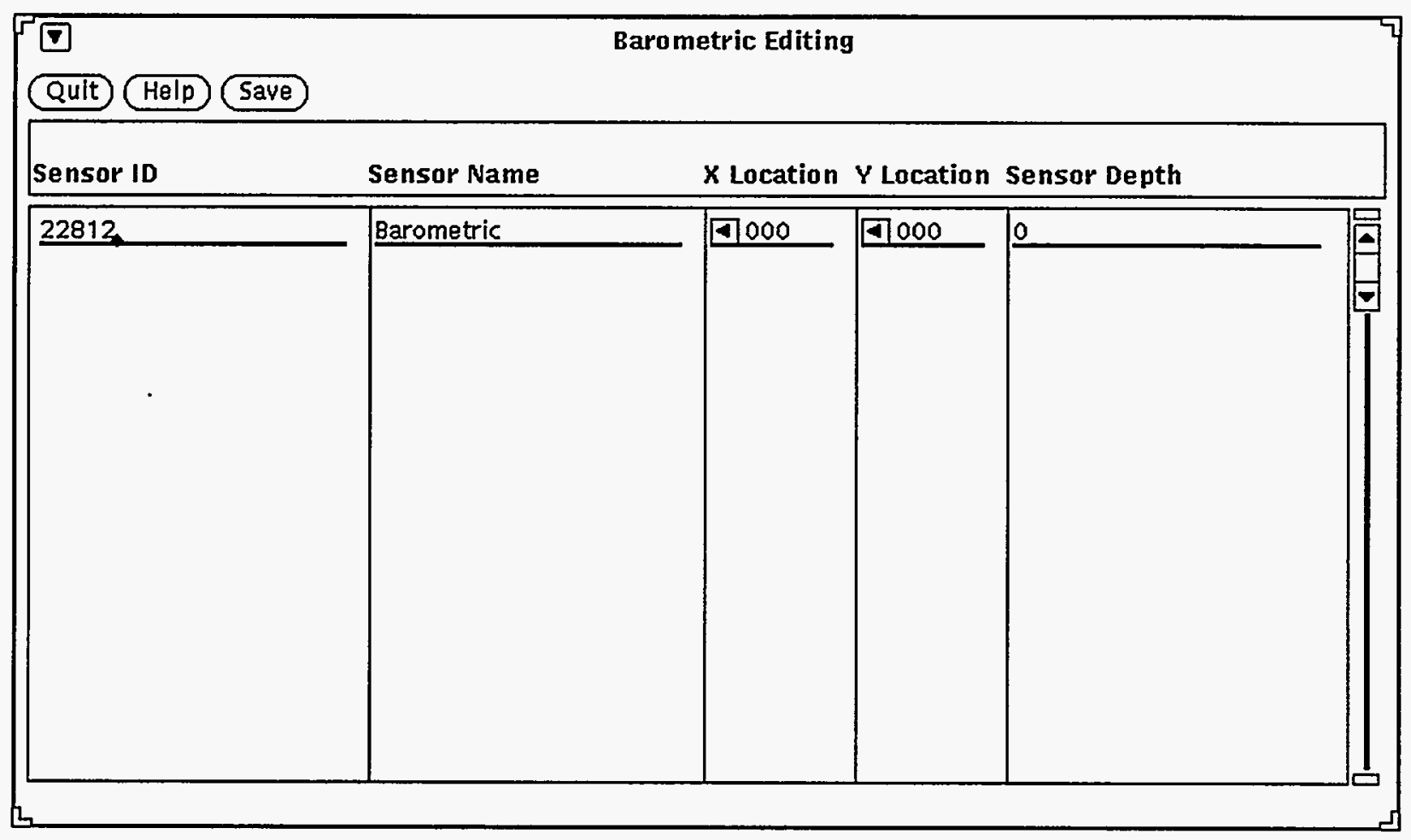

FIGURE 3.12 Barometric Editing Window

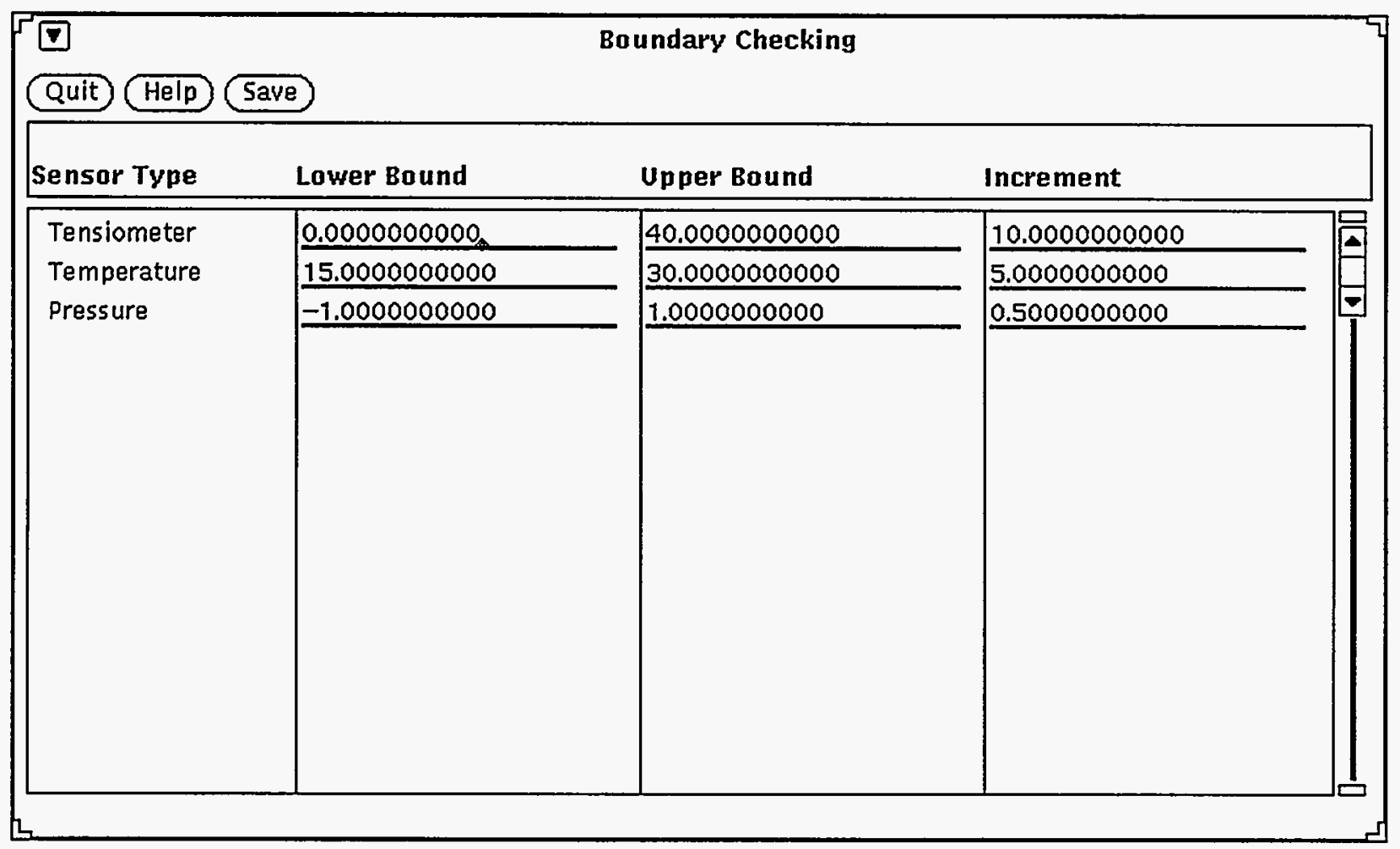

FIGURE 3.13 Boundaries Editing Window 
The main purposes of these windows are viewing and minor editing. It is unlikely that the parameters in most of these windows will ever be changed. If these values are changed, the data files created with the Query Tool will contain different data.

The Boundaries Editing window serves several additional purposes. When subsampling data files, the Query Tool uses these boundaries to eliminate outlying data points. When graphing data, these boundaries may be used in specifying the scale of the y-axis on plots. Care should be exercised to avoid eliminating data points by inadvertently selecting a range that is too narrow.

\subsection{SELECT WINDOW}

The Select window assists in selecting the temperature and/or pressure sensors that correspond to particular wells and stations, as shown in Figure 3.14. The Sensor Types choice is used to specify the sensor data types that should be changed. By selecting the well and station names in the two scrolling tables, you indicate which combinations should be affected. Existing selections that do not match the criteria are not affected.

The buttons in this window perform the following actions:

Quit Press this button to exit this window.

Help Press this button to bring up the Help window for the Select window.

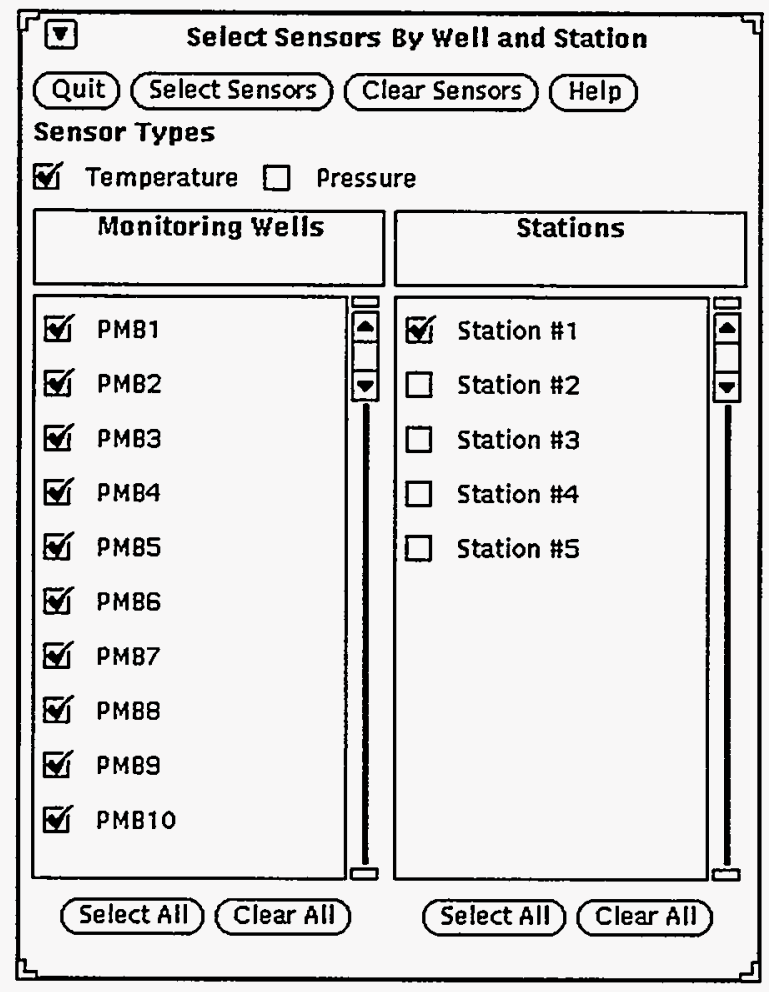

FIGURE 3.14 Select Window 
Select Sensors Press this button to select the choices in the main window that match the criteria.

Clear Sensors Press this button to clear or deselect the choices in the main window that match the criteria.

The final set of selections in the main window is a combination of the old set and the matching set. For example, if the PMB1-STA3 sensor was selected and the Select window was used to select all wells with a station of STA1, PMB1-STA3 would remain selected.

\subsection{TEMPERATURE \& PRESSURE ASCII OUTPUT WINDOW}

The Temperature \& Pressure ASCII Output window creates a comma-delimited output file for import into Xess, Excel, or other software packages. As shown in Figure 3.15, the window contains a number of text fields and other options for specifying the set of data for inclusion in the generated data set. This window uses the temperature and pressure sensors selected in the main window to create the data set, which includes only those well and station locations in which both types of sensors have been selected.

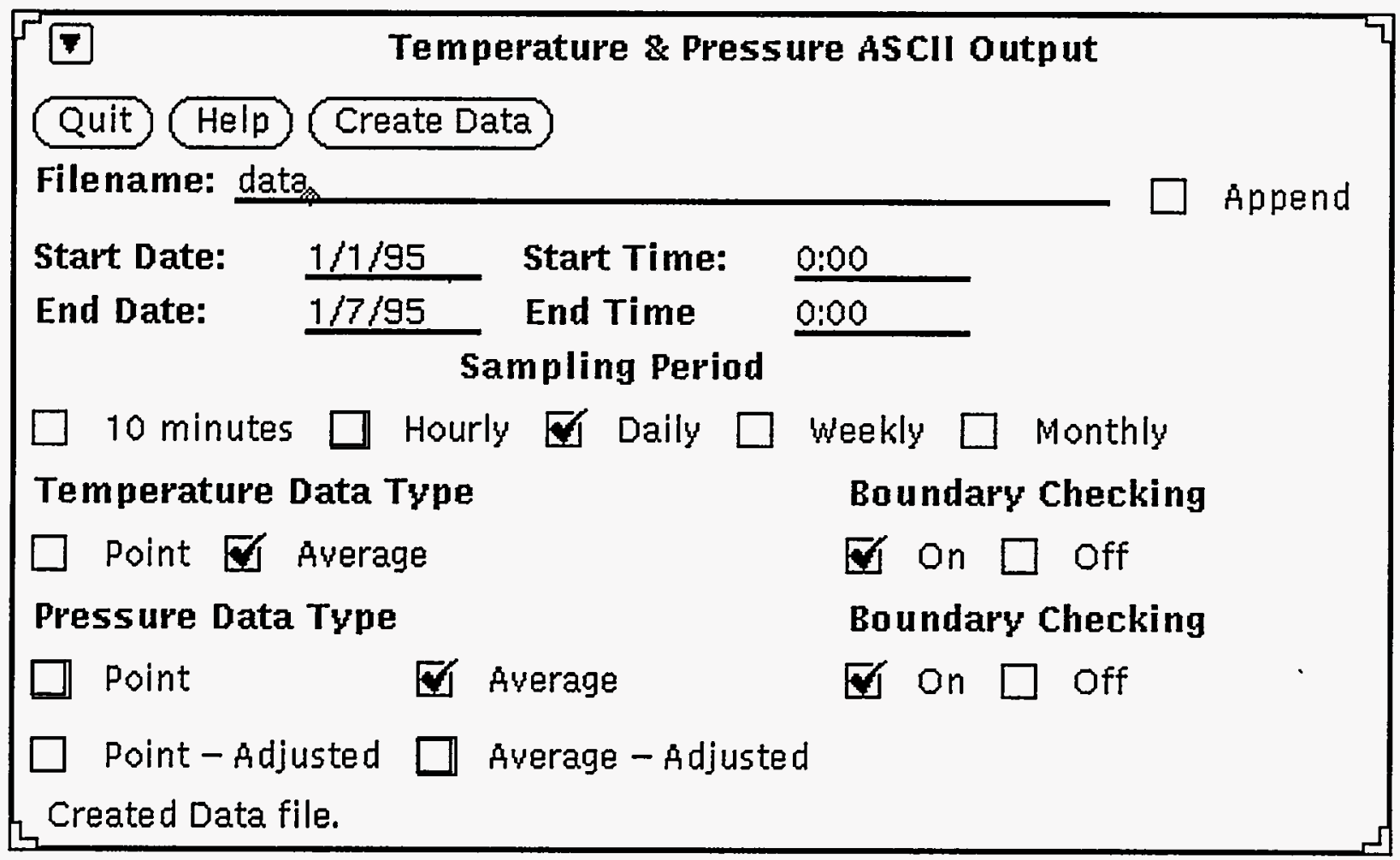

FIGURE 3.15 Temperature \& Pressure ASCII Output Window 
The buttons in this window perform the following actions:

Quit

Help

Create Data
Press this button to exit this window.

Press this button to bring up the Help window for this window.

Press this button to create a new set of data by using the name specified in the Filename field, including data specified in the window. An extension of ".csv" is added to the end of the filename.

The text and choice fields in this window are used extensively throughout other data set creation windows in the Query Tool. The filename options are described as follows:

Filename: $\quad$ Type in the name of the file to be used for the new data set.

Append This choice is used to indicate whether a new file should be created or the new data set should be appended to the specified file.

The time period options are described as follows:

Start Date:

Type in the first date to be included in the data set. The date should be in the form $\mathrm{mm} / \mathrm{dd} / \mathrm{yy}$.

Start Time:

Type in the first time on the specified first date to be included in the data set. The time should be in the form hh:dd in Greenwich Mean Time (GMT).

End Date:

Type in the last date to be included in the data set. The date should be in the form $\mathrm{mm} / \mathrm{dd} / \mathrm{yy}$.

End Time:

Type in the last time on the specified last date to be included in the data set. The time should be in the form hh:dd in GMT.

Sampling Period: Select the choice corresponding to the subsampling interval you want to use for specifying the data files to be included in the new data set. The readings between these times are not averaged to form values in the data set.

Multiple data values can be selected for each sensor selected in the main window. A temperature probe has two values: a point value read at the end of the datalogger sampling period and an average value computed from all readings over the datalogger sampling period. For example, if the datalogger sampling period is one hour, 60 readings will be averaged to form the average value, which is output along with the last reading made in that hour. A pressure transducer has four values: a point value, an average value, a point value adjusted for the barometric pressure at that time, and an average value adjusted for the barometric pressure at that time. All pressure values indicate the change or delta in pressure from the start of the baseline period, not the absolute pressure. For pressure probes, an internal thermistor is also recorded as a point reading and is output along with the pressure value. 
To specify which readings should be used, the following options are available:

Temperature

Data Type:

Boundary

Checking:

Pressure

Data Type:

Boundary

Checking:
Select the choice corresponding to the temperature reading to be included.

Select the choice indicating whether or not boundary checking should be performed on the temperature value by using the boundaries specified in the Edit Boundaries window.

Select the choice corresponding to the pressure reading to be included. The temperature value from the internal thermistor on the pressure transducer is also included.

Select the choice indicating whether or not boundary checking should be performed on the pressure and temperature values by using the boundaries specified in the Boundaries Editing window.

As the program creates a data file, the window shows the time of the data currently being accessed in the bottom left footer of the window. This message indicates the progress of the data creation process. When the file is complete, the message "Created Data File." is displayed in this footer on the window.

\subsection{SITEPLANNER TIME INTERVAL WINDOW}

The SitePlanner Time Interval window creates a comma-delimited output file for import into Xess, Excel, or other software packages and an Xess file for input into SitePlanner. As shown in Figure 3.16, the window contains a number of text fields and other options for specifying the set of data for inclusion in the generated data set. To create the data set, this window uses the temperature, pressure, and tensiometer sensors selected in the main window in addition to the barometric pressure sensor. The text and choice options in this window are the same as those defined in Section 3.7 for the Temperature \& Pressure ASCII Output window. Three SitePlanner template files are created toassist in importing sensor data into objects. These files end with the following extensions: "-temp.spi," "-press.spi," and "-tens.spi."

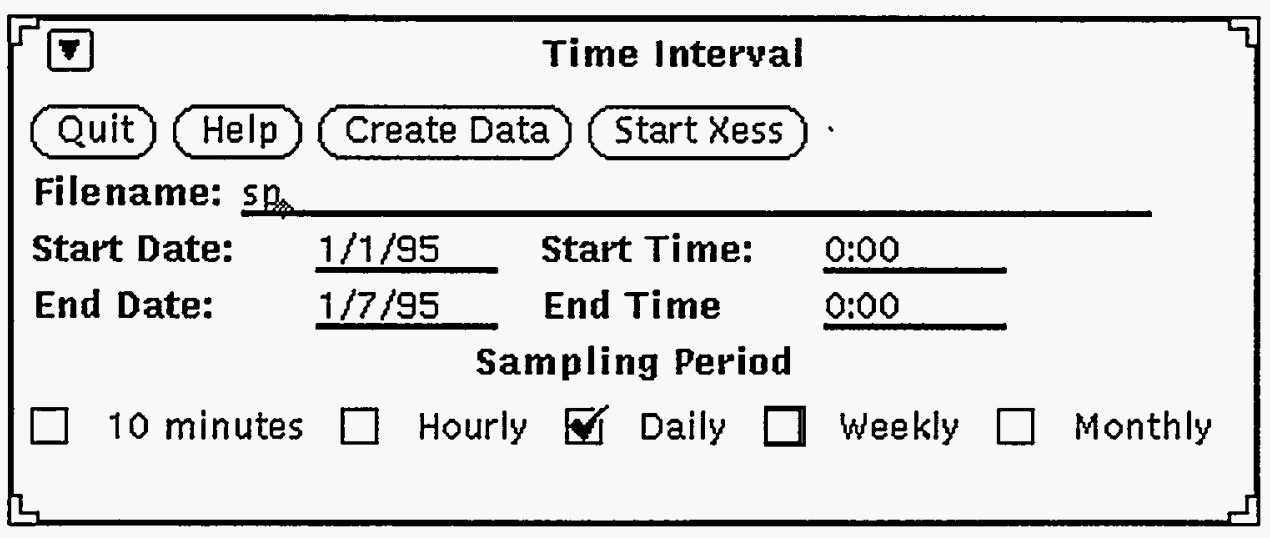


To create the Xess file properly, Xess must be running. Xess can be started either in a shell window or through the use of the Start Xess button. To start Xess from a shell window, type the following command:

\section{xess -i connect a\&}

These command line options ensure that the Xess session can accept connections from other programs.

The buttons in this window perform the following actions:

Quit Press this button to exit this window.

Help Press this button to bring up the Help window for this window.

Create Data Press this button to create a new set of data by using the name specified in the Filename field, including data specified in the window. An extension of ".csv" is added to the end of the name of the comma-delimited file. An extension of ".xs" is added to the end of the name of the Xess file.

Start Xess Press this button to start a new Xess session. The Xess icon shown in Figure 2.2 will appear on the screen.

\subsection{SAS GRAPH WINDOWS}

Data files can be created for each of the five types of data listed below:

- Temperature thermistors,

- Pressure transducers,

- Tensiometers,

- Temperature thermistors and pressure transducers together, and

- The barometric pressure transducer.

For each of these types of data, a series of windows can be used to create data files, calculate statistics, and display SAS graphs. These windows share general characteristics with slight differences. The SAS Graph windows shown in Figures 3.17 through 3.21 are used to create data files for SAS. By using filename, time periods, and data type information, the program creates a data file. If any data are missing, the Error window shown in Figure 3.22 is displayed (Section 3.10). The menu shown in Figure 3.23 is used to calculate statistics. The Query Tool creates a SAS program and sends it to SAS by using background system calls. The results are then listed in the Statistics window shown in Figure 3.24 (Section 3.11). 


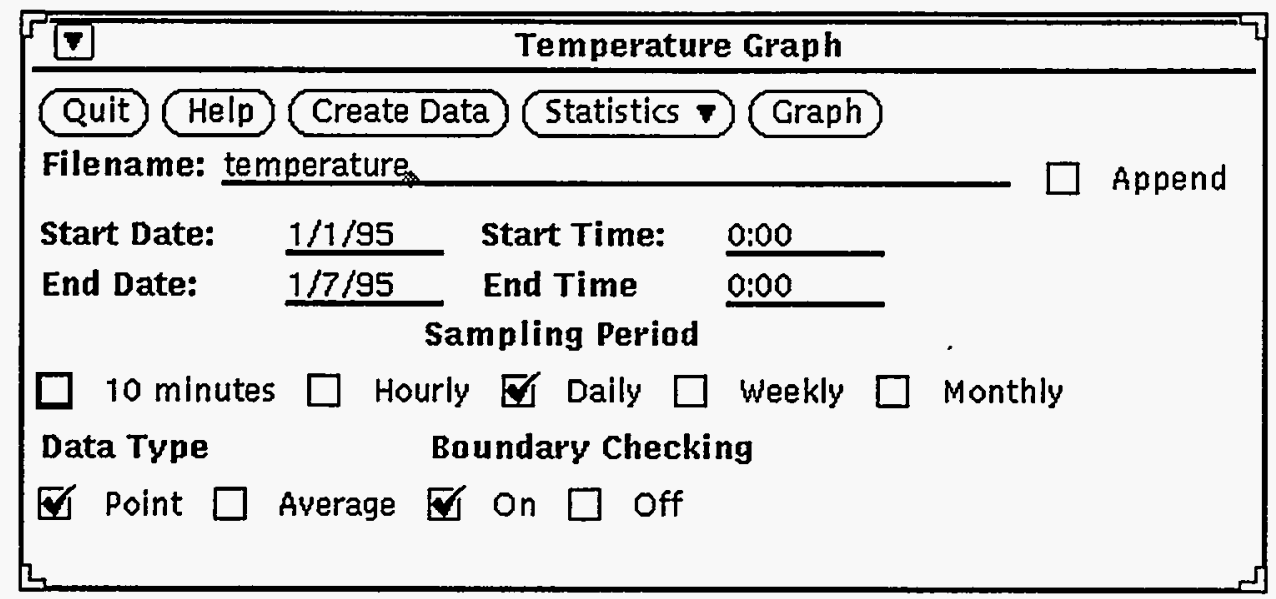

FIGURE 3.17 Temperature Graph Window

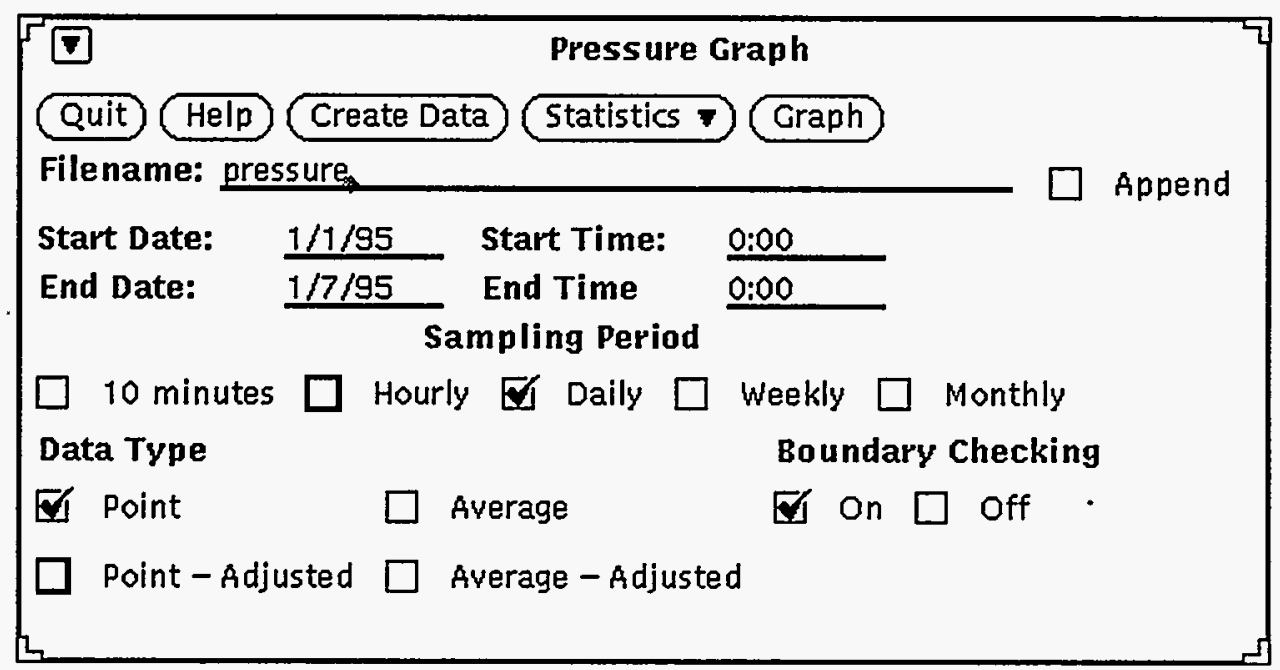

FIGURE 3.18 Pressure Graph Window

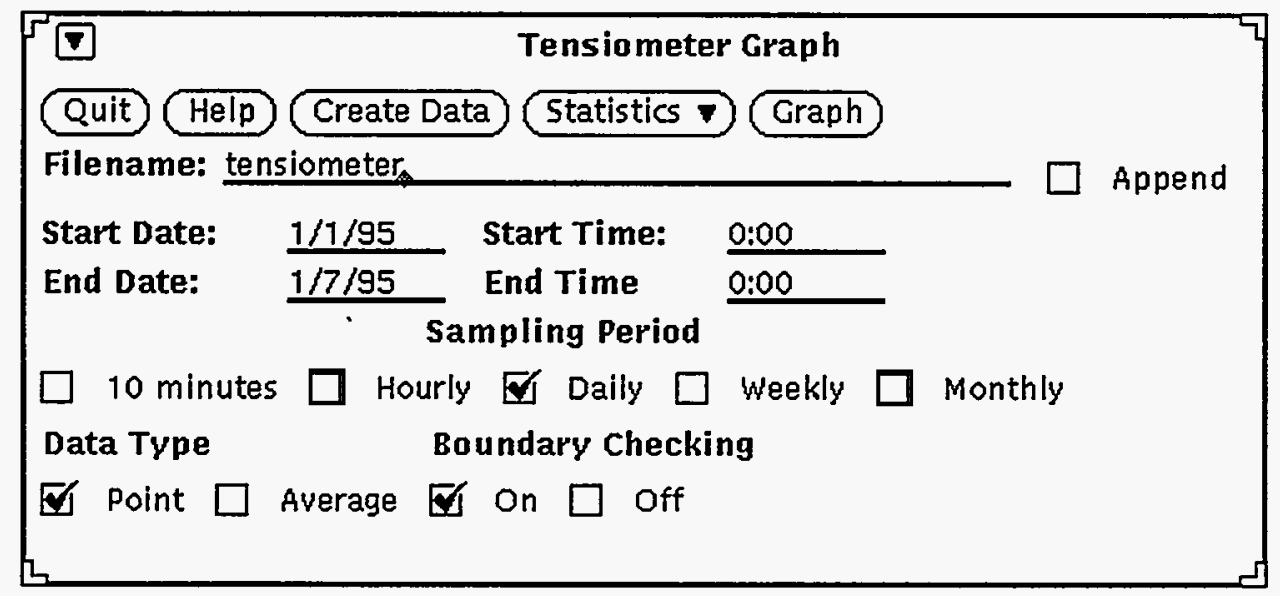

FIGURE 3.19 Tensiometer Graph Window 


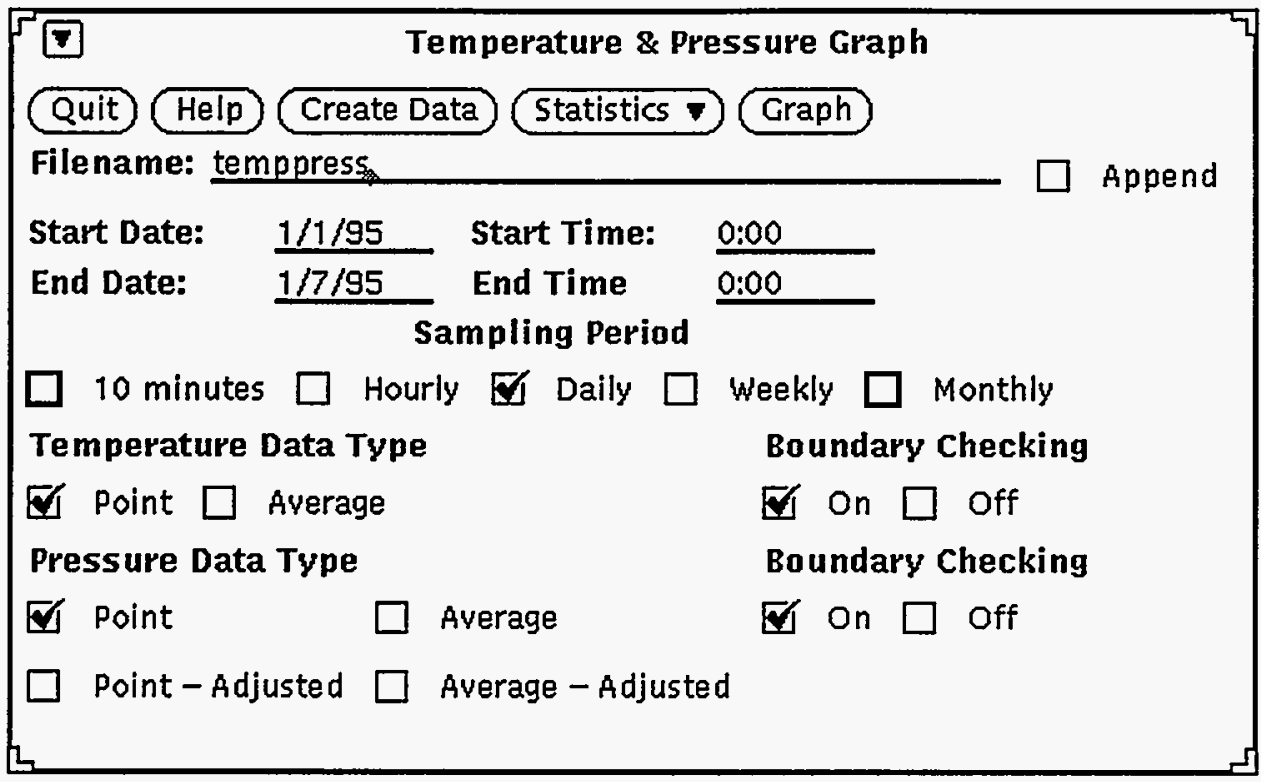

FIGURE 3.20 Temperature \& Pressure Graph Window

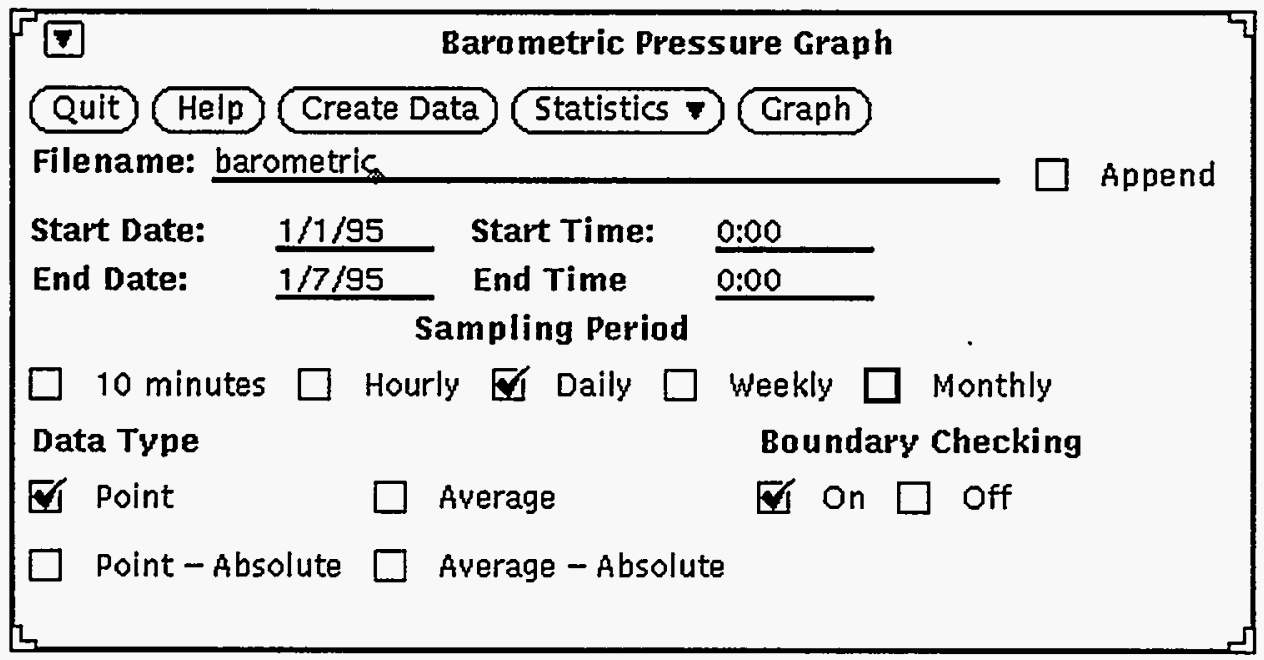

FIGURE 3.21 Barometric Pressure Graph Window 


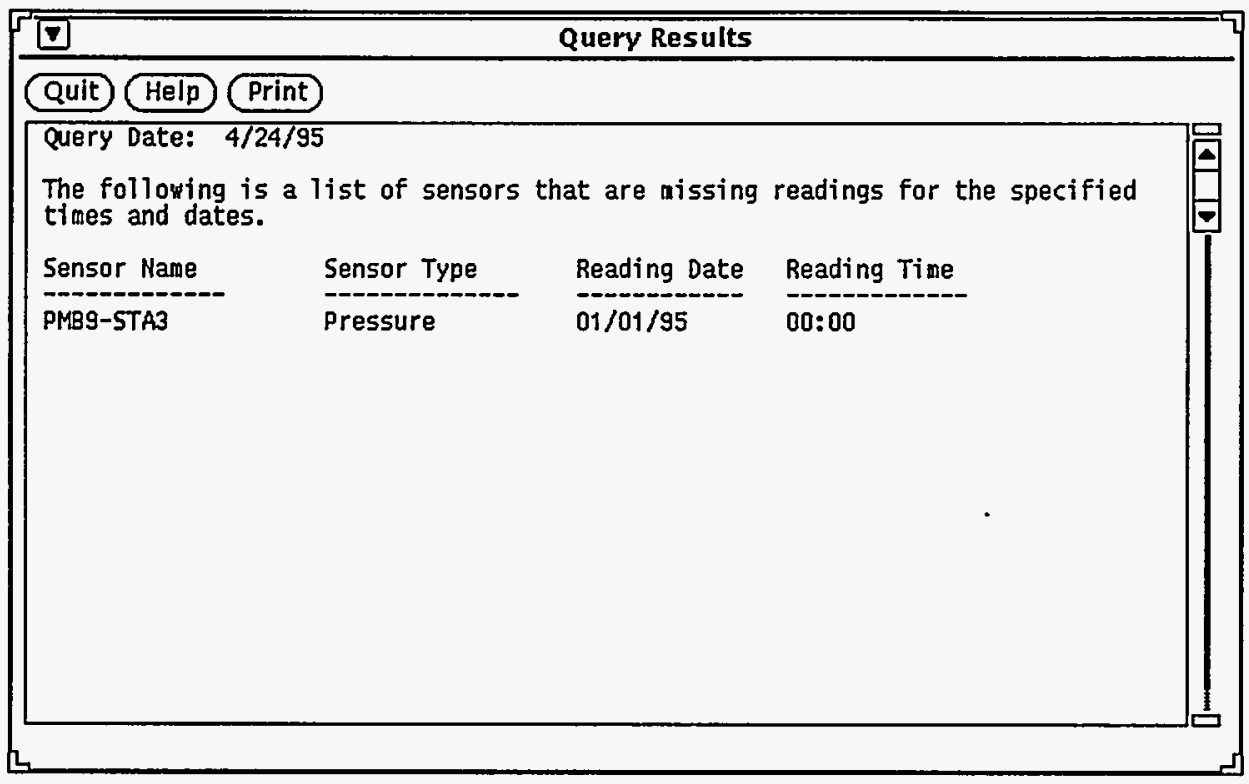

FIGURE 3.22 Error Window

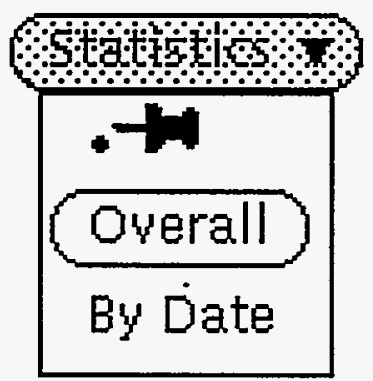

FIGURE 3.23 Statistics

Menu

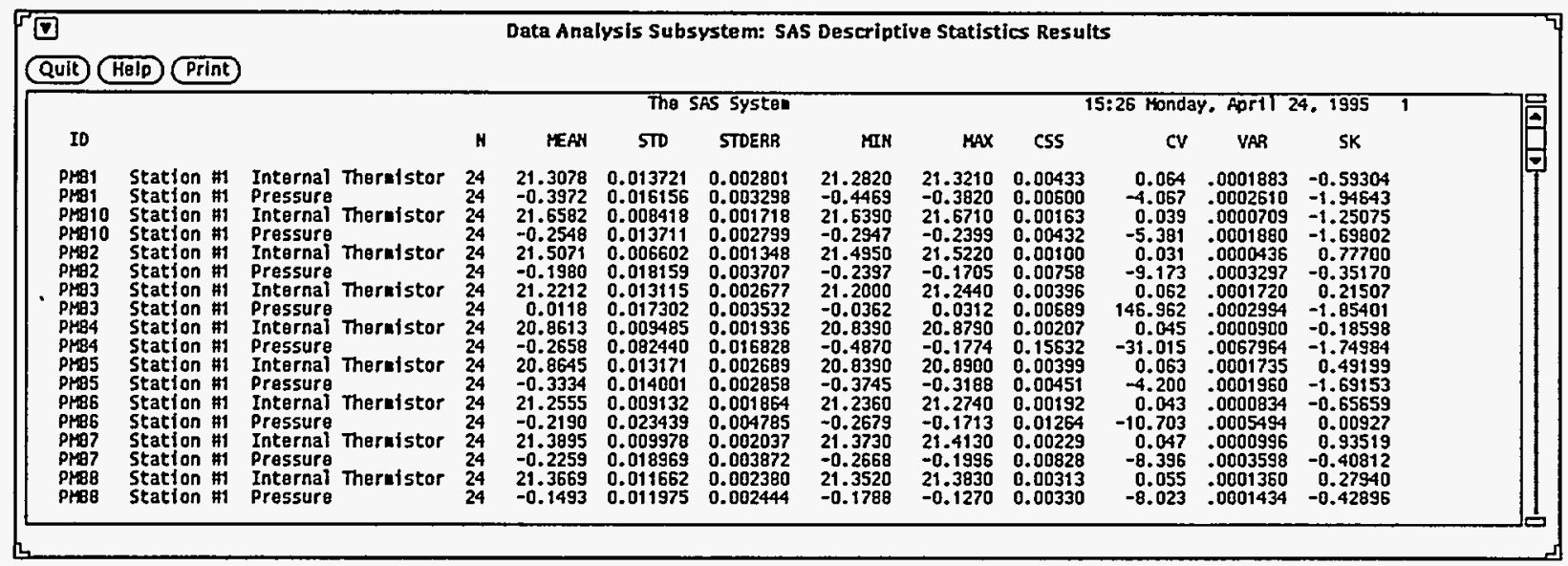

FIGURE 3.24 Statistics Window 
The SAS Graph windows contain the following buttons:

Quit

Help

Create Data

Statistics

Graph
Press this button to exit this window.

Press this button to bring up the Help window for this window.

Press this button to create a new set of data that uses the name specified in the Filename field, including data specified in the window. An extension of ".dat" is added to the end of the name of the file.

Press this button to view a menu with the two statistics options shown in Figure 3.23. Specify whether the statistics should be collected separately for each day or for the entire time period.

Press this button to bring up a Graph Options window for displaying and printing graphs that use the data set (Section 3.12).

The filename, dates, and data type fields are the same as those discussed in Section 3.7 for the Temperature \& Pressure ASCII Output window. The tensiometer data type contains the same options as the temperature data type.

\subsection{DATA ERROR WINDOW}

If the Query Tool fails to find data for a selected sensor in a file for a specified date, the window shown in Figure 3.22 appears. This window contains a text region that lists the missing sensor data values.

The buttons in this window perform the following actions:

Quit

Press this button to exit this window.

Help

Press this button to bring up the Help window for this window.

Print

Press this button to print the "Error.log" file, which contains the error messages.

\subsection{STATISTICS WINDOW}

After SAS calculates statistics on sensor readings, the Query Tool displays the Statistics window shown in Figure 3.24. This window contains a text region that lists the different statistical calculations. If the statistics were created by using the By Date option, an additional column is shown that lists the day for which that line of statistics applies. Statistics are calculated separately for each day. If the Overall option is used, the statistics apply to all readings in the time period. The 
statistics shown are as follows: number of readings, mean, standard deviation, standard error, minimum, maximum, corrected sum of squares, coefficient of variance, variance, and skewness.

The buttons in this window perform the following actions:

Quit Press this button to exit this window.

Help Press this button to bring up the Help window for this window.

Print Press this button to print the statistics shown in the window.

\subsection{SAS GRAPH OPTIONS WINDOWS}

The Graph Options windows display a set of data in a SAS graph. The five versions of these windows are shown in Figures 3.25 through 3.29. The windows share general characteristics with slight differences. By using user-specified graph appearance options, the Query Tool creates a SAS program to display or print the graphs. SAS is run in the background to perform the graphing, as shown in Figure 3.30. Multiple graphs can be produced by one call to SAS. The generated SAS program is written to the "sensor.graphs.sas" file in the current directory. You can copy and modify this file to create custom graphs. SAS writes the "sensor.graphs.log" file with an activity log that contains error messages, if any, encountered while processing the program file. Appendix B contains * several sample graphs that illustrate the use of the options in this window.

The buttons in the Graph Options windows perform the following actions:

Quit $\quad$ Press this button to exit this window.

Help Press this button to bring up the Help window for this window.

Display Press this button to display a graph that uses the selected options.

Print Press this button to print the statistics shown in the window.

For pressure data, either the pressure reading or the internal thermistor reading can be graphed. This option is described below:

Sensor Select the option corresponding to the data type that should be graphed.

Readings

For temperature and pressure graphs, you can choose the data values to be shown on the same graph. This option is described below:

Sensor

Readings
Select the two options corresponding to the data types that should be graphed. If Temperature and Pressure or Pressure and Internal Thermistor are selected, graphs with two y-axes are shown. 


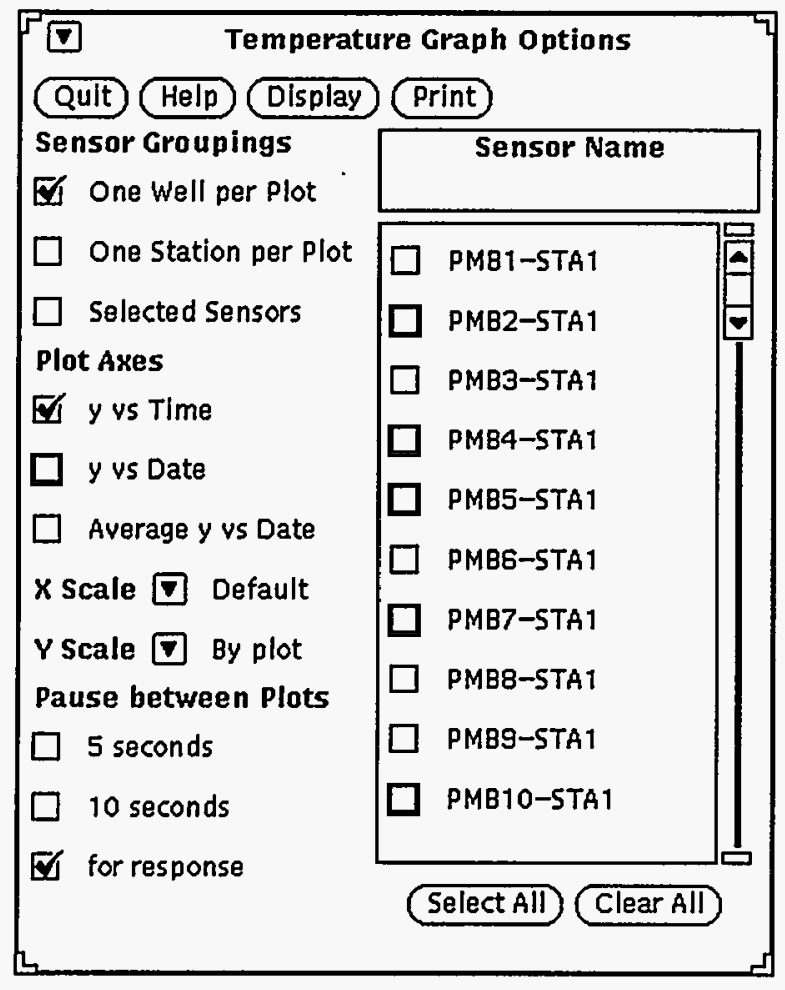

FIGURE 3.25 Temperature Graph Options Window

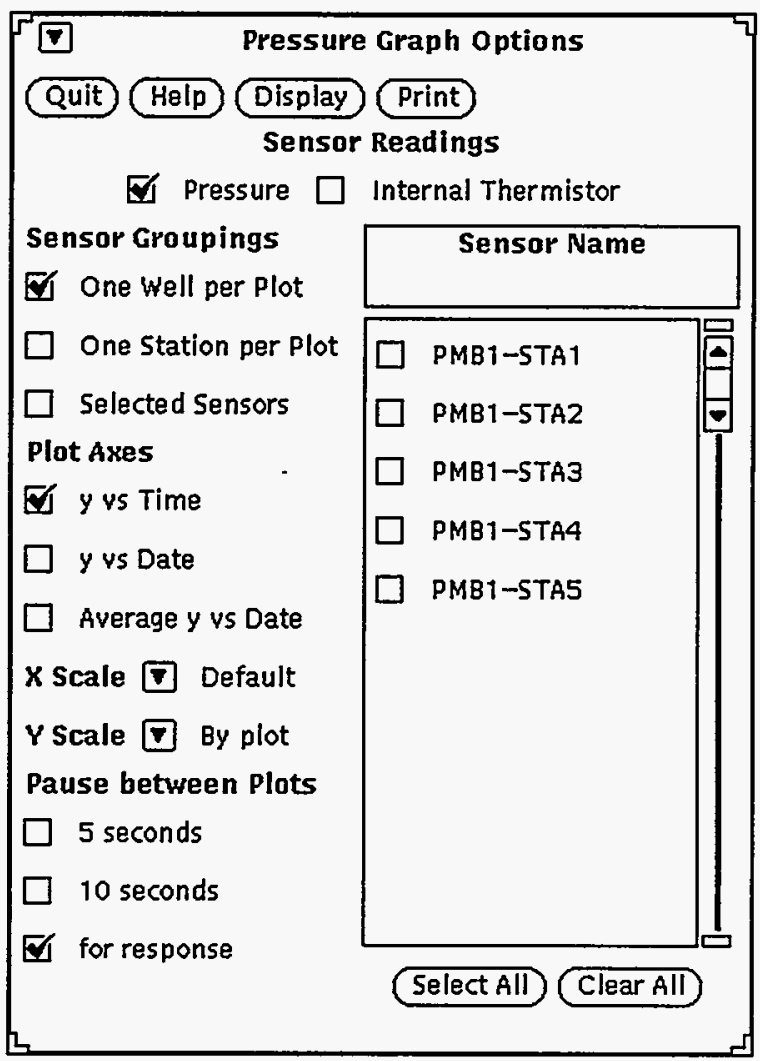

FIGURE 3.26 Pressure Graph Options Window

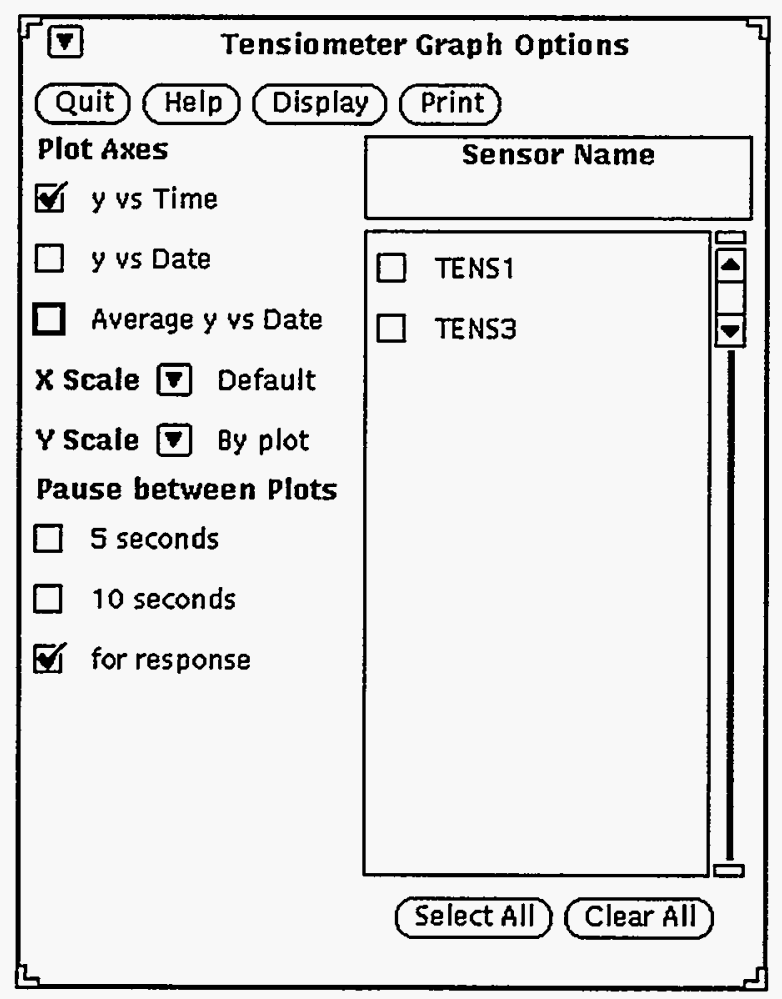

FIGURE 3.27 Tensiometer Graph

Options Window 


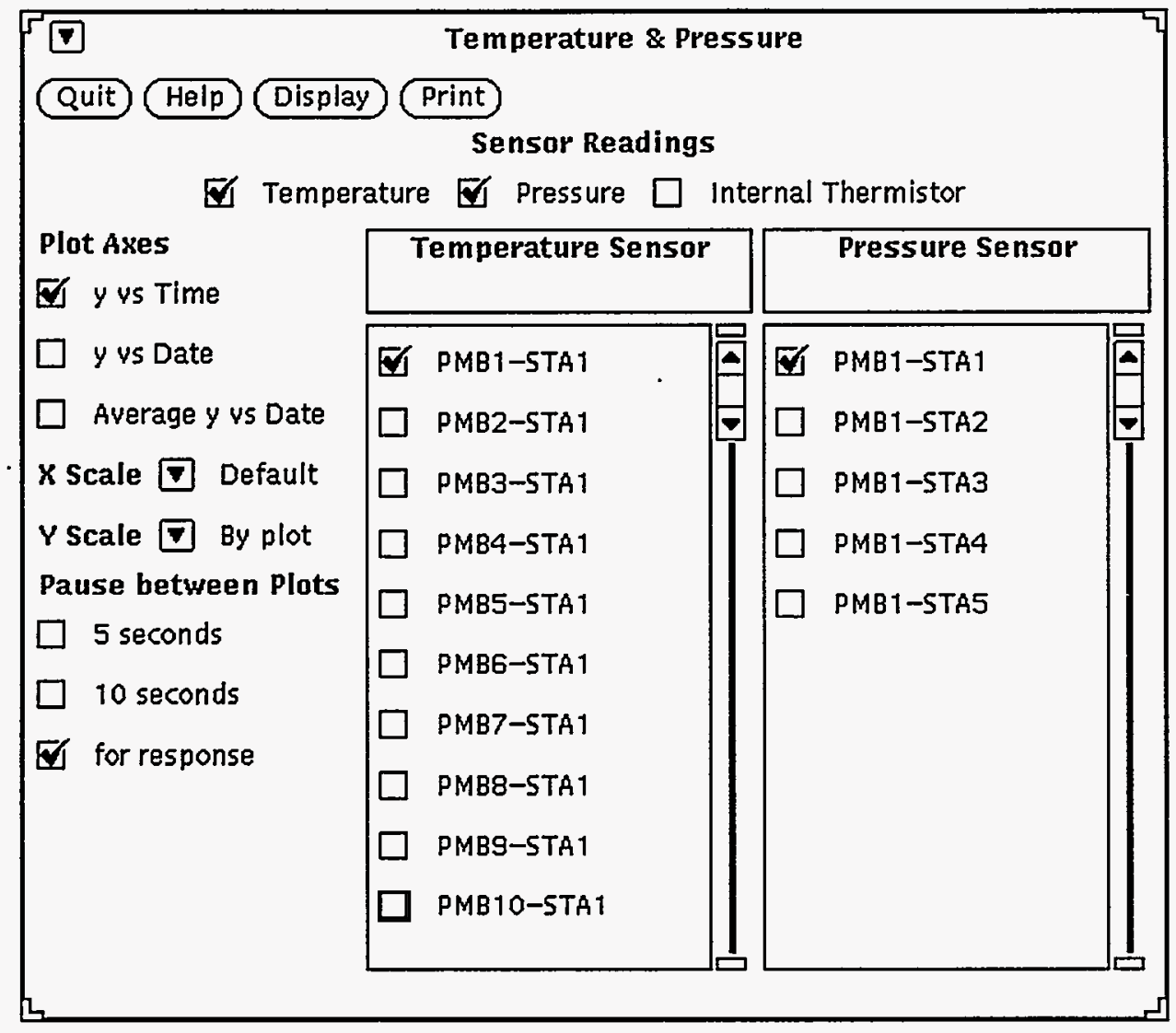

FIGURE 3.28 Temperature \& Pressure Graph Options Window

\begin{tabular}{|c|} 
Quit \\
Selp Display Print \\
Pressure $\square$ Internal Thermistor \\
Plot Axes \\
$\square$ y vs Time \\
$\square$ y vs Date \\
$\square$ Average y vs Date \\
x Scale $\nabla$ Default \\
Y Scale $\square$ By plot \\
Pause between Plots \\
$\square$ 5 seconds \\
$\square$ 10 seconds \\
$\square$ for response
\end{tabular}

FIGURE 3.29 Barometric Pressure Graph Options Window 


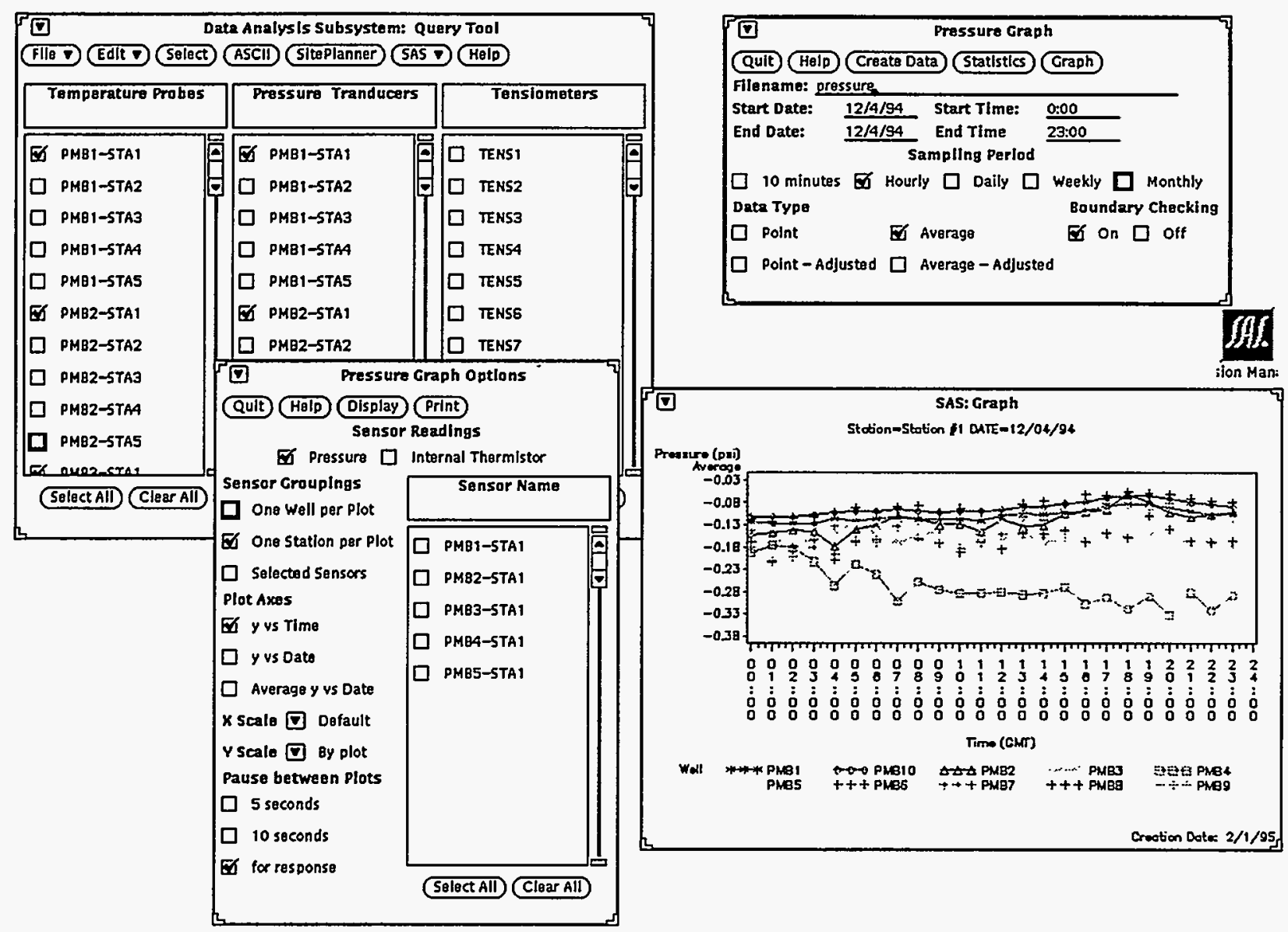

FIGURE 3.30 Sample SAS Screen

For graphs with pressure or temperature readings, multiple graphs may be created. The program needs information on how data should be grouped:

Sensor Select the option that corresponds to the way data should be grouped. You Groupings: can specify whether each graph should show all sensors for one well, all sensors for one station, or all sensors in the selection list on the right side of the window.

The following three options apply to all Graph Options windows:

Plot Axes:

Select the choice option that corresponds to the axes on the graph. The $\mathrm{x}$-axis can be labeled on the basis of either time or date. In addition, $y$ readings can be averaged over each day before creating graphs. If this option is not selected correctly, SAS may display an extremely large number of graphs. If this occurs, use SAS menu options to terminate the display by accessing the SAS icon on the right side of the screen. In addition, the average option should only be used for data created with a Sampling Period: option of less than a day in the SAS Graph window. 
X Scale: $\quad$ Use this option to select how scaling on the $\mathrm{x}$-axis should be performed. The menu shown in Figure 3.31 shows the available options. The Default option scales the $\mathrm{x}$-axis on the basis of the data values. The other options increment the $\mathrm{x}$-scale by days, weeks, or months. If SAS cannot display the x-scale in this way, the graphs are not created, and an error message is listed in the "sensor.graphs.log" file.

Y Scale: $\quad$ Use this option to select how scaling on the $y$-axis should be performed. The menu shown in Figure 3.32 shows the available options. The By plot option scales each graph individually by using the range of all data values. The Uniform option scales all plots the same by using the range of all data values. The Standard option scales all plots by using the minimum and maximum values specified in the Boundaries Editing window.

The tables at the right side of the Graph Options windows show the sensors that should be displayed on the graphs. For the Temperature \& Pressure window, only one sensor of each type can be selected. For all other windows, multiple sensors can be selected, and the Sensor Groupings option determines whether the list is used. This table is not present for the Barometric Pressure window because there is only one sensor of this type, and it is specified in the Barometric Editing window.

\subsection{HELP WINDOW}

The Help window shown in Figure 3.33 shows help information on windows in the Query Tool. The buttons in the Help window perform the following actions:

Quit Press this button to exit this window.

Print Press this button to print the help information.

$X$ Scale $:$ Default

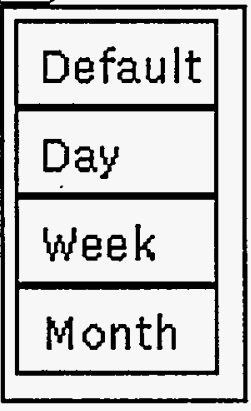

$\checkmark$ Scale $\rightarrow$ By plot

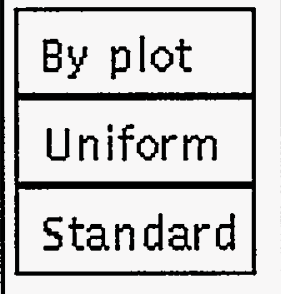

FIGURE 3.32 Y Scale Menu

FIGURE 3.31 X Scale Menu 


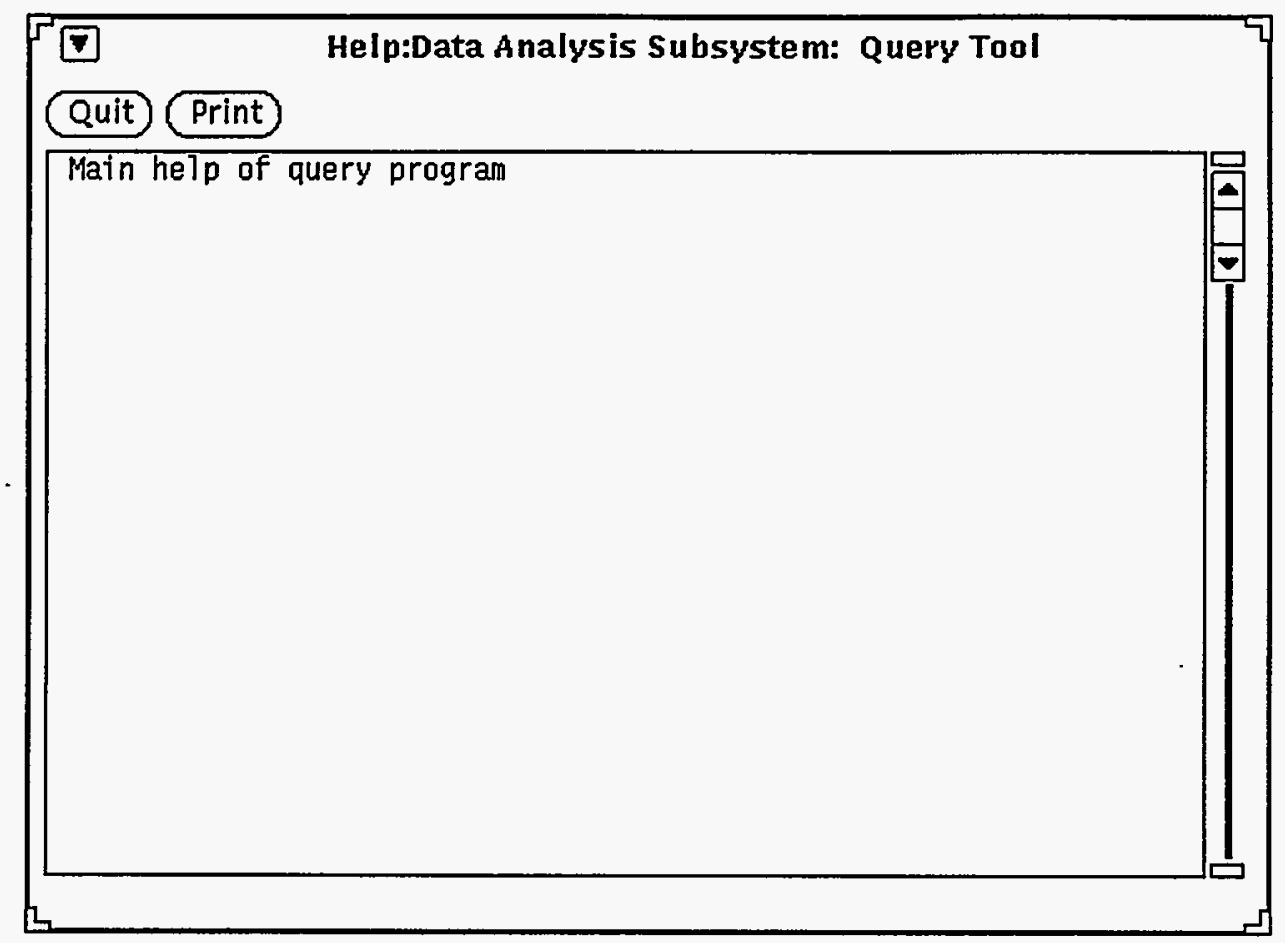

FIGURE 3.33 Help Window

\subsection{SITEPLANNER IMPORT CAPABILITY}

After creating data files as discussed in Section 3.8, you can import these data into objects in SitePlanner. Consult SitePlanner for detailed information on this site analysis package. A sample screen showing the import process is shown in Figure 3.34. To load in sensor data, follow the steps below:

1. Select the Import Spreadsheet option for the SitePlanner menu.

2. Press the Load Template button.

3. Select the name of the template file that corresponds to the first type of sensor data. If the filename is not listed, you must create the file by using the Query Tool. The spreadsheet cell references and object type should appear in the Import Spreadsheet window.

4. Press the Import button. Several small windows will appear with status information.

5. Repeat steps 2 through 4 for the other data types.

When this process is successful, new objects will appear on the SitePlanner stack list. If you encounter problems with this procedure, check your data dictionary to ensure that it contains the correct object for the sensor data. 


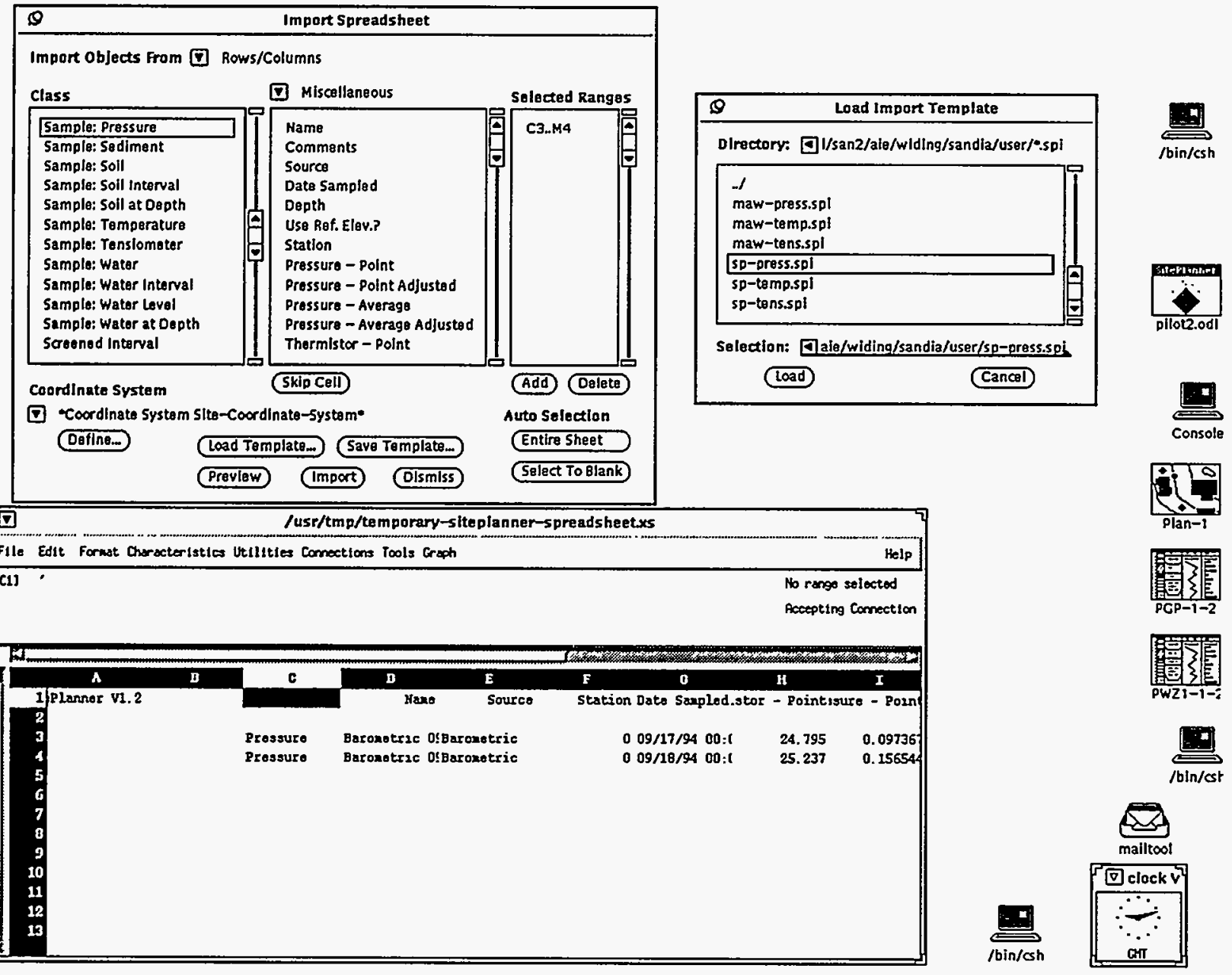

\section{FIGURE 3.34 SitePlanner Import Screen}




\section{CHEMICAL ANALYSIS INTERFACE}

\subsection{CHEMICAL ANALYSIS INTERFACE OVERVIEW}

The Chemical Analysis Interface assists you in entering, verifying, and viewing chemical analysis data. To use this program, enter OpenWindows and change to your working directory. This directory should contain the following files:

Parameters This file contains parameters that specify the directory locations of files used by the program.

detect.Ist This file contains names of chemical compounds, unit types, and detection limits.

sample.ids This file contains the names of the sample source locations.

The program creates other files in the user directory during execution. These files contain reports and export data sets. The chemical data files follow the same naming convention as shown in Figure 2.1. The time is always represented as "0000," because only dates are recorded on chemical samples. The characters "w" and "a" are used to represent water and air sample types.

To run the Chemical Analysis Interface, enter the following command in a shell window:

\section{chem}

\subsection{CHEMICAL ANALYSIS INTERFACE WINDOW}

The main window of the Chemical Analysis Interface is shown in Figure 4.1. This window is used to start the different areas of the program. To edit or verify data, the user must be registered in a password file used by the program. After receiving a chemical report, one user should use the Chemical Analysis Interface to enter the data. A different user should use the program to verify that the entered data is correct. Any user may view or export data.

The buttons on the window perform the following actions:

Quit Press this button to exit the Chemical Analysis Interface.

Help Press this button to bring up the Help window for this window (Figure 3.33).

Enter Data Press this button to enter the series of windows for entering chemical data. 


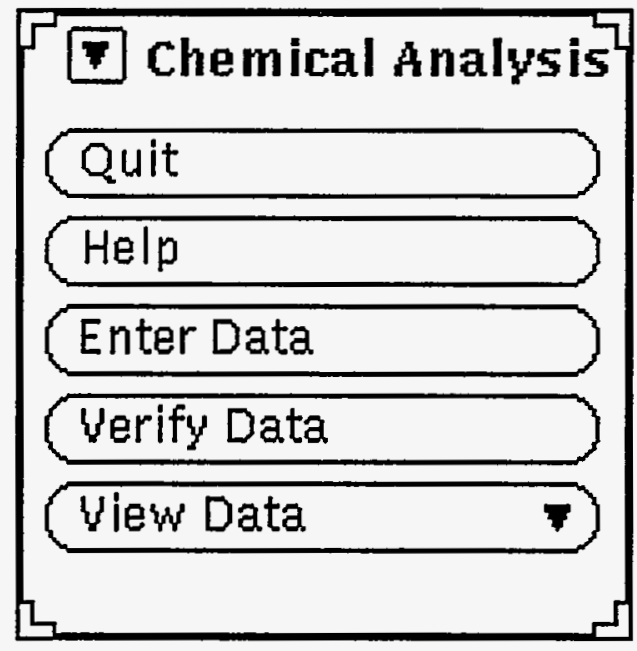

FIGURE 4.1 Chemical Analysis Interface Window

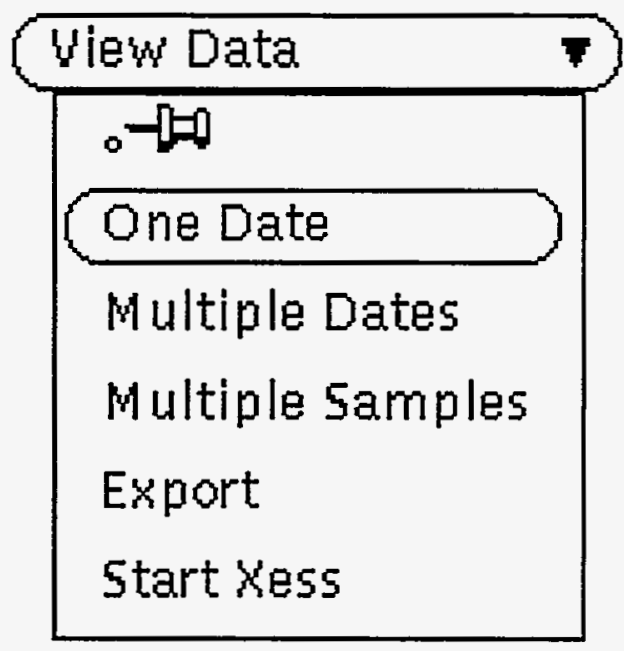

FIGURE 4.2 View Data Menu

Verify Data Press this button to enter the series of windows for verifying chemical data.

View Data Press this button to display the menu for viewing and exporting data (Figure 4.2).

The options in the View Data menu perform the following actions:

One Date

Multiple

Dates

Multiple

Samples

Export

Start Xess
Select this option to view all data for one date (Section 4.16).

Select this option to compare samples from one source on multiple dates (Section 4.20).

Select this option to compare samples from multiple sources on one date (Section 4.22).

Select this option to export all data on multiple dates (Section 4.28).

Press this option to start the Xess process. This action must be performed before using Xess to export data. It may also be performed from the command line, as described in Section 3.8.

\subsection{VERIFY USER WINDOW}

After you press the Enter Data or Verify Data button, the Verify User window appears to verify your login and password (Figure 4.3). The following text fields are used in this window: 


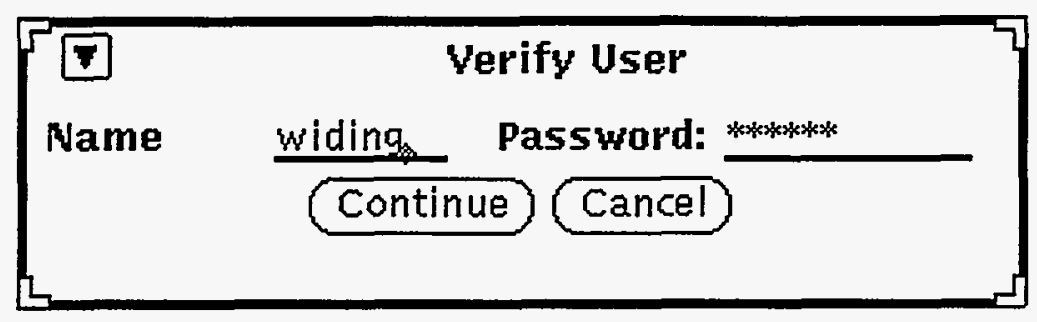

\section{FIGURE 4.3 Verify User Window}

Password: $\quad$ Enter your Chemical Analysis Interface password, not the Sun login password. The characters you type are echoed with the asterisk character.

This window (Figure 4.3) is an example of a Continue-Cancel window. Such windows allow you to enter data before proceeding to the next window, and they do not remain on the screen after a button is pressed. This window has the options listed below:

Continue Press this button to check the password and continue to the next window if the information is valid.

Cancel Press this button to cancel the series of windows.

\subsection{ENTER BASIC DATA WINDOW}

If the login and password entered in the Verify User window are valid, the Enter Basic Data window appears (Figure 4.4).

The buttons on the window perform the following actions:

Quit

Press this button to exit this window. Several notices will appear to ensure that data are saved, if desired.

Help

Press this button to bring up the Help window for this window.

Sample

Data

Press this button to edit an existing data file or create a new one for the date

Detection shown in the window. The Enter Sample Ids window appears.

Limits

Press this button to bring up a window for editing the default detection limits for the chemical compounds.

The other options in this window perform the following functions:

Sample Date:

Type in the date for the data to be entered or changed, in the format $\mathrm{mm} / \mathrm{dd} / \mathrm{yy}$.

Matrix

Select the type of data to be entered from the options shown in Figure 4.5. 


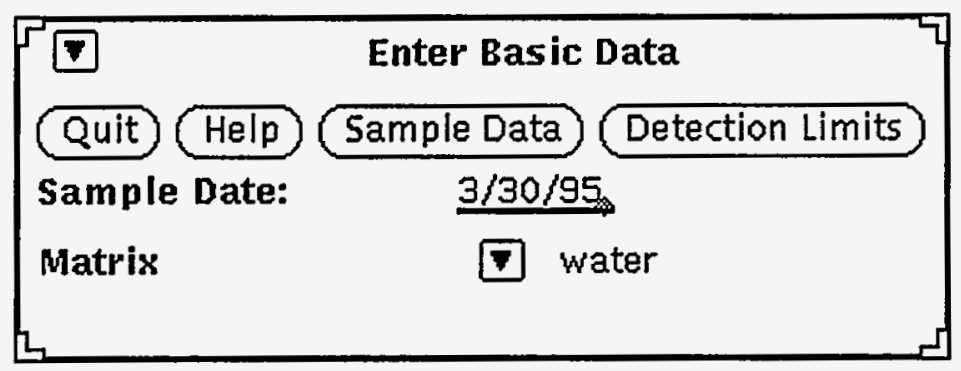

Matrix

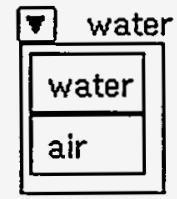

FIGURE 4.5 Matrix Menu

\section{FIGURE 4.4 Enter Basic Data Window}

\subsection{DEFAULT DETECTION LIMITS WINDOW}

The Default Detection Limits window shown in Figure 4.6 allows you to change the number and names of chemical compound types. A table in the window displays compound names, units types, and detection limits. Each user has a private copy of the file "detect.Ist" that stores these values. Changing these values will affect only your private version of the file, and the changes are not retroactive. Data files created with old values will contain the compounds present at the time the data were entered. Only new data files are affected by changes to the compound list. You can also change the unit types and detection limits for each compound. These changes affect the default values shown in creating new data files. The unit type for each compound is not saved with each data file, so changing a unit type does not alter concentration values previously entered.

The buttons on the window perform the following actions:

Quit

Press this button to exit this window. Several notices will appear to ensure that data are saved, if desired.

Help Press this button to bring up the Help window for this window.

Save Press this button to save the data to the "detect.lst" file.

Report Press this button to write a report on the data displayed in the detection limits table.

Add

Press this button to add a new compound type to the list in the table. The new compound will appear at the bottom on the table.

Delete

Press this button to delete the item currently selected in the table.

The table in this window is similar to many others in the Chemical Analysis Interface in that it contains rows of compounds of the following classes: organic, inorganic, or tracers. These tables provide an option that allows you to choose the class of compounds currently displayed. You can select one class, or the All option for all classes. Report and export capabilities apply only to the compounds currently displayed. Appendix A contains a list of these compounds. 


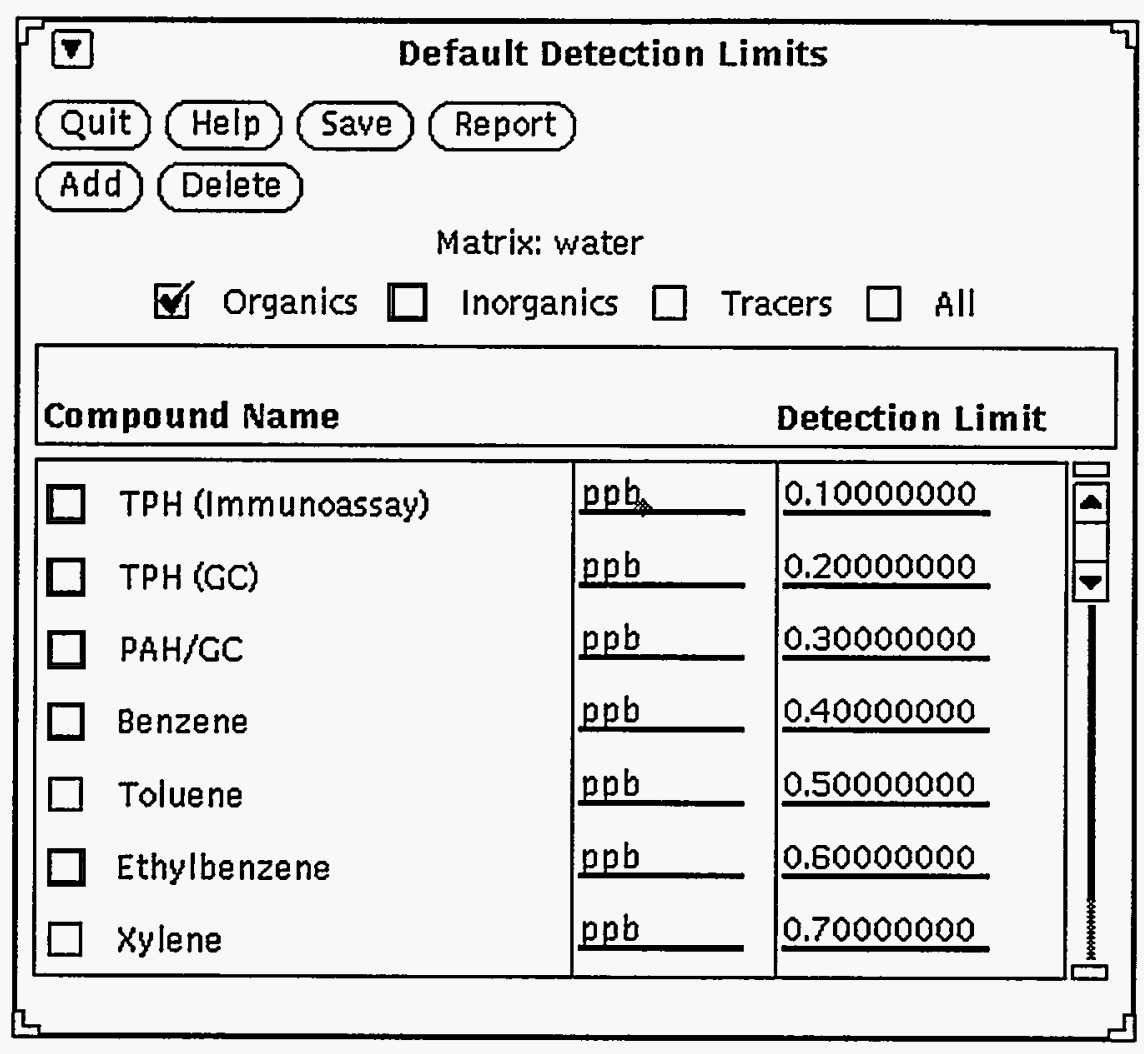

FIGURE 4.6 Default Detection Limits Window

\subsection{REPORT WINDOW}

The Report window shown in Figure 4.7 is used in many of the windows in the program. The label of the Report window reflects the window that originated it. Reports created by the window include data from the originating window. Enter the full name of the file in the Filename field. Select Append to indicate that new report information should be appended to the file, if it exists. Select Print to indicate that the report file should be printed. In report files, each table starts on a new page. If you create a report without immediately printing it, you can print it from a shell window in your working directory by typing the following command:

Ipr test.txt

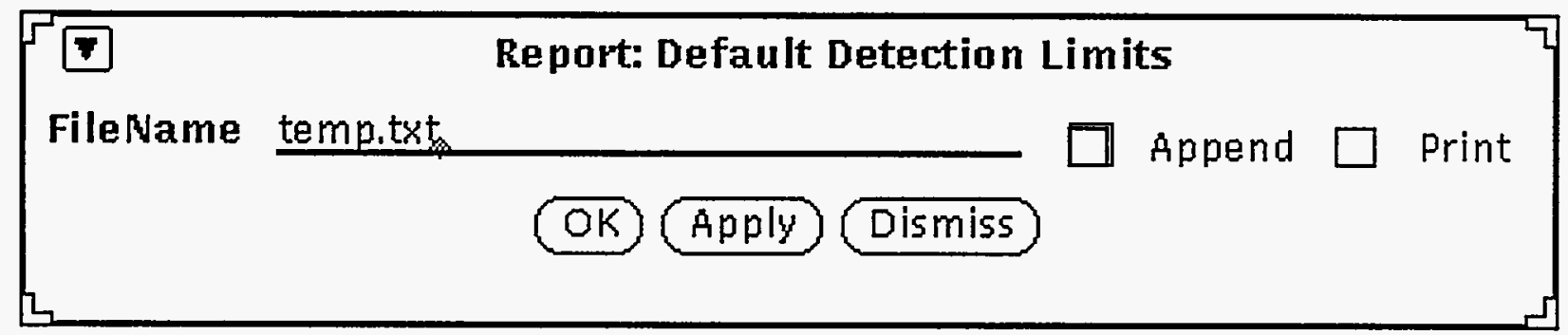

FIGURE 4.7 Report Window 
The Report window is an example of an OK-Apply-Dismiss window. If you press OK, an action occurs, but the window remains on the screen so you can select future actions. If you press Apply, an action occurs and the window disappears. If you press Dismiss, no further actions occur and the window disappears.

The buttons on the window perform the following actions:

OK Press this button to write the report and exit this window.

Apply Press this button to write the report and leave the window on the screen.

Dismiss Press this button to exit the window.

It is important to distinguish between the OK and Dismiss buttons. If you press the Apply button and then the OK button, the same data may be written out twice.

\subsection{ADD NEW COMPOUND WINDOW}

The Add New Compound window allows you to create additional chemical compounds for the Default Detection Limits window. As shown in Figure 4.8, the window contains a Name text field for entering the name of the compound.

The buttons on the window perform the following actions:

OK

Apply

Dismiss
Press this button to add the compound name and exit this window.

Press this button to add the compound. Use this option to add multiple compounds to the Default Detection Limits window.

Press this button to exit the window.

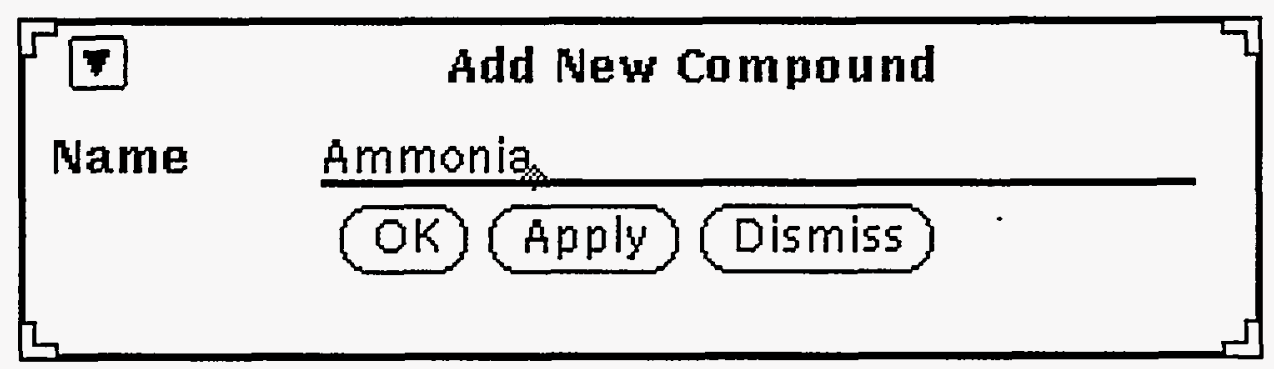

FIGURE 4.8 Add New Compound Window 


\subsection{ENTER SAMPLE Ids WINDOW}

The Enter Sample Ids window is used to enter data for a particular date. As shown in Figure 4.9, the window has a header that contains overall information on the data, along with a table containing previously entered sample identifiers. One sample in the table can be selected at a time. Figure 4.10 shows the form of sample identifiers. The source of the sample is the location where the sample was collected, usually a combination of a well and a station identifier. The next field is the date, in $\mathrm{mm} / \mathrm{dd} / \mathrm{yy}$ format. The next field shows the sample type. The sample types are field blank (FB), trip blank (TB), field duplicate (FD), field duplicate spike (FDS), matrix spike (MS), and matrix spike duplicate (MSD). If the field contains no value, the sample was normal. The final field indicates whether a water sample was obtained by using an air-lift sampler. A value of " $A$ " indicates the water came from an air-lift sampler. If it contains no value, the water came from a lysimeter.

The Enter Sample Ids window contains the following buttons:

Quit

Press this button to exit this window. Several notices will appear to ensure that data are saved, if desired.

Help

Press this button to bring up the Help window for this window.

Save

Press this button to save the data to a file. The file naming convention described in Section 2.1 is used.

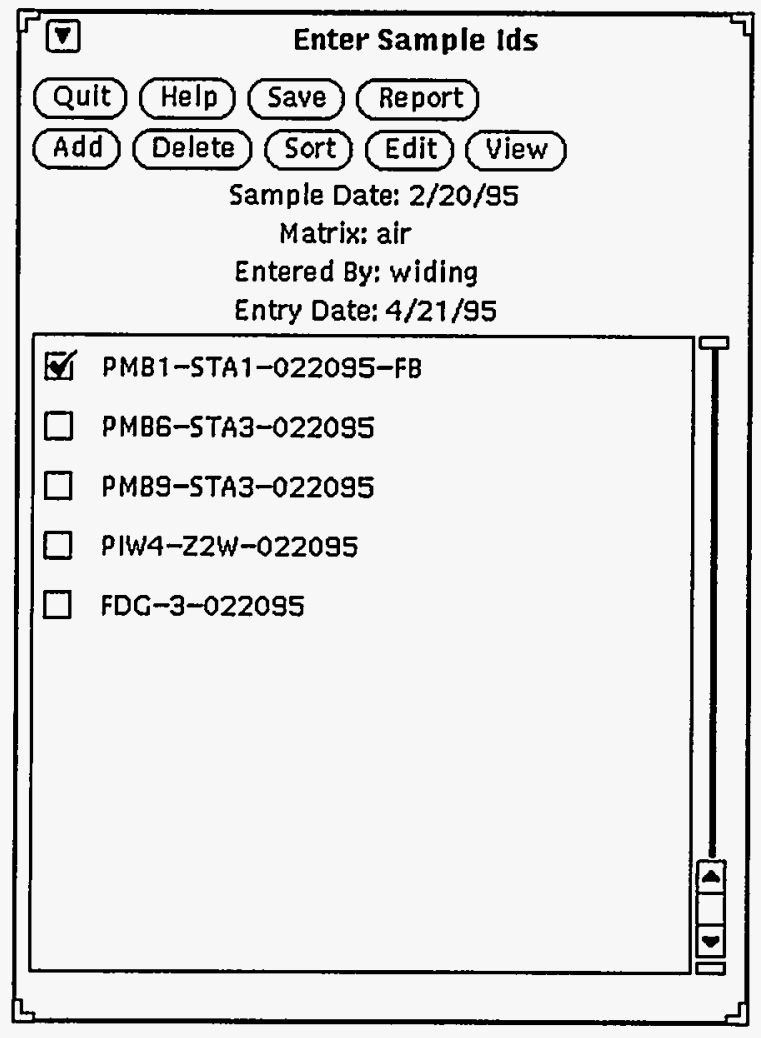

FIGURE 4.9 Enter Sample Ids Window

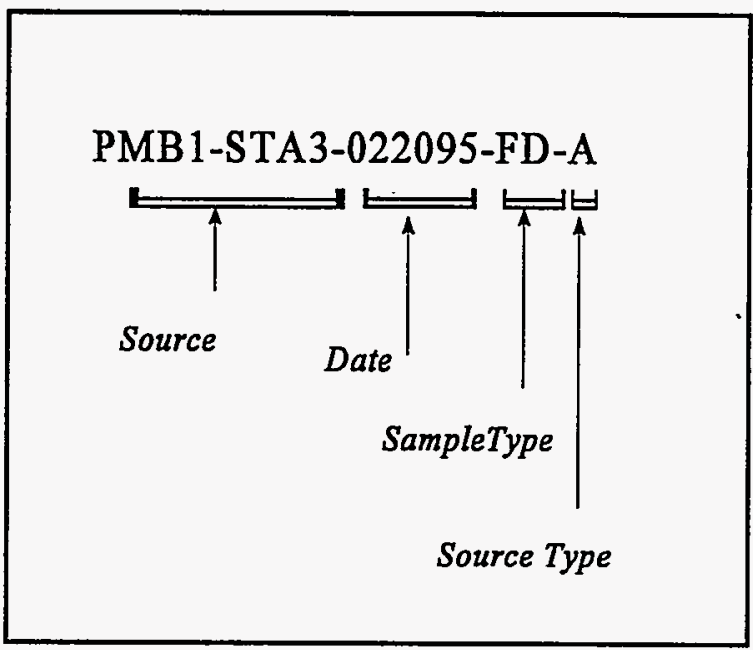

FIGURE 4.10 Sample Identifiers 
Report

Add

Delete

Sort

Edit

View
Press this button to write a report on all the samples listed in the window. This method is the easiest way to create a report with all the data for one date.

Press this button to add a new sample to the list in the table. The new sample will appear at the bottom on the table with a default sample type of normal. This type can be changed in the Enter Samples:Edit window (Section 4.10).

Press this button to delete the sample currently selected in the table. A notice is used to verify the action.

Press this button to sort the samples alphabetically.

Press this button to edit the selected sample.

Press this button to view the selected sample.

\subsection{ADD NEW SAMPLE WINDOW}

The Add New Sample window allows you to add new samples to the Enter Sample Ids window. As shown in Figure 4.11, the window lists all source locations where samples can be taken. Multiple sources can be selected.

\begin{tabular}{|c|c|c|c|c|c|c|c|c|}
\hline ( & & & Add & New Sample & & & & \\
\hline EJ & PMB1-STA1 $\square$ & PMB5-STA1 & $\square$ & PHB9-5TA1 & 口 & PIW3-23I & $\square$ & $F M-11$ \\
\hline$\square$ & PMB1-STA2 $\square$ & PMB5-STAZ & $\square$ & PMB9-STA2 & $\square$ & PIW3-z3W & $\square$ & $F M-12$ \\
\hline$\square$ & PMB1-STA3 $\square$ & PMB5-STA3 & $\mathbb{6}$ & PMBS-STA3 & $\square$ & PIW4-Z2I & $\square$ & $F M-13$ \\
\hline$\square$ & PMBI-STA4 $\square$ & PMB5-STA4 & 口] & PMB9-5TA4 & E & PIW4-Z2W & $\square$ & FM-14 \\
\hline 口] & PMBI-STA5 $\square$ & PMB5-STA5 & $\square$ & PME9-5TA5 & $\square$ & PIW4-Z3i & $\square$ & FDC-1 \\
\hline$\square$ & PMB2-STA1 $\square$ & PMBG-STA1 & $\square$ & PMB10-STAT & 미 & PIW4-Z3W & $\square$ & FDC -2 \\
\hline 口 & PMB2-STA2 $\square$ & PMBG-STA2 & $\square$ & PMB10-STA2 & $\square$ & PWZ1-1 & 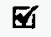 & $F D G-3$ \\
\hline$\square$ & PMB2-STA3 & PMBG-STA3 & $\square$ & PMB10-SִTA3 & $\square$ & PWZ1-2 & & \\
\hline$\square$ & PMB2-STA4 $\square$ & PMB6-STA4 & $\square$ & РМВ10-5TA4 & $\square$ & PWZ1-3 & & \\
\hline$\square$ & PMB2-STAS $\square$ & PMBG-STAS & $\square$ & PMBI0-STA5 & $\square$ & PWZ1-4 & & \\
\hline$\square$ & PMB3-STAI $\square$ & PMB7-STAI & $\square$ & PIW1-Z2| & ㅁ] & $F M-1$ & & \\
\hline$\square$ & PMB3-STAZ $\square$ & PMB7-STA2 & $\square$ & PIW1-Z2W & $\square$ & $F M-2$ & & \\
\hline$\square$ & РМВ3-STA3 $\square$ & PHB7-STA3 & $\square$ & P|W1-Z3| & $\square$ & $F M-3$ & & \\
\hline$\square$ & РМВ3-5TA4 $\square$ & PMB7-STA4 & $\square$ & PIW1-Z3W & $\square$ & $F M-4$ & & \\
\hline$\square$ & РM日3-STA5 $\square$ & PMB7-STA5 & $\square$ & P|W2-Z2| & $\square$ & $F M-5$ & & \\
\hline$\square$ & PMB4-STA1 D & PMB8-STA1 & $\square$ & PIW2-Z2W & $\square$ & $F M-6$ & & \\
\hline$\square$ & PMB4-STA2 $\square$ & PMBB-STA2 & $\square$ & PIWZ-Z3! & $\square$ & $F M-7$ & & \\
\hline 口] & PMB4-STA3 $\square$ & PMBQ-STA3 & $\square$ & PIW2-Z3W & $\square$ & $F M-8$ & & \\
\hline$\square$ & PMB4-STA4 $\square$ & PMBQ-STAA & $\square$ & PIW3-Z2| & $\square$ & $F M-9$ & & \\
\hline $\begin{array}{l}\square \\
50\end{array}$ & $\begin{array}{l}\text { PMB4-5TA5 } \square \\
\text { lect AII Clear Al }\end{array}$ & $\begin{array}{l}\text { PMB8-STAS } \\
\text { II) }\end{array}$ & $\square$ & PIW3-Z2W & 口] & $F M-10$ & & \\
\hline
\end{tabular}


The Add New Sample window has the following options:

Select All Press this button to select all samples in the window.

Clear All Press this button to clear or deselect all samples in the window.

Continue $\quad$ Press this button to add a new sample for each sample selected in this window. Previously added samples are not deleted.

Cancel Press this button to leave the window without adding a new sample.

\subsection{ENTER SAMPLES:EDIT WINDOW}

The Enter Samples:Edit window allows you to edit data for one sample. As shown in Figure 4.12, the window contains a header with general information on the sample. A table in the window allows you to edit compounds for the current sample. This table can be changed to display compounds for different compound classes (i.e., organic, inorganic, or tracers), as described for the Default Detection Limits table (Section 4.5). The last two columns in the table are tied together. A concentration may consist of a real value or one of the following strings: "ND" (not detected) or "NS" (not sampled). If a choice is selected, the concentration number for that row is set to 0.0. If a nonzero value is entered, no choices are selected for that row.

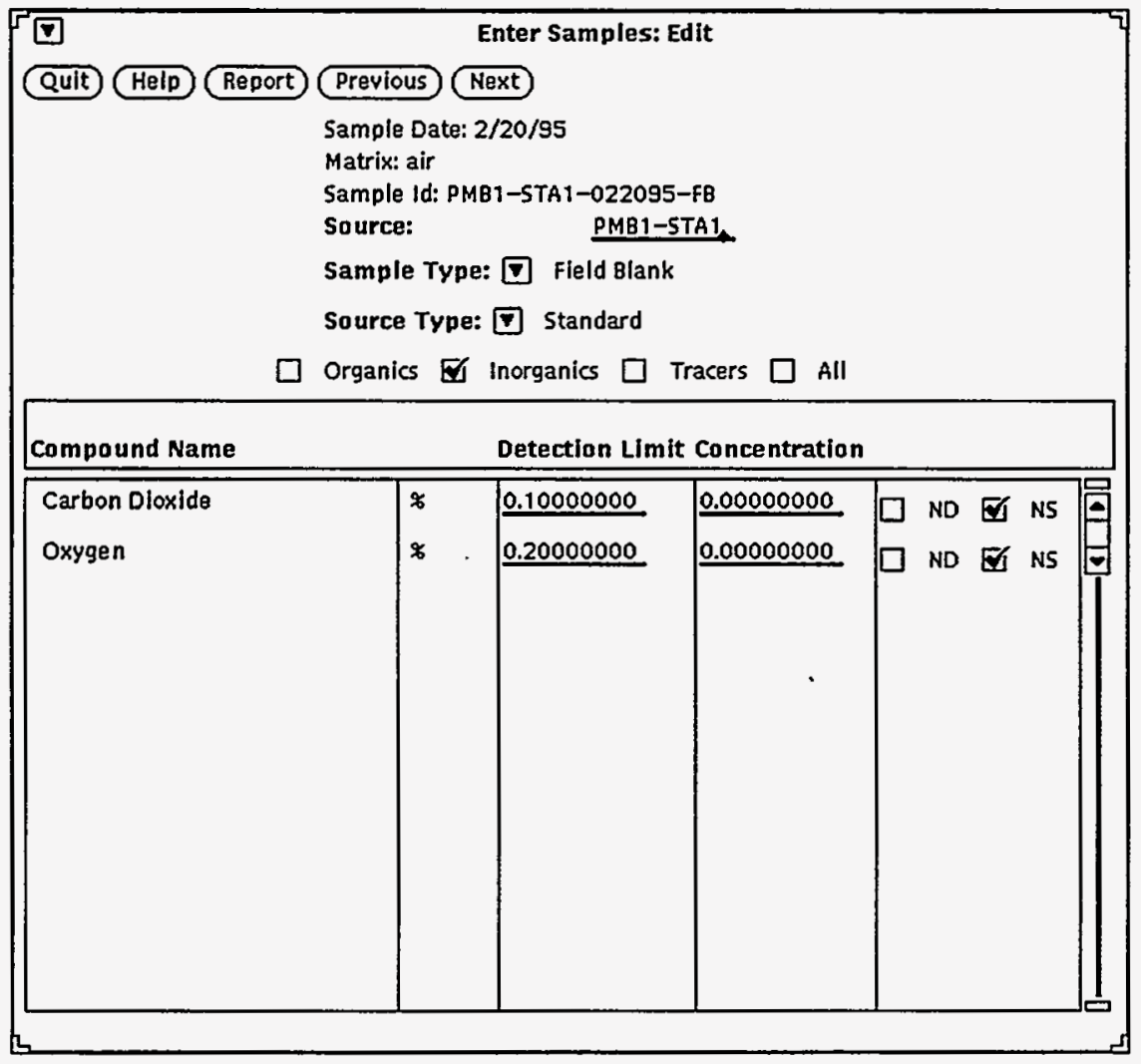

FIGURE 4.12 Enter Samples:Edit Window 
The buttons on the window perform the following actions:

Quit Press this button to exit this window.

Help Press this button to bring up the Help window for this window.

Report Press this button to write a report on the data currently displayed in the table.

Previous Press this button to edit the data for the sample before the current one in the Enter Sample Ids window.

Next Press this button to edit the data for the sample after the current one in the Enter Sample Ids window.

The Sample Id: field is automatically updated when new parameters are selected for the sample. The corresponding identifier in the Enter Sample Ids window is also updated in response to these changes. The following options affect the sample identifier:

Source:

Type the name of the source of the sample. This field should be used infrequently.

Sample Type: $\quad$ Select the type of sample from the choices shown in Figure 4.13.

Source Type: $\quad$ For a water sample, select the type of source from the choices shown in Figure 4.14. For an air sample, this choice is always set to Standard.

\subsection{ENTER SAMPLES:VIEW WINDOW}

The Enter Samples:View window allows you to view the data for one sample. As shown in Figure 4.15, the window is very similar to the Enter Samples:Edit window. However, none of the items can be edited. For a description of the buttons in this window, refer to Section 4.10.

\begin{tabular}{l|l|} 
Sample Type: & Normal \\
\hline & Normal \\
\hline Field Blank \\
\hline Trip Blank \\
\hline Field Duplicate \\
\hline Field Duplicate Spike \\
\hline Matrix Spike \\
\hline Matrix Spike Duplicate \\
\hline
\end{tabular}

FIGURE 4.13 Sample Type Choice
Source Type: 7 Lysimeter

\begin{tabular}{|l|}
\hline Lysimeter \\
\hline Air Lift Sampler \\
\hline
\end{tabular}




\subsection{VERIFY SAMPLE DATA WINDOW}

If the login and password entered in the Verify User window are valid after the Verify Data option is selected from the main window, the Verify Basic Data window appears (Figure 4.16). This window allows you to view data files entered previously. This window is similar to the Enter Basic Data window. For a description of the items on this window, refer to Section 4.4. A Detection Limits button is not available, however, because the default values are used only for initializing newly entered data.

\subsection{VERIFY SAMPLE Ids WINDOW}

The Verify Sample Ids window allows you to view and verify a sample for a particular date for accuracy. As shown in Figure 4.17, this window is similar to the Enter Sample Ids window. Refer to Section 4.8 for a description of the buttons and options in this window. The header in the Verify Sample Ids window also contains the name of the user performing the verification and the date.

\subsection{VERIFY SAMPLES:EDIT WINDOW}

The Verify Samples:Edit window allows you to verify and edit one sample. As shown in Figure 4.18, this window is similar to the Enter Samples:Edit window. Refer to Section 4.10 for a description of the buttons and options in this window. The header in the Verify Samples:Edit window also contains the name of the user performing the verification and the date.

\subsection{VERIFY SAMPLES:VIEW WINDOW}

The Verify Samples:View window allows you to view one sample. As shown in Figure 4.19, this window is similar to the Enter Samples:View window. Refer to Section 4.11 for a description of the buttons and options in this window. The header in the Verify Samples:View window also contains the name of the user performing the verification and the date.

\subsection{VIEW DATES WINDOW}

The View Dates window, is used to view all sample data for one date. As shown in Figure 4.20, a date can be selected from a scrolling list. A choice at the bottom on the window will update the list of dates on the basis of the selected matrix type, either water or air. 


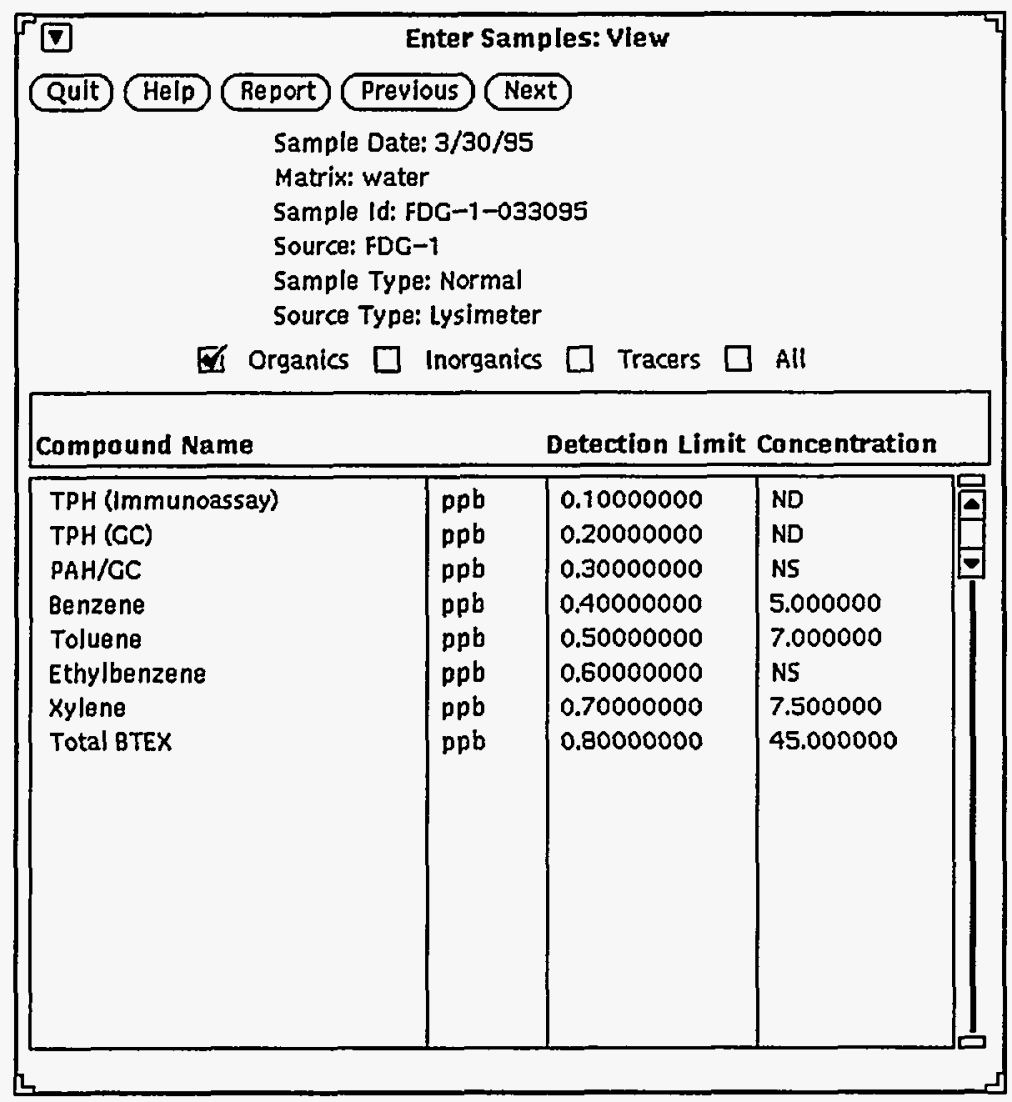

FIGURE 4.15 Enter Samples: View Window

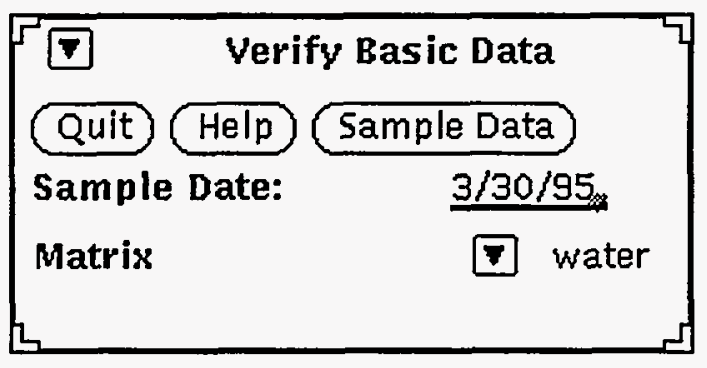

FIGURE 4.16 Verify Basic Data Window

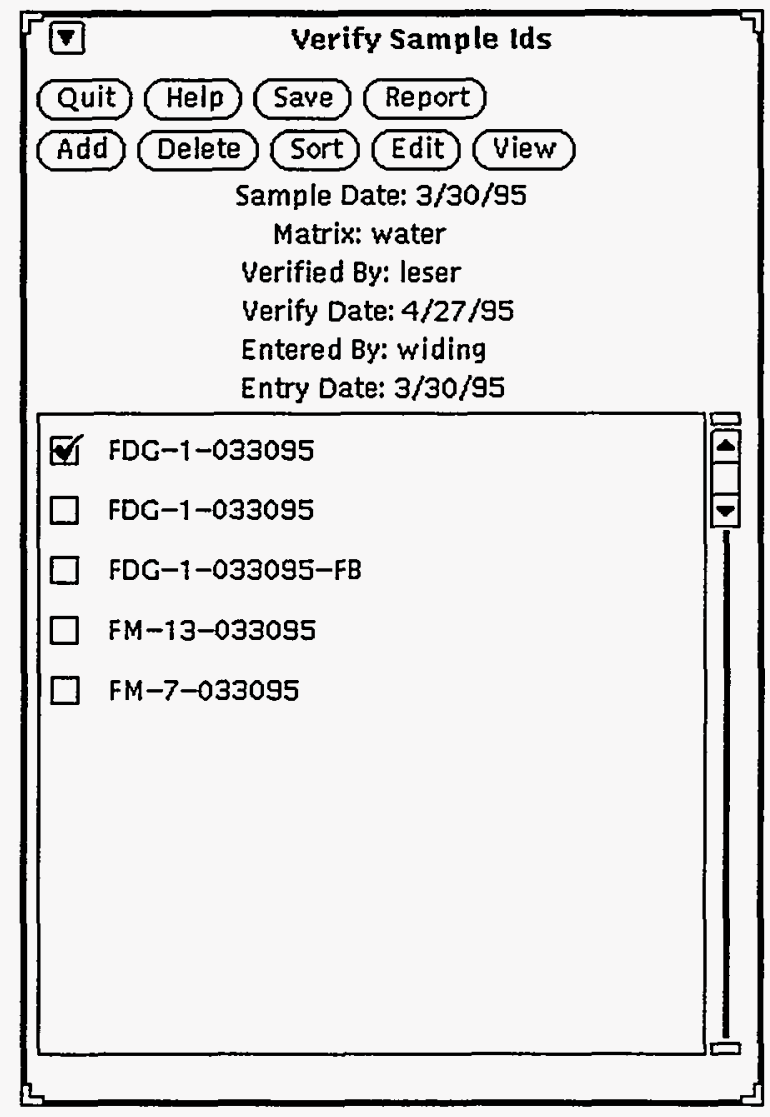

FIGURE 4.17 Verify Sample Ids Window 


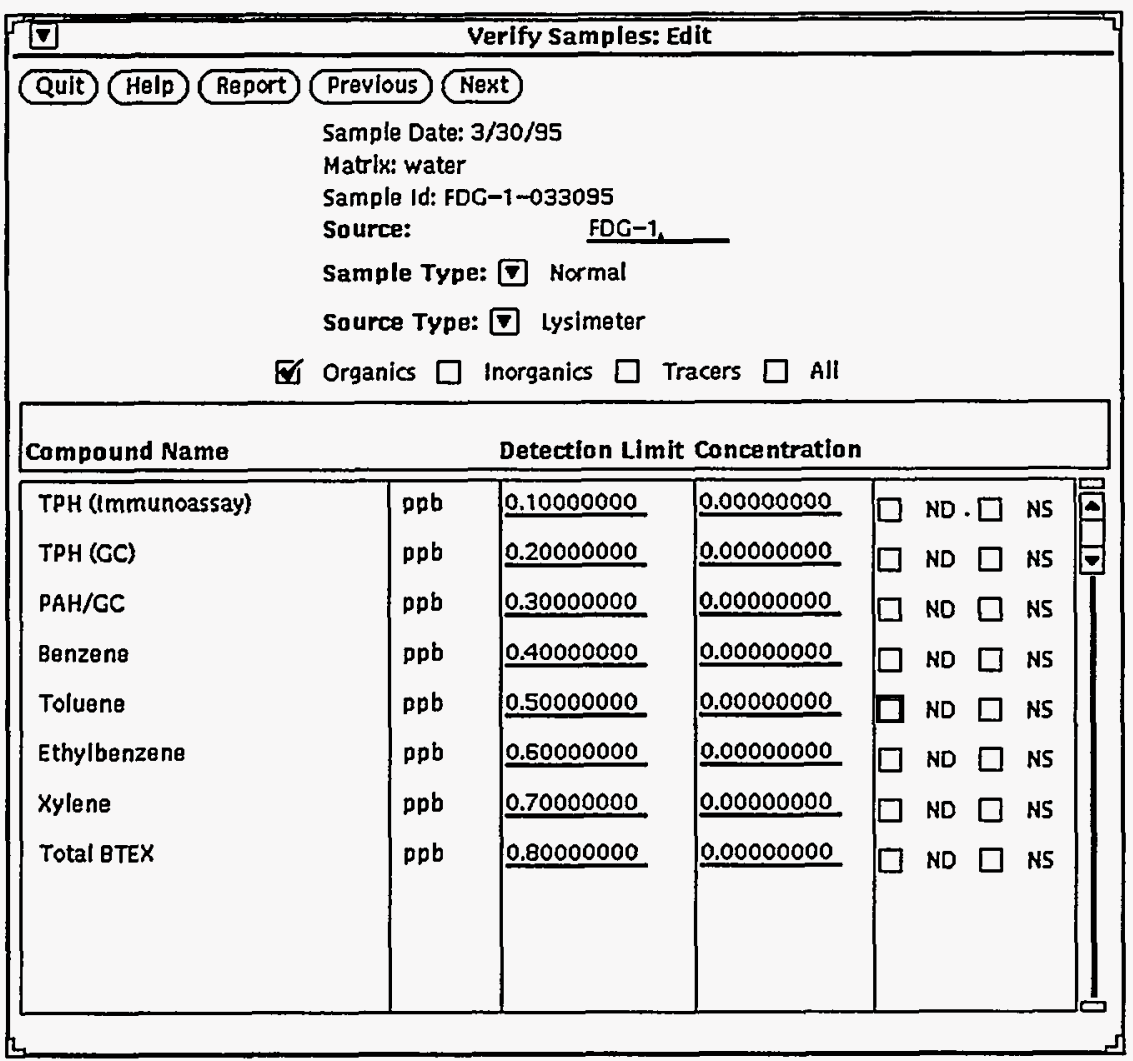

FIGURE 4.18 Verify Samples: Edit Window

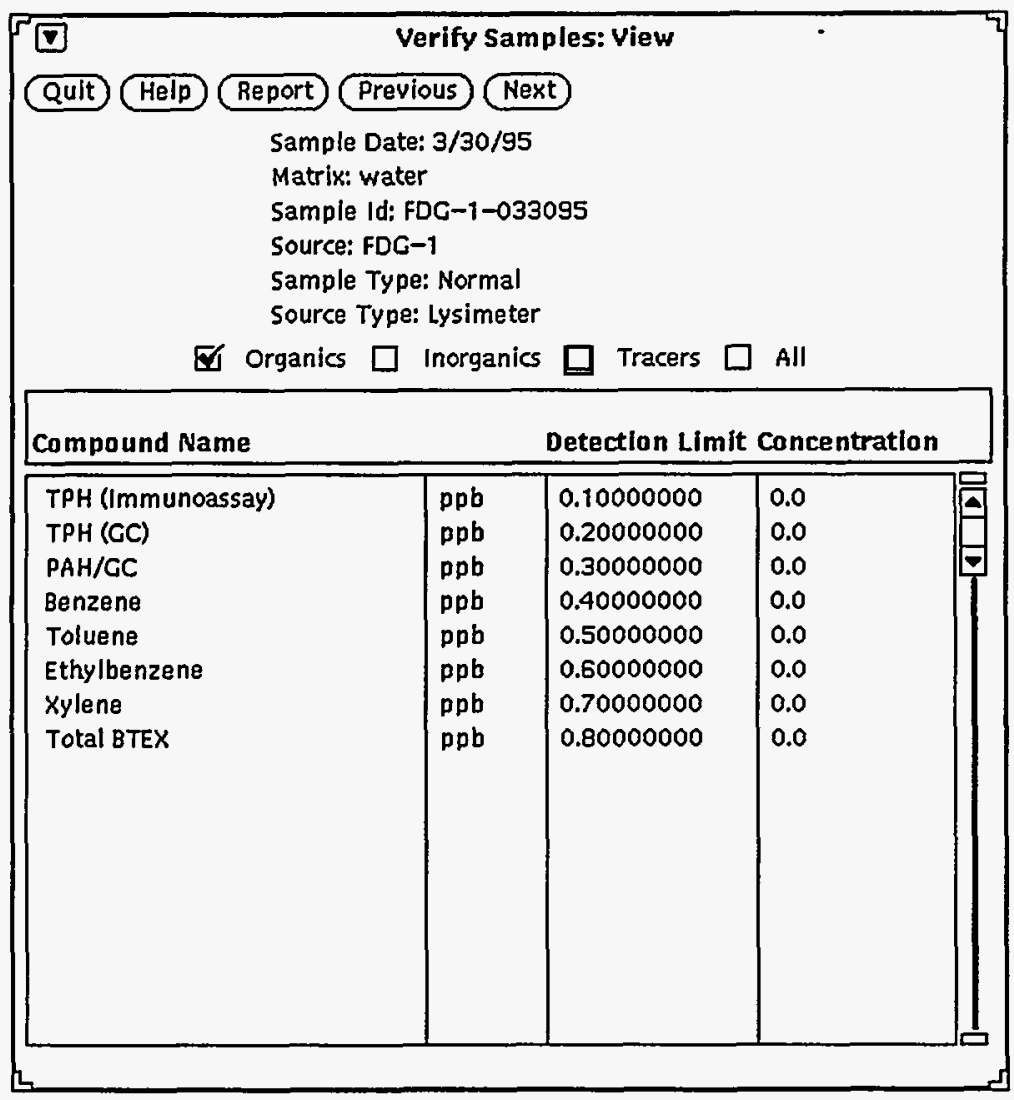

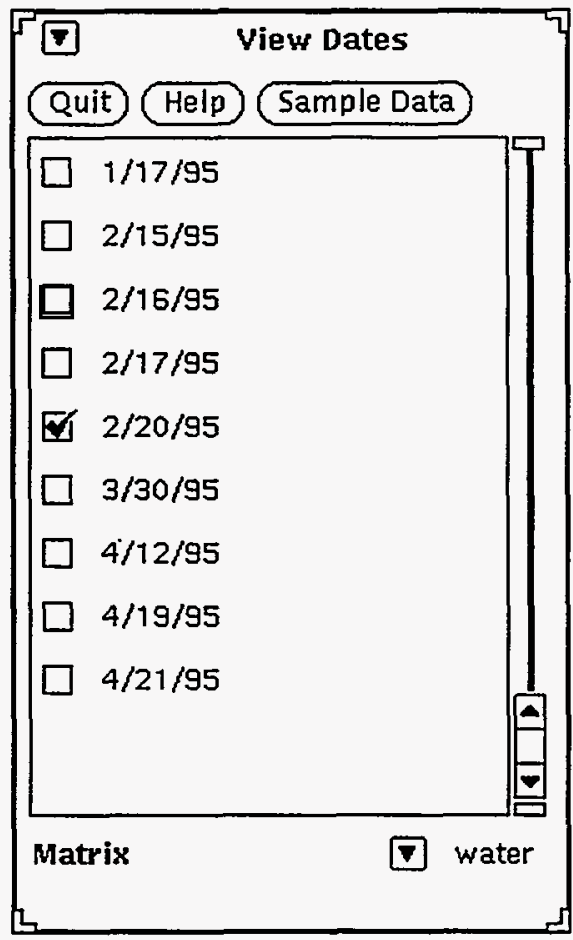


The buttons on the View Dates window perform the following actions:

Quit

Help

Sample

Data
Press this button to exit this window.

Press this button to bring up the Help window for this window.

Press this button to bring up the View Sample Ids window with information from the data file for the indicated matrix and date.

\subsection{VIEW SAMPLE Ids WINDOW}

The View Sample Ids window contains a header with general information and a list of samples collected on one date. As shown in Figure 4.21, a sample identifier can be selected from the window for viewing.

\begin{tabular}{|c|c|c|}
\hline $\begin{array}{l}\text { Qui } \\
\text { Qui }\end{array}$ & 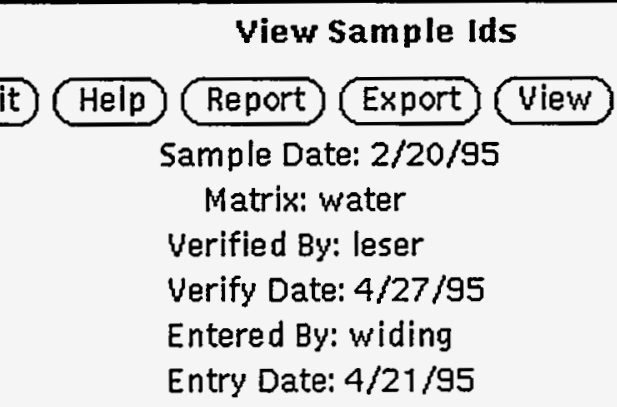 & \\
\hline$\nabla$ & FDG-3-022095 & 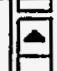 \\
\hline$\square$ & PIW4-Z2W-022095 & $\theta$ \\
\hline$\square$ & PMB1-STA1-022095 & \\
\hline$\square$ & PMB1-STA3-022095 & \\
\hline$\square$ & PMB1-STA3-022095-FD & \\
\hline$\square$ & PMB1-STA4-022095 & \\
\hline & PMB1-STA5-022095 & \\
\hline$\square$ & PMB6-STA3-022095 & \\
\hline & PMB9-STA3-022095 & \\
\hline
\end{tabular}

FIGURE 4.21 View Sample Ids Window 
The buttons on this window perform the following actions:

Quit Press this button to exit this window.

Help Press this button to bring up the Help window for this window.

Report Press this button to write a report with all the samples on this date.

Export Press this button to export all the samples on this date.

View Press this button to bring up the View Samples window with information on the selected sample.

\subsection{EXPORT WINDOW}

The Export window allows you to write out data to a comma-delimited output file for later inport into other software packages such as Excel or Xess. As shown in Figure 4.22, this window is similar to the Report window (Section 4.6). This window contains an additional option, the Xess Conversion option. When this choice is selected (the default), an additional action is taken during an export: Xess is used to read in the export file and write it out in its format. If Xess is not running, this action will not be performed, and only one file will be created. The filename you enter forms the new Xess output filename. If the filename has a ".csv" extension, the extension is removed before adding the extension ".xs." If the extension ".csv" was not added to the filename, the extension ".xs" is added to the filename the user entered. If the Xess connection works correctly, two files are created by the export operation.

\subsection{VIEW SAMPLES WINDOW}

The View Samples window is used to view one sample. As shown in Figure 4.23, this window is similar to the Verify Samples:View window (Section 4.15). The window also contains the following button:

Export Press this button to display the Export Window (Section 4.18) to export the data displayed in this window. Only data for this sample are exported.

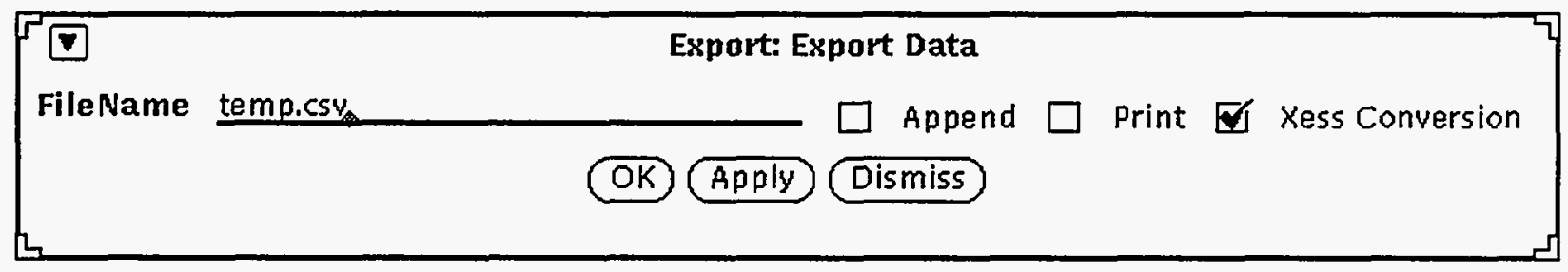

FIGURE 4.22 Export Window 


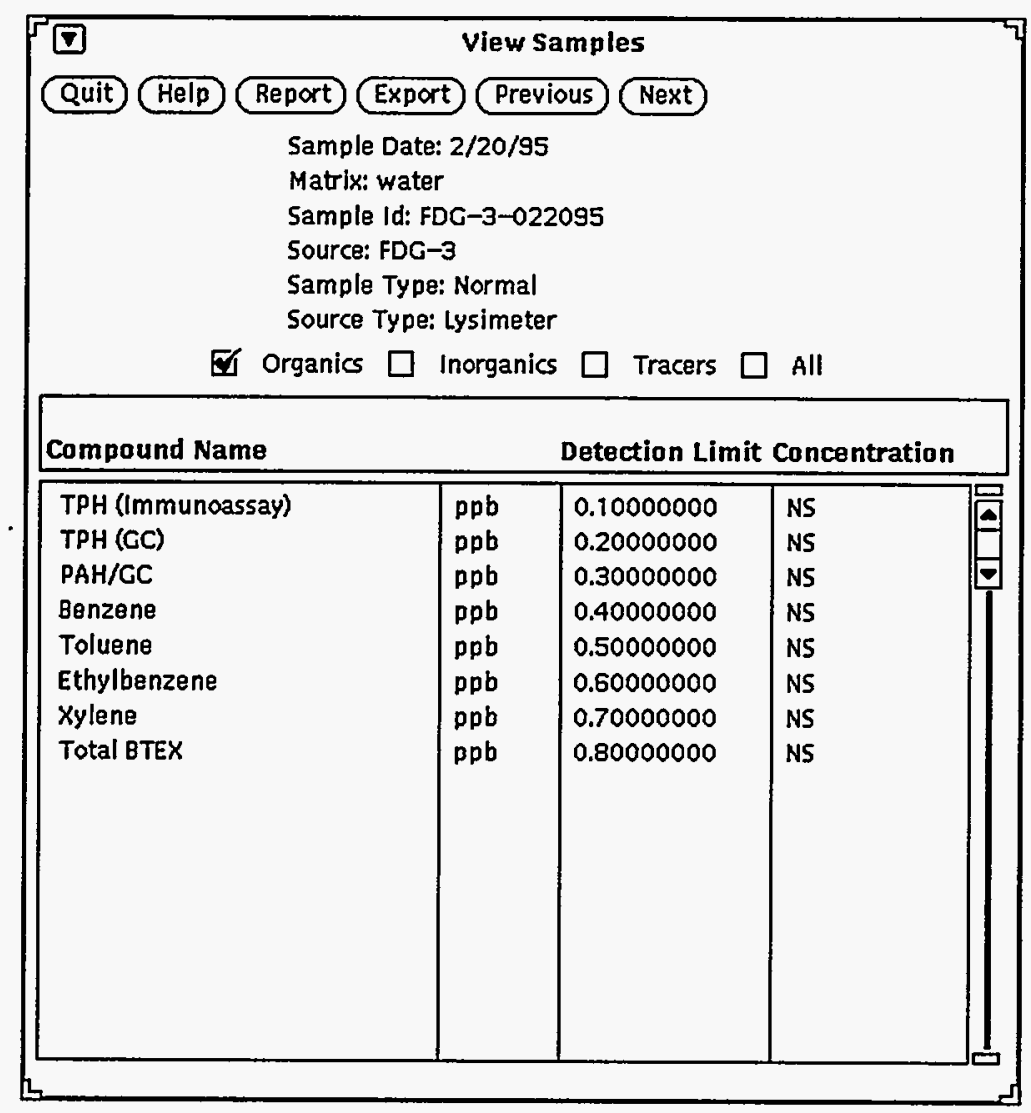

FIGURE 4.23 View Samples Window

\subsection{VIEW ONE SAMPLE ON MULTIPLE DATES WINDOW}

The View One Sample on Multiple Dates window allows you to select one sample from multiple dates to view. As shown in Figure 4.24, the window contains two tables: one with dates and one with sample sources. Up to five dates can be selected from the first table, but only one sample source can be selected from the second table. The date options in the first table are updated on the basis of the current setting of the Matrix choice below the table. All samples are assumed to be of normal type. An additional option is the Source Type: choice. This option is used to further clarify the sample identifiers that should be shown in the viewing window.

The buttons on this window perform the following actions:

Quit

Help

Sample

Data
Press this button to exit this window.

Press this button to bring up the Help window for this window.

Press this button to bring up the View Sample at Dates window with information on the selected dates and sample. 


\subsection{VIEW SAMPLE AT DATES WINDOW}

The View Sample at Dates window shows the data entered for a particular sample on multiple dates. As shown in Figure 4.25, the main element in the window is a large table. This table contains the compound names, units, and concentrations on the indicated dates. One concentration column is used for each date. If a compound was not in the compound list or a specific sample was never entered on a date, the concentration field contains the character string "--.". This value is not the same as an "NS" designation, which means that the user entered a "not sampled" value for a compound on the date.

The buttons on this window perform the following actions:

Quit

Press this button to exit this window.

Help

Press this button to bring up the Help window for this window.

Report

Export
Press this button to write a report with the data shown in the table. Only compounds currently in the table are written.

Press this button to display the Export Window to export the data shown in the table. Only compounds currently in the table are written.

\subsection{VIEW MULTIPLE SAMPLES ON ONE DATE WINDOW}

The View Multiple Samples on One Date window allows you to select and view multiple samples from one date. As shown in Figure 4.26, the window contains two tables similar to the ones in the View One Sample on Multiple Dates window. Only one date can be selected from the first table, but more than one sample source can be selected from the second table.

The buttons on this window perform the following actions:

Quit

Help

Sample

Data
Press this button to exit this window.

Press this button to bring up the Help window for this window.

Press this button to bring up the View Samples at Date window with information on the selected date and samples. 


\begin{tabular}{|c|c|c|c|}
\hline \multicolumn{4}{|c|}{ Quit Help Sample Data } \\
\hline$\square \quad 1 / 17 / 95$ & & E1 PMB1-STA1 & $\Delta$ \\
\hline$\square \quad 2 / 15 / 95$ & & $\square \quad$ PMB1-STA2 & $\nabla$ \\
\hline$\square$ 2/16/95 & & $\square$ PMB1-STA3 & \\
\hline$\square \quad 2 / 17 / 95$ & & $\square$ PMB1-STA4 & \\
\hline (4) $2 / 20 / 95$ & & $\square$ PMB1-STA5 & \\
\hline$\square \quad 3 / 30 / 95$ & & $\square$ PMB2-STA1 & \\
\hline$\square$ 4/12/95 & & $\square$ PMB2-STA2 & \\
\hline$\square$ 4/19/95 & & $\square$ РМВ2-STA3 & \\
\hline \multirow[t]{3}{*}{ EJ $4 / 21 / 95$} & 6 & $\square$ PMB2-STA4 & \\
\hline & $\theta$ & $\square$ PMB2-STA5 & \\
\hline & & $\square$ OMR2_STO1 & \\
\hline Matrix & $\nabla$ water & Source Type: 7 & \\
\hline
\end{tabular}

FIGURE 4.24 View One Sample on Multiple Dates Window

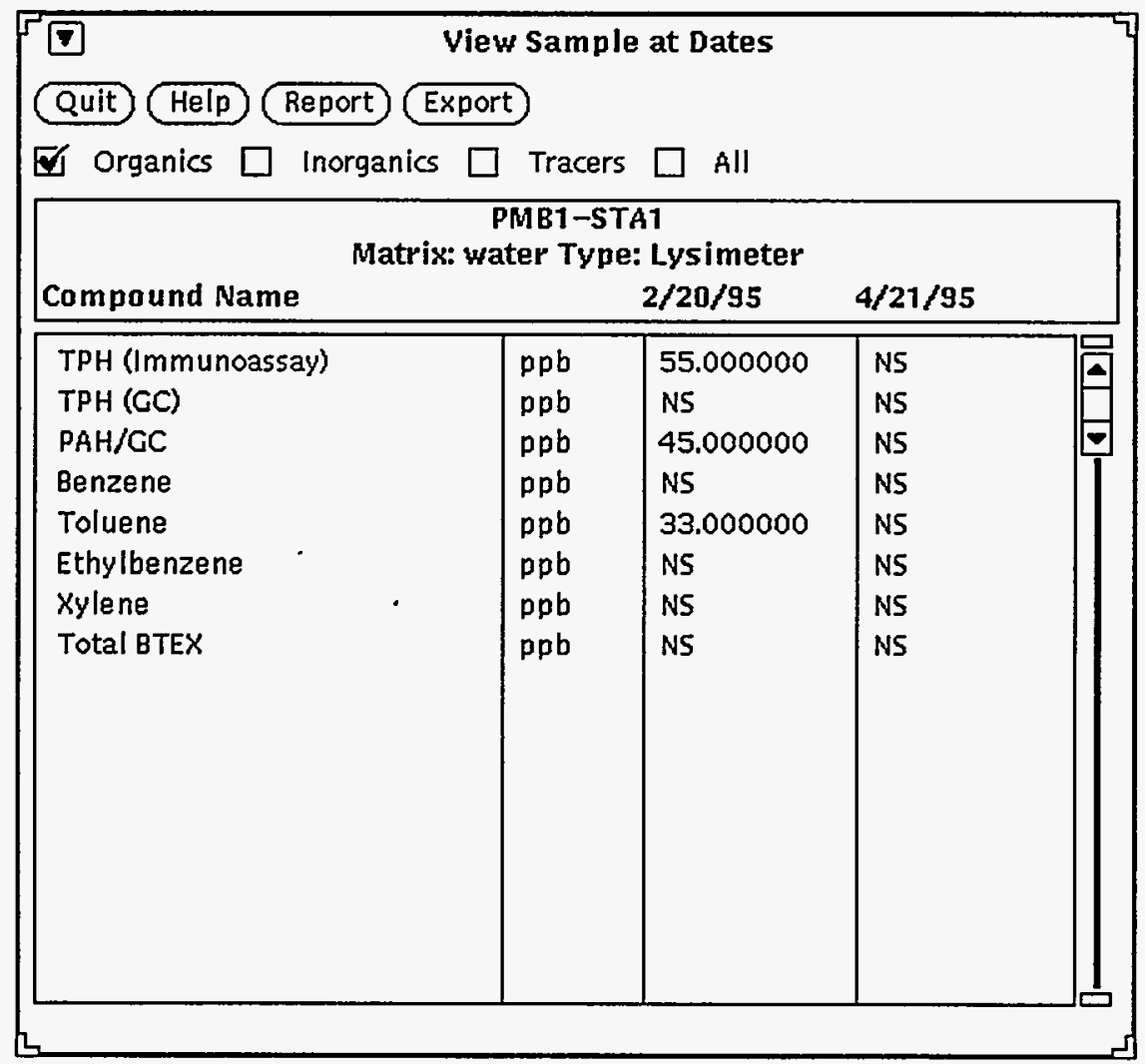

FIGURE 4.25 View Sample at Dates Window 


\subsection{VIEW SAMPLES AT DATE WINDOW}

The View Sample at Dates window shows the data entered for multiple samples on a particular date. As shown in Figure 4.27, the main element in the window is a large table. This table

\begin{tabular}{|c|c|c|c|}
\hline \multicolumn{3}{|c|}{ Quit Help Sample Data } & \\
\hline$\square$ 1/17/95 & & $\Phi$ PMB1-STA1 & 禺 \\
\hline$\square$ 2/15/95 & & EI & $\theta$ \\
\hline$\square \quad 2 / 16 / 95$ & & E) РMB1-STA3 & \\
\hline$\square \quad 2 / 17 / 95$ & & $\square$ РМВ1-5TA4 & \\
\hline 2/20/95 & & $\square$ PM81-STA5 & \\
\hline$\square$ 3/30/95 & & $\square$ PMB2-STA1 & \\
\hline$\square$ 4/12/95 & & $\square$ PMB2-STA2 & \\
\hline$\square$ 4/19/95 & & $\square$ РMB2-STA3 & \\
\hline \multirow[t]{2}{*}{ 4/21/95 } & 1 & $\square$ PMB2-STA4 & \\
\hline & 百 & $\square$ PMB2-STA5 & \\
\hline Matrix & water & Source Type: $\nabla$ & \\
\hline
\end{tabular}

FIGURE 4.26 View Multiple Samples on One Date Window

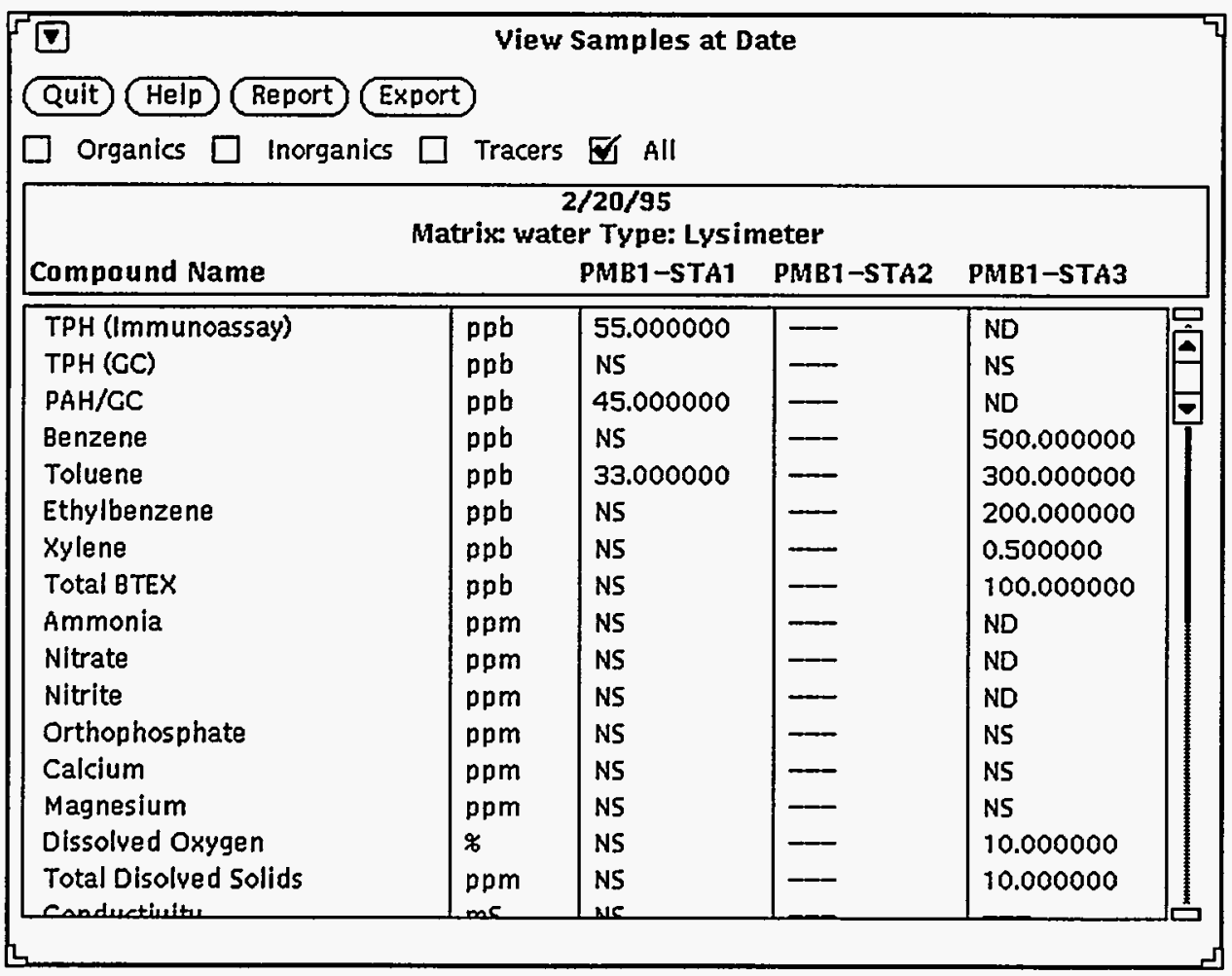

FIGURE 4.27 View Samples at Date Window 
contains the compound names, units, and concentrations of the indicated samples on the selected date. One concentration column is used for each different sample. If a compound was not in the compound list or a specific sample was never entered on the date, the concentration field contains the character string "---" for the sample. This value is not the same as an "NS" designation, which means that the user entered a "not sampled" value for a compound in the sample on the date.

The buttons on this window perform the following actions:

Quit

Press this button to exit this window.

Help

Press this button to bring up the Help window for this window.

Report

Press this button to write a report with the data shown in the table. Only compounds currently in the table are written.

Export

Press this button to display the Export window to export the data shown in the table. Only compounds currently in the table are written.

\subsection{EXPORT DATA. WINDOW}

The Export Data window allows all data on multiple dates to be exported. As shown in Figure 4.28 , the window lists dates for a specified matrix type.

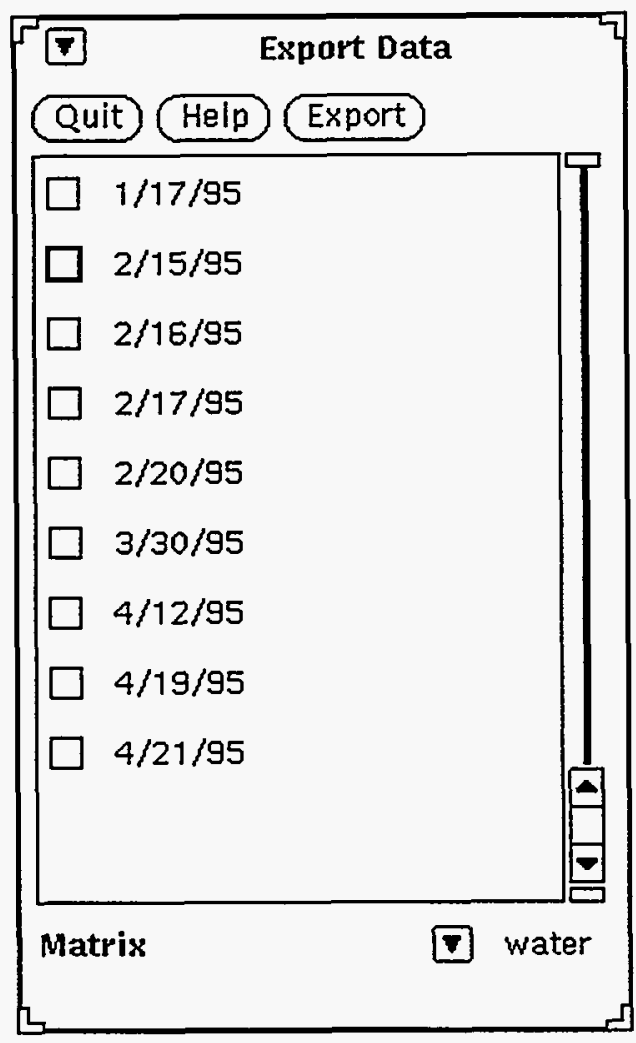

FIGURE 4.28 Export Data Window 
The buttons on this window perform the following actions:

Quit

Help

Export
Press this button to exit this window.

Press this button to bring up the Help window for this window.

Press this button to display the Export Window to export all data for the dates selected in the list. The Export window appears when you press this button.

\subsection{SAMPLE EXPORT SESSION}

Figure 4.29 shows the screen during a sample export session. After you select dates from the Export Data window, the Export window appears. When you press the OK or Apply button, the data are exported to the "temp.csv" file, listed in the window. If Xess is running, the sheet loads in the data from the file and writes it out in the "temp.xs" file. When the sheet is open, it displays the exported data. This file can be imported into SitePlanner.

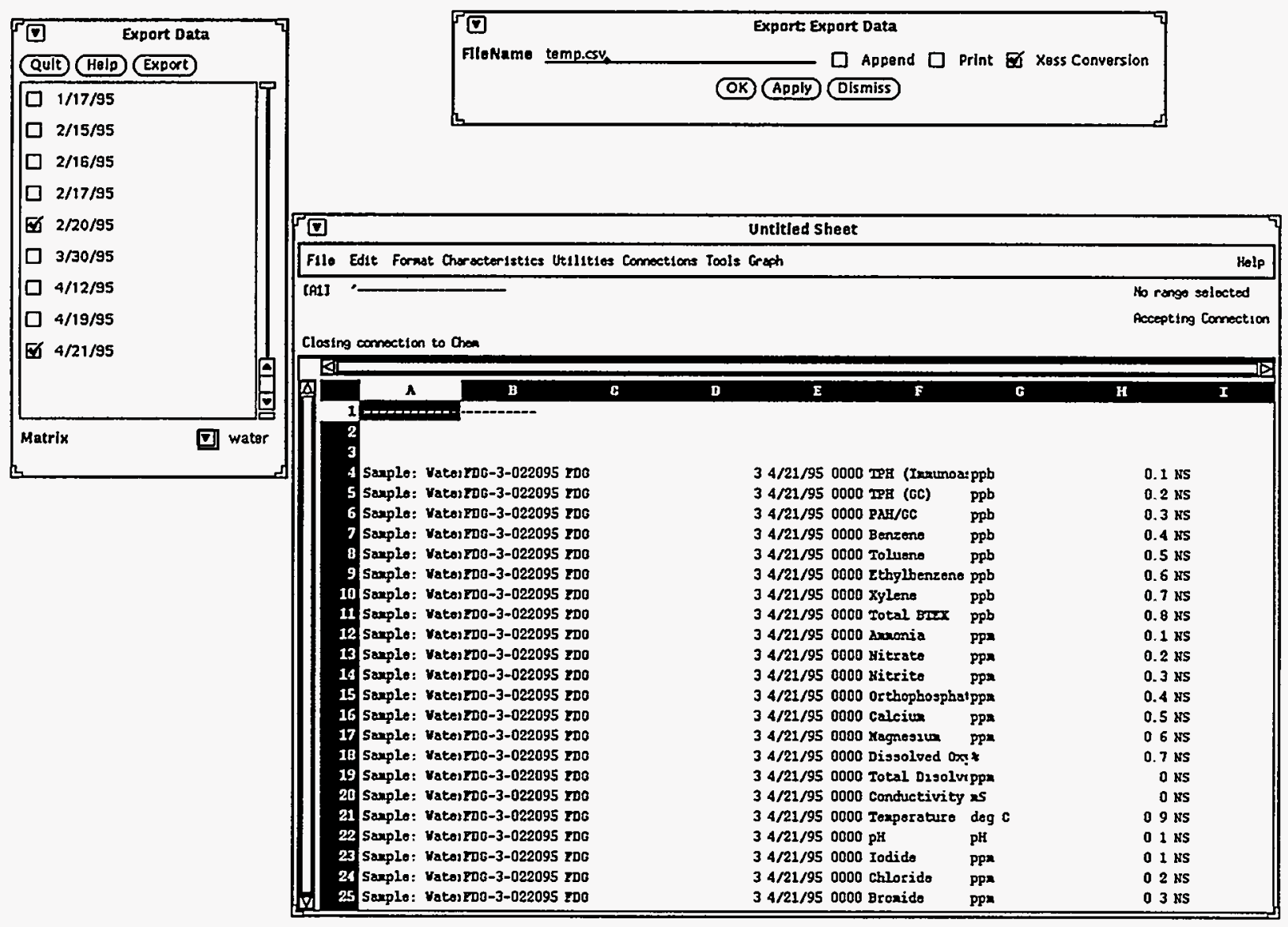




\section{DATA DISTRIBUTION}

\subsection{DATA DISTRIBUTION OVERVIEW}

The Data Distribution program is used to create diskettes with sample data for distribution to analysts at off-site locations and for backup copies. The program performs UNIX system commands for the user.

To start the Data Distribution program, enter OpenWindows and use a shell window. Change to the data directory that contains the desired data. This program works for both physical and chemical data. For the electronically sampled data, type the following command:

\section{cd /haw0/data}

Run the Data Distribution program by typing the following command in the same shell window:

\section{datadst}

\subsection{DATA DISTRIBUTION WINDOW}

The main window of the Data Distribution program is shown in Figure 5.1. The originating shell is also shown in this figure. The Data Distribution window contains two text fields for specifying the range of data to be included:

First Enter the first date to be included, in $\mathrm{mm} / \mathrm{dd} / \mathrm{yy}$ format. When you press return, the date: conversion to a Julian day is shown in the shell window.

Second Enter the last date to be included, in $\mathrm{mm} / \mathrm{dd} / \mathrm{yy}$ format. When you press return, the date: conversion to a Julian day is shown in the shell window.

The buttons on this window perform the following actions:

Quit Press this button to exit the Data Distribution program.

Create Press this button to create a tar file with data files in the specified range.

Tar

Copy to Press this button to copy the current tar file to a floppy disk. This button can Disk be pressed multiple times for multiple disks. Before pressing this button, insert a DOS-formatted, write-enabled floppy disk into the disk drive.

The window uses the UNIX tar command to create a tar file containing the data files in the current directory within the specified date range. First, the program creates a "/tmp/tar.lst" file. If 
this file cannot be overwritten because of permission conflicts, this process is unsuccessful. As the program creates this file, it lists the files that match the selected date range in the shell window (Figure 5.1). After creating the listing file, it issues a tar command to actually read in those files and create one composite "/tmp/tarfile" file. The program then compresses the file with the compress command to reduce its size, resulting in the "/tmp/tarfile.Z" file. Again, the permissions must be correct or these commands will not work. The best way to ensure that the permissions are correct is to have one user perform all data distribution functions.

After creating the tar file, the program copies it to a floppy disk when requested. The program uses the following command sequence:

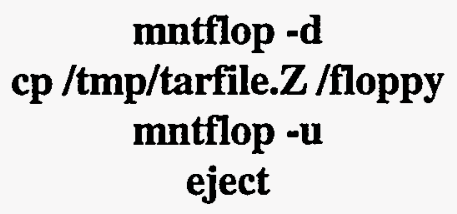

The diskette is ejected from the drive at the end of this sequence. If there is a problem mounting the floppy, an error message appears, as shown in Figure 5.2. A correct message is shown after this message in the figure. When completing a Data Distribution session, you can check to see whether the tar files were correctly created by using the following command:

\section{Is -ltr /tmp/tar*.*}

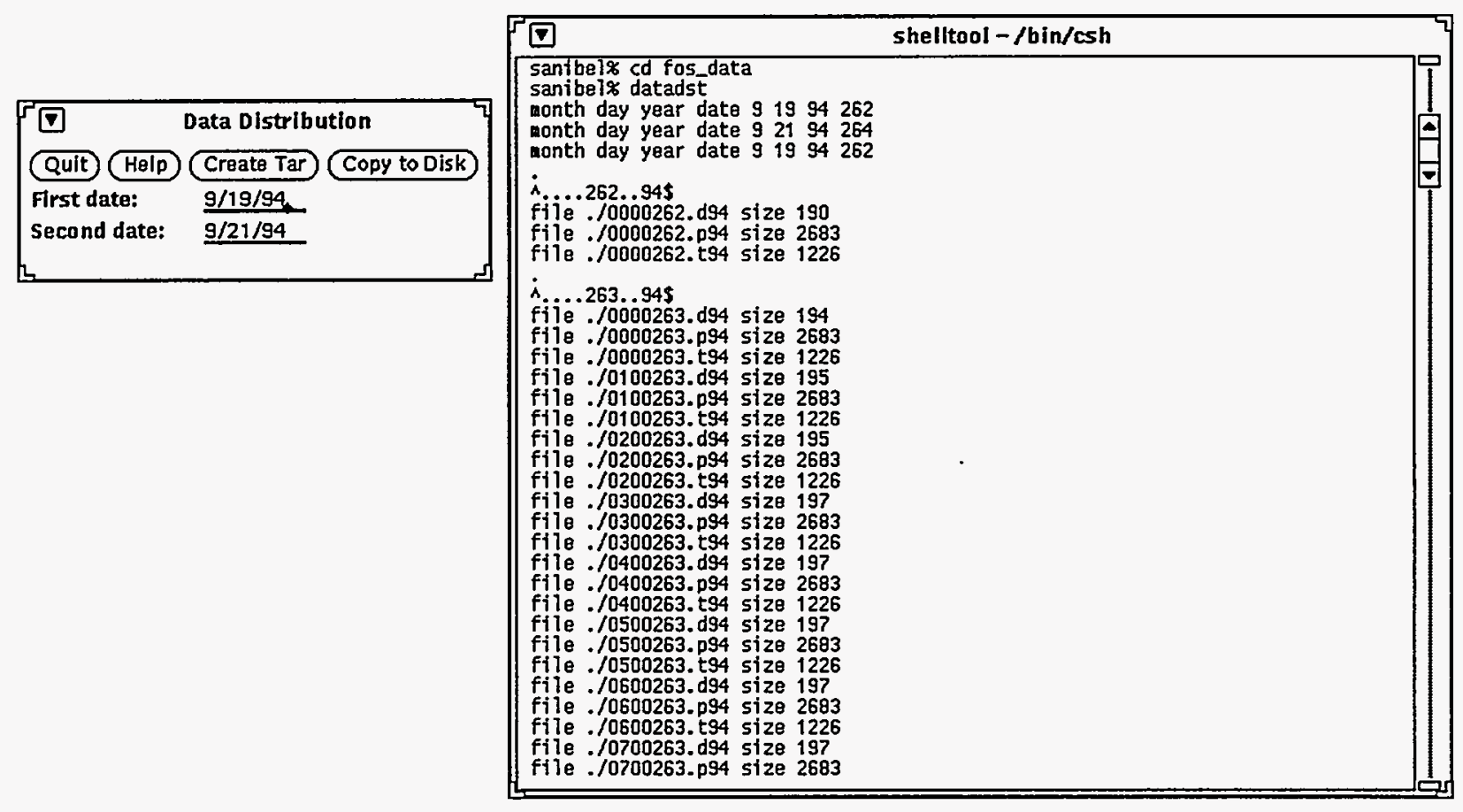

FIGURE 5.1 Data Distribution Window 
As shown in Figure 5.2, the files should be newly created and of a reasonable size. If this is not the case, there may be permission problems. Consult UNIX reference books for information on the "chmod," "umask," and other basic UNIX commands that control file permissions. On-line UNIX help is available through the "man" command on the Sun workstation.

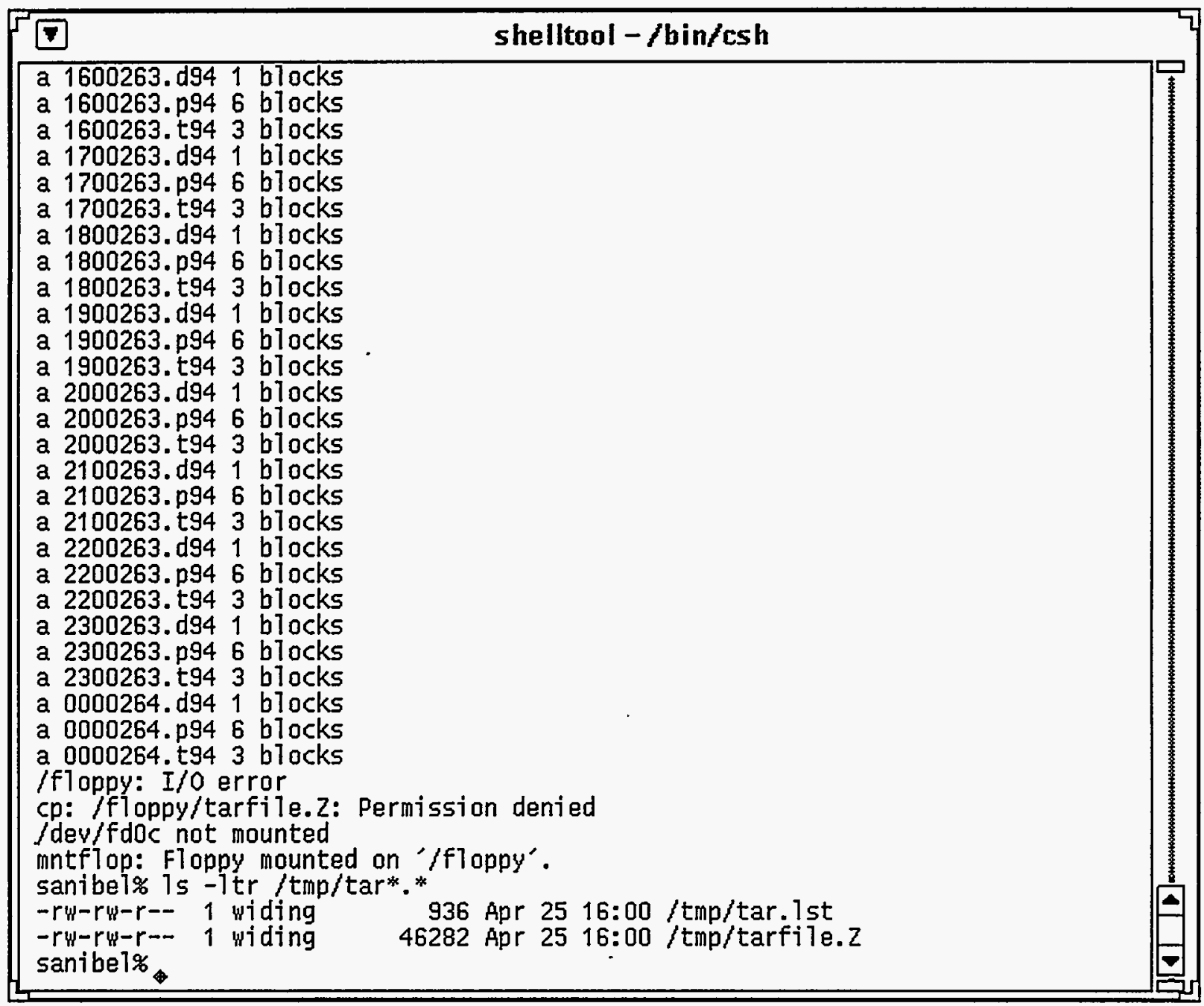

FIGURE 5.2 Shell Window after Data Distribution 


\section{TAPE BACKUP}

\subsection{TAPE BACKUP OVERVIEW}

The Tape Backup program is used to initialize new tapes each Monday. The program creates several text files for performing automated backups. The following files are used by the Tape Backup program:

backup.count This file stores three numbers corresponding to the current day of the week, number of the tape, and number of backup sets on the current tape. This file is in the "/usr/local/Backup" directory.

backup.status This file stores the status of all backups done on the computer. This file is in the "/usr/local/Backup" directory.

tape.head

This file stores the initialization data on the current tape. This file is in the "/haw0/data" directory.

To use the backup program, login as "operator" and enter OpenWindows. Use a shell window to bring up the program with the following commands:

\section{cd /usr/local/Backup bkup}

Remove the old tape for safe storage. Label and insert a new tape in the tape drive before proceeding.

\subsection{TAPE BACKUP WINDOW}

The Tape Backup window is used to initialize a tape and check on the status of the backups. As shown in Figure 6.1, the window contains a scrolling text region listing the status of the backups. Any problems are listed in the "backup.status" file displayed in this window. Mail is also sent to users when problems occur with the automated backups. A backup to tape is not performed every day. The data files from "/haw0/data" are copied to a backup data directory in the "/usr/local/Backup" area every day. Once a week, the data are dumped to the tape.

The buttons in this window perform the following actions:

Quit

Help
Press this button to exit the Tape Backup program.

Press this button to bring up the Help window for this window. This window is similar to the Help window in the Sensor Query Tool (Section 3.13). 
New Tape $\quad$ Press this button to initialize a tape for the backup utility to use.

Force Backup Press this button to force the backup utility to perform an immediate backup. The "/haw0/data" directory is copied to the backup area. A tape backup is only performed if it is the correct day, Sunday.

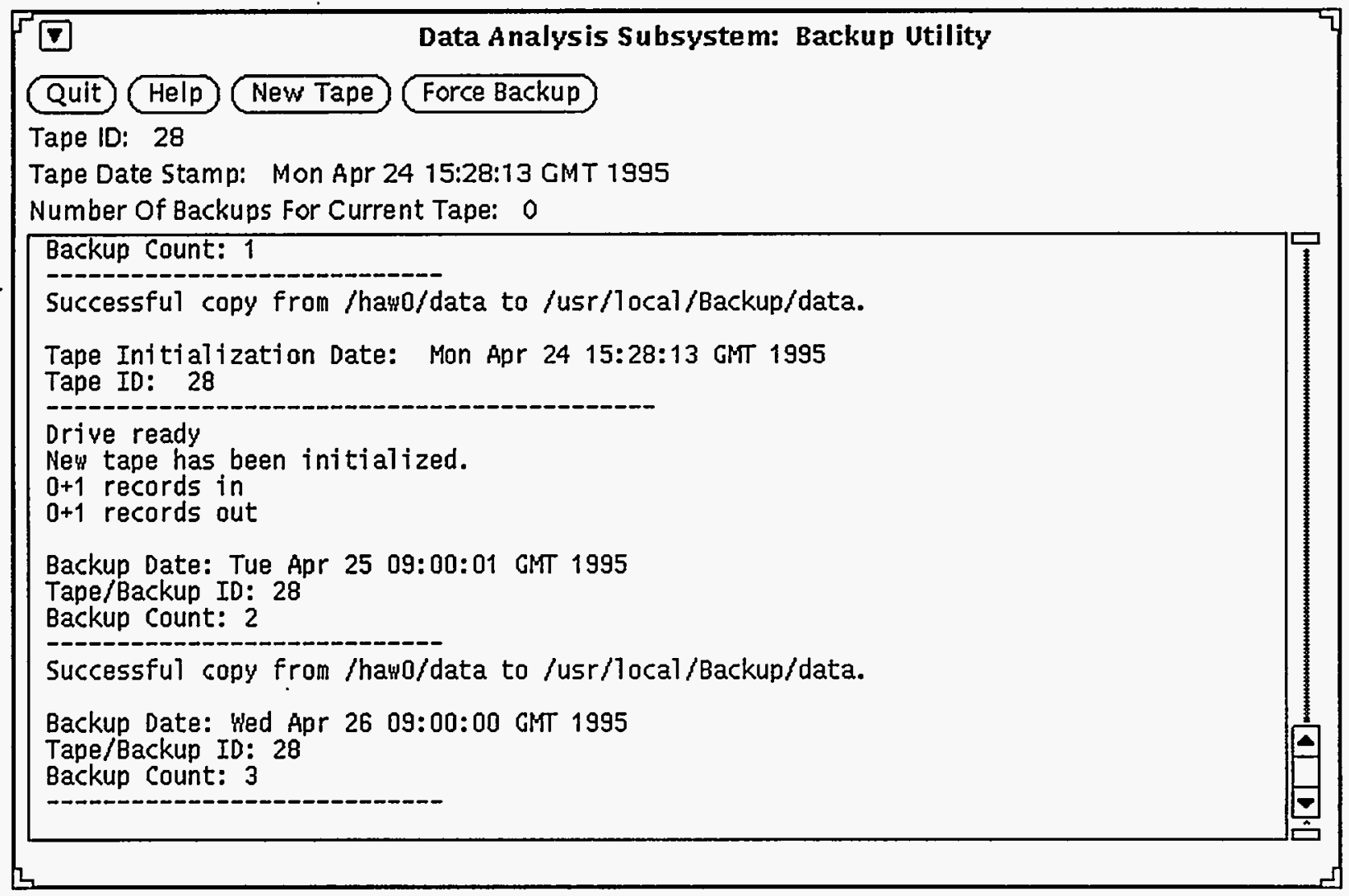

\section{FIGURE 6.1 Tape Backup Window}


APPENDIX A:

CHEMICAL COMPOUND LIST 
TABLE A.1 Chemical Compounds

\begin{tabular}{|c|c|c|}
\hline & Water & Air \\
\hline \multirow[t]{8}{*}{ Organics } & TPH (Immunoassay) & \\
\hline & TPH (GC) & \\
\hline & $\mathrm{PAH} / \mathrm{GC}$ & \\
\hline & Benzene & \\
\hline & Toluene & \\
\hline & Ethylbenzene & \\
\hline & Xylene & \\
\hline & Total BTEX & \\
\hline \multirow[t]{11}{*}{ Inorganics } & Ammonia & Carbon Dioxide \\
\hline & Nitrite & Oxygen \\
\hline & Nitrate & \\
\hline & Orthophosphate & \\
\hline & Calcium & \\
\hline & Magnesium & \\
\hline & Dissolved Oxygen & \\
\hline & Total Dissolved Solids & \\
\hline & Conductivity & \\
\hline & Temperature & \\
\hline & $\mathrm{pH}$ & \\
\hline \multirow[t]{14}{*}{ Tracers } & Iodide & \\
\hline & Chloride & \\
\hline & Bromide & \\
\hline & Rhodamine WT & \\
\hline & Fluorescein & \\
\hline & Pentafluorobenzoate & \\
\hline & 2,6-difluorobenzoate & \\
\hline & 2,3-difluorobenzoate & \\
\hline & 3,4-difluorobenzoate & \\
\hline & 3,5-difluorobenzoate & \\
\hline & Particle Tracer \#1 & \\
\hline & Particle Tracer \#2 & \\
\hline & Particle Tracer \#3 & \\
\hline & Particle Tracer \#4 & \\
\hline
\end{tabular}


APPENDIX B:

SAMPLE GRAPHS 
A data set was created by using all five stations for the wells PMB6, PMB7, and PMB8. The average adjusted pressure values were used. Data were saved with an hourly sampling period. The graphs in Figures B.1 through B.3 show the effect of changing the Sensor Groupings choice.

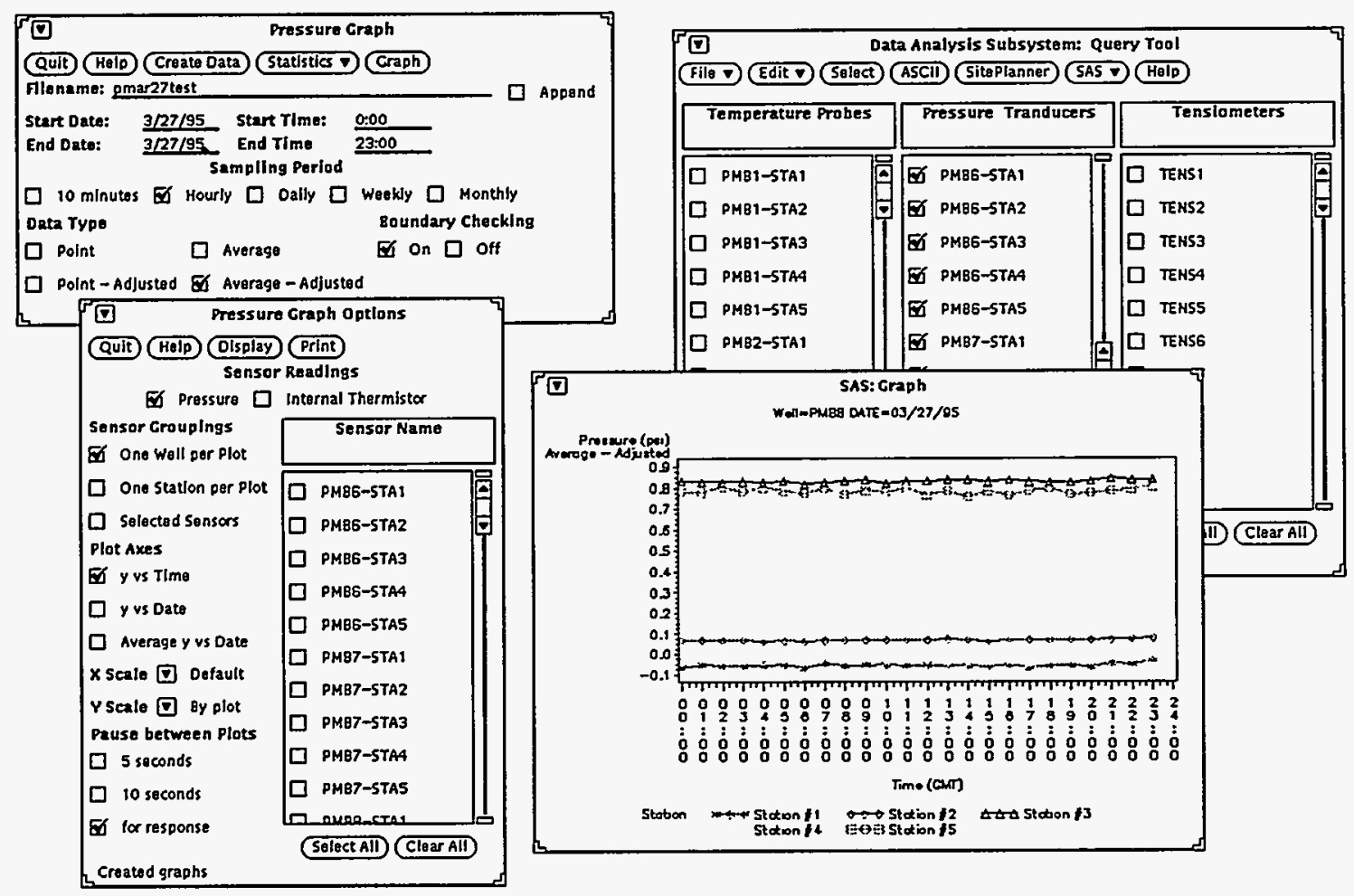

FIGURE B.1 One Well per Plot 


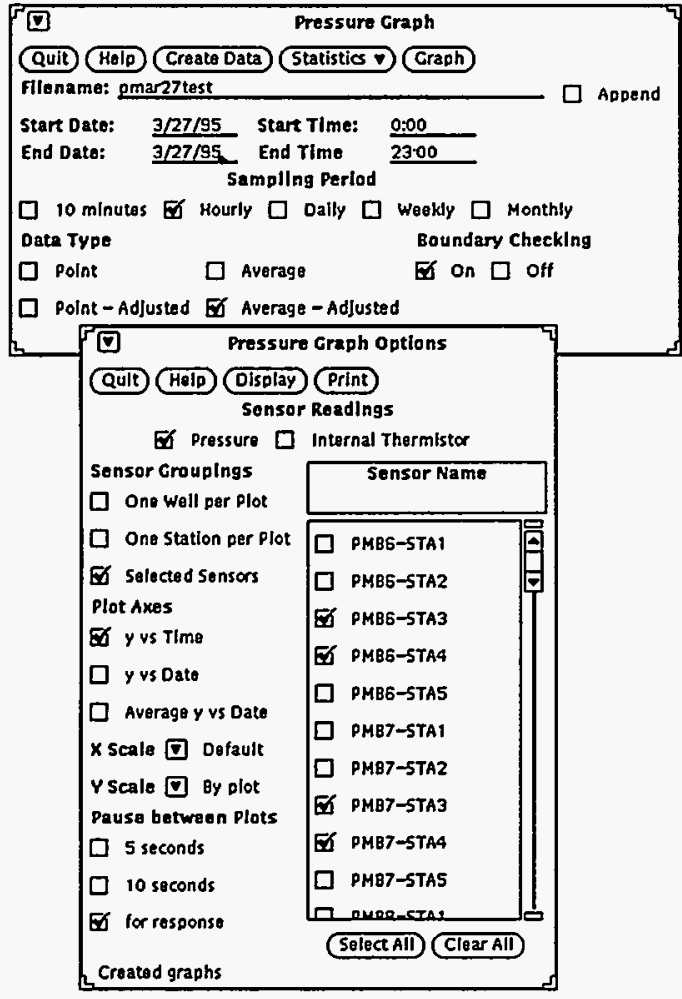

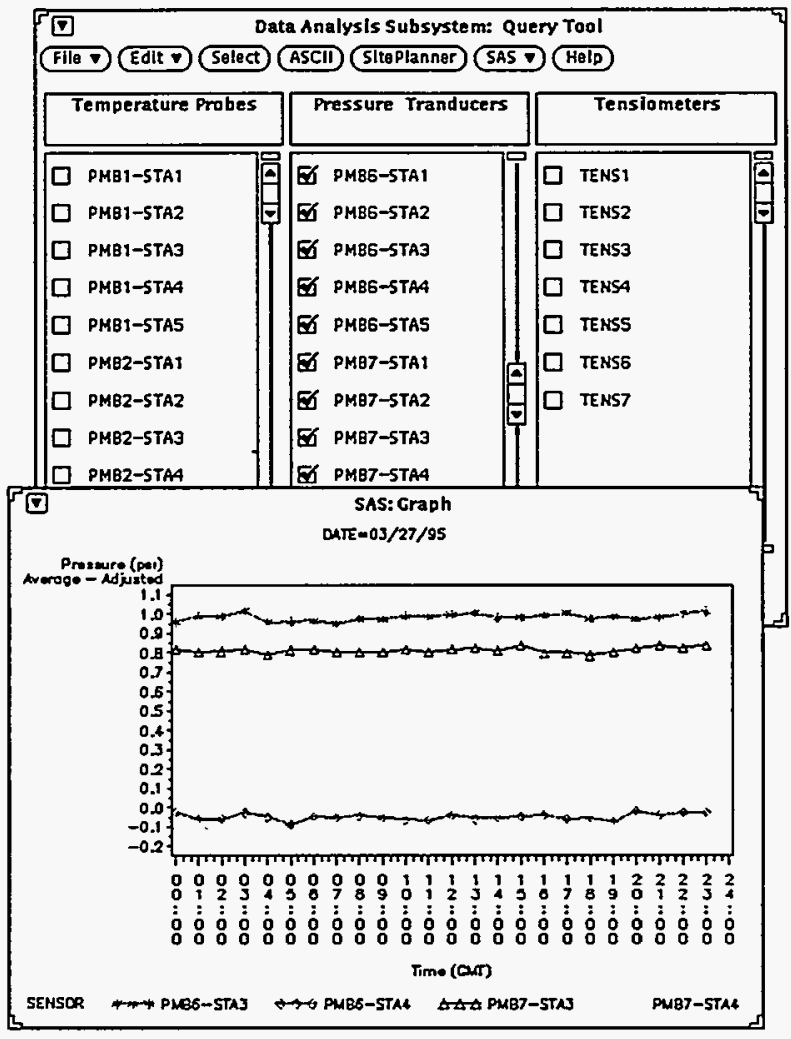

\section{FIGURE B.2 One Station per Plot}

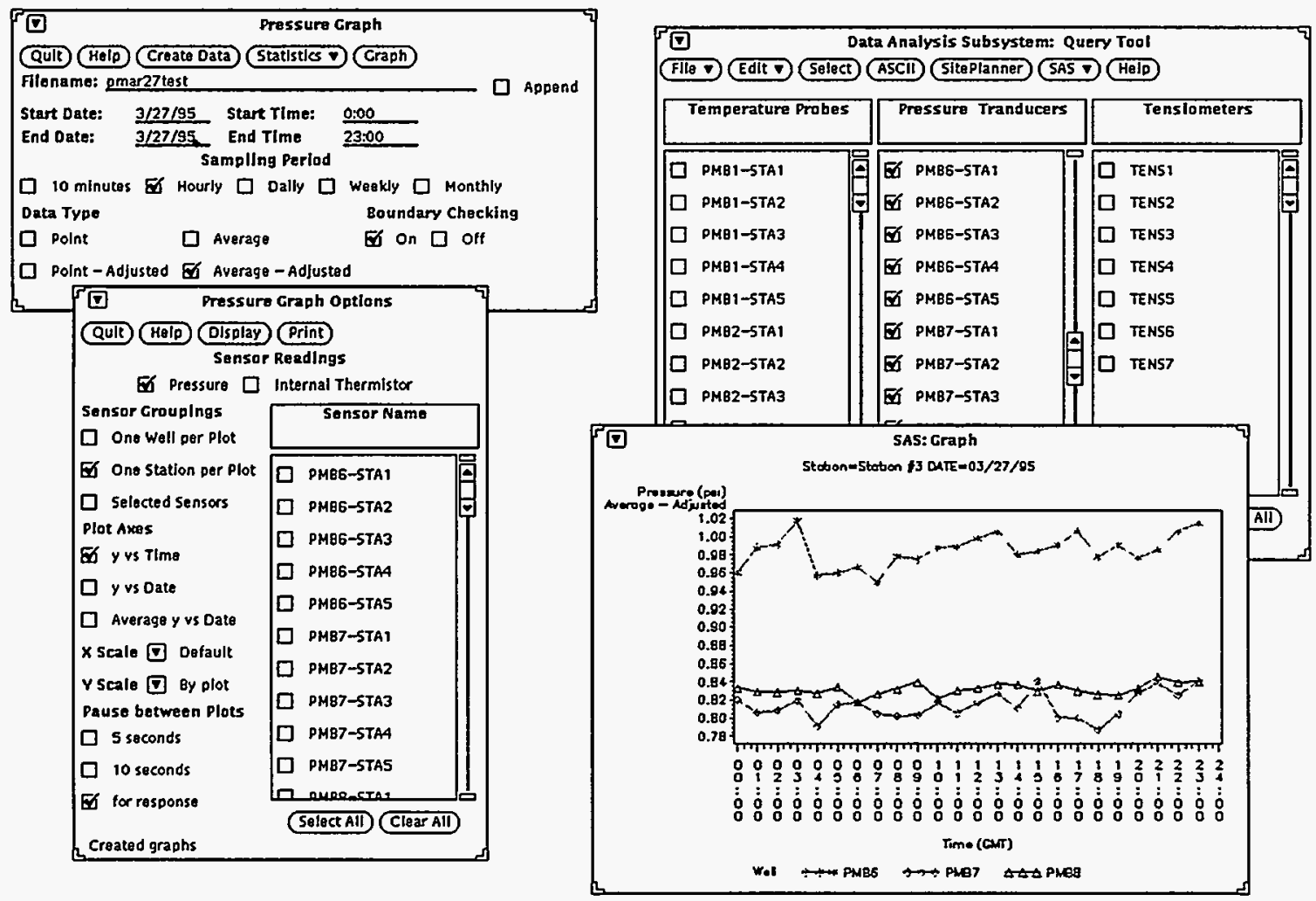


The next two plots show the use of the Y Scale choice. In Figure B.1, a value of Default was selected. In Figure B.4, a value of Uniform was selected. In Figure B.5, a value of Standard was selected. Note the relationship between the Boundaries Editing window and the final plot.

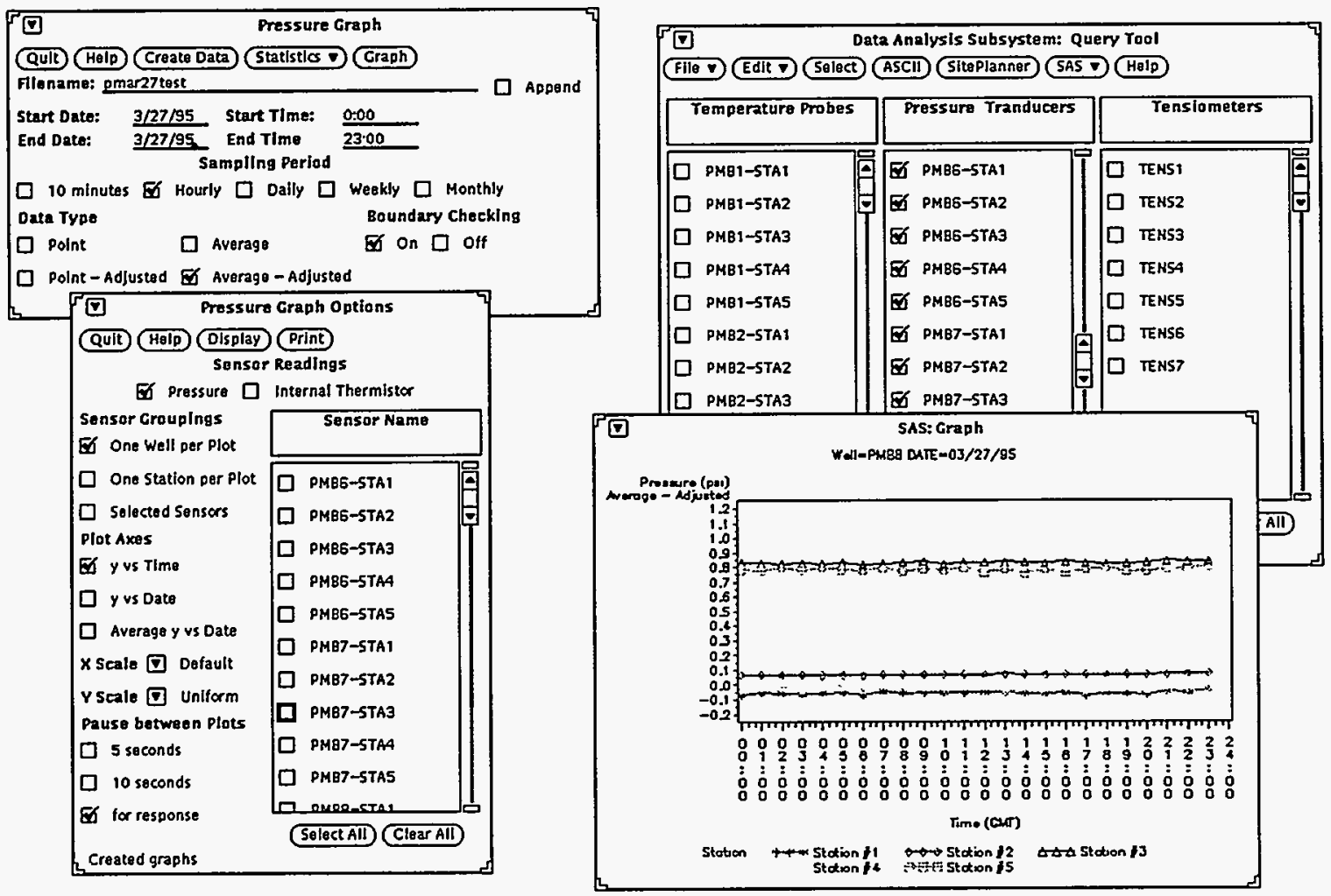

FIGURE B.4 Uniform Scaling on Y-Axis 


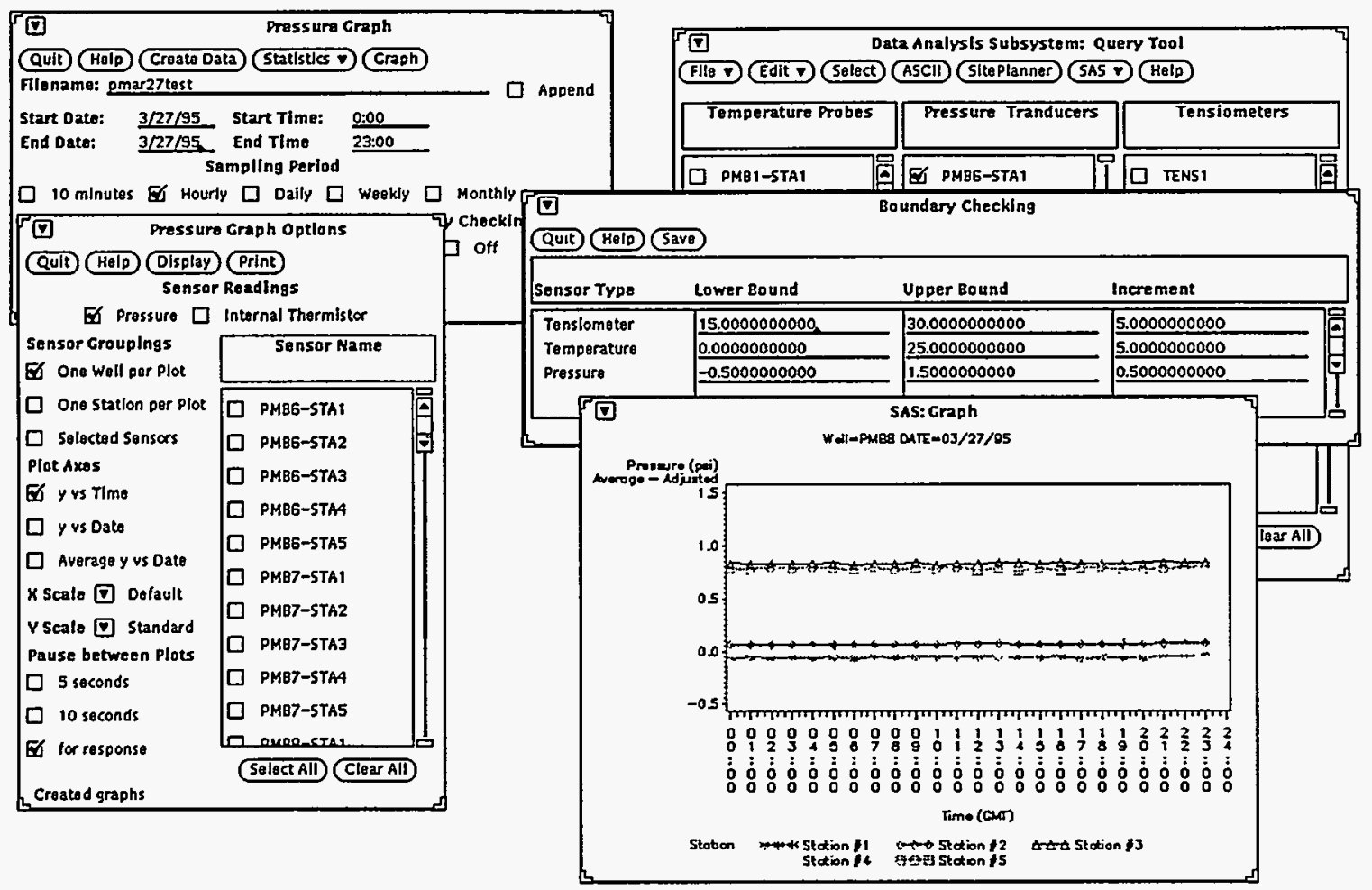

\section{FIGURE B.5 Standard Scaling on Y-Axis}


Figures B.6 through B.8 show graphs created with data sampled daily. Figure B.6 shows a graph with a X Scale choice of Default and a Y Scale choice of By Plot. Figure B.7 shows a graph with a X Scale choice of Day and a Y Scale choice of Standard. Figure B.8 shows a graph with an X Scale choice of Week. This figure illustrates the result of selecting an inappropriate scale.

\begin{tabular}{|c|c|c|}
\hline \multicolumn{3}{|c|}{$\begin{array}{l}\text { Pressura Craph } \\
\text { Quile (Hold Create Data) Statistlos D Craph }\end{array}$} \\
\hline \multicolumn{2}{|c|}{ 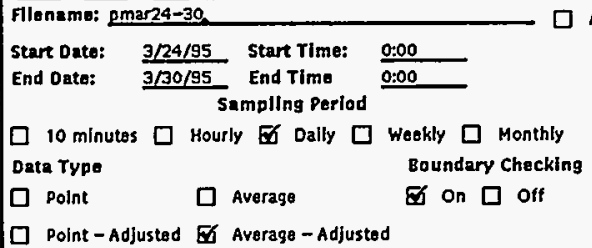 } & \\
\hline 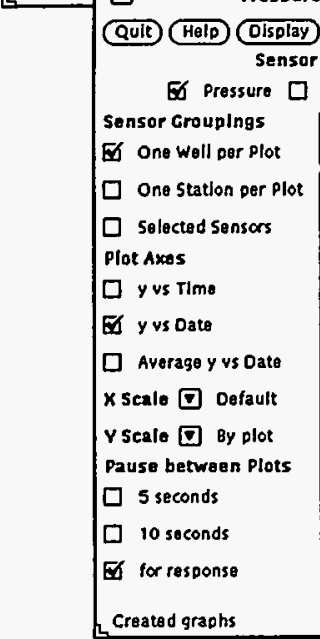 & 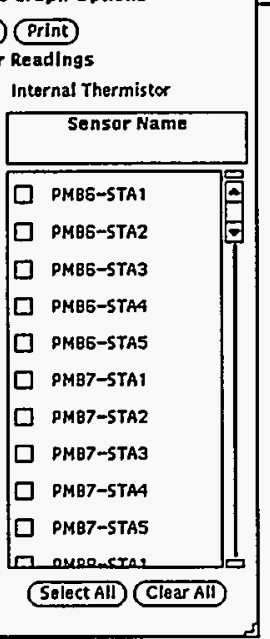 & \\
\hline
\end{tabular}

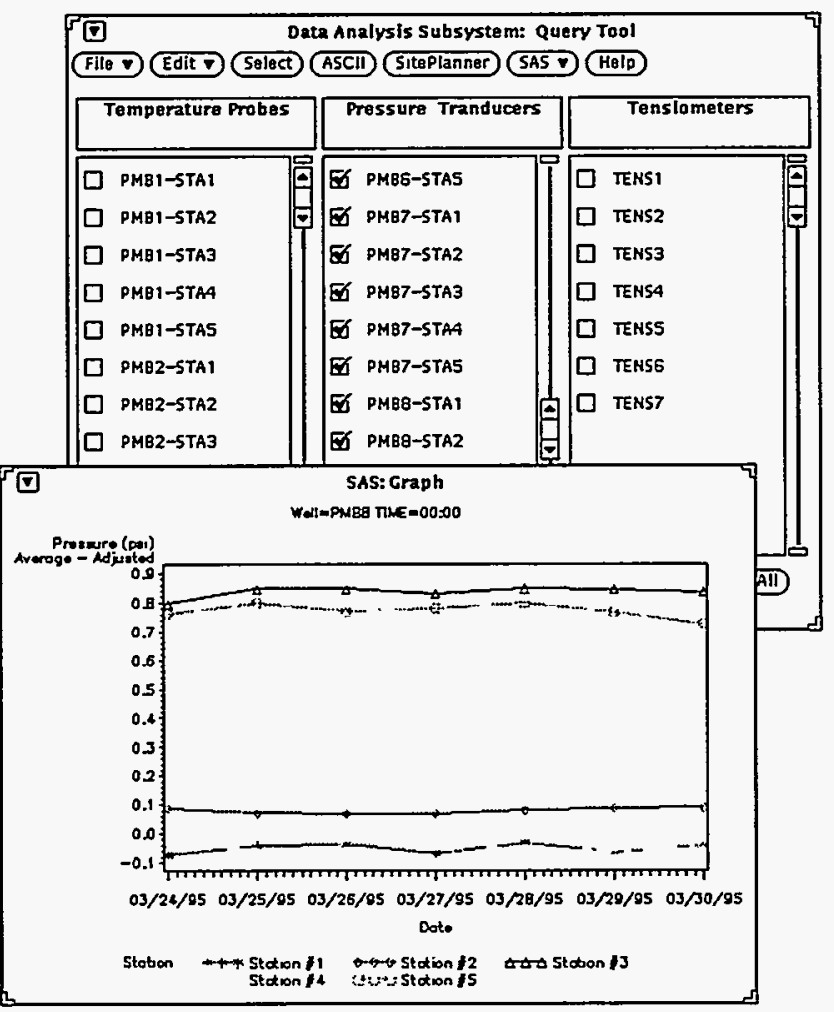

FIGURE B.6 Default Scaling on X-Axis 


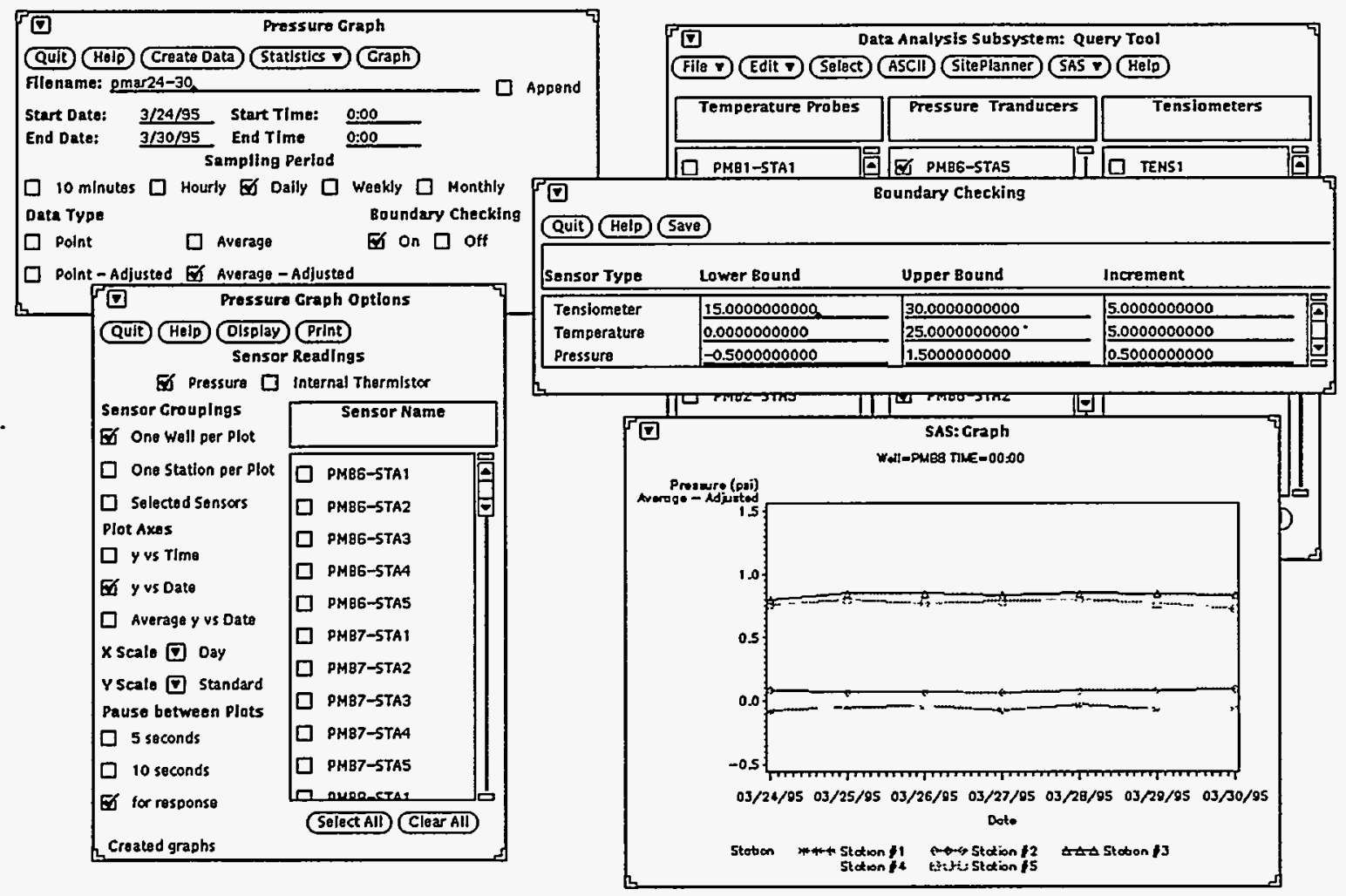

FIGURE B.7 Day Scaling on X-Axis

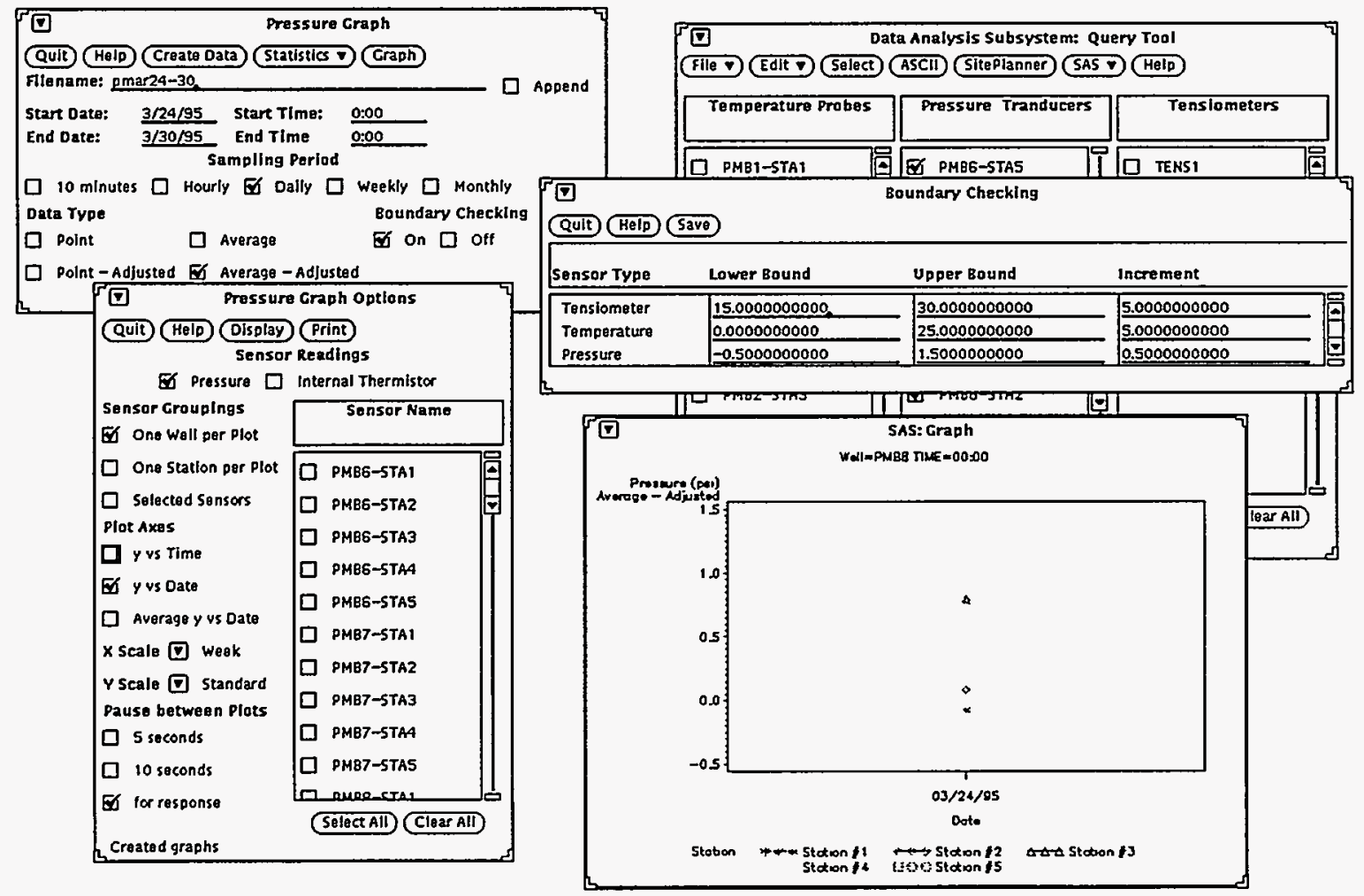


The next figure shows data sampled weekly. Figure B.9 shows an X Scale choice of Week and a Y Scale choice of By Plot.

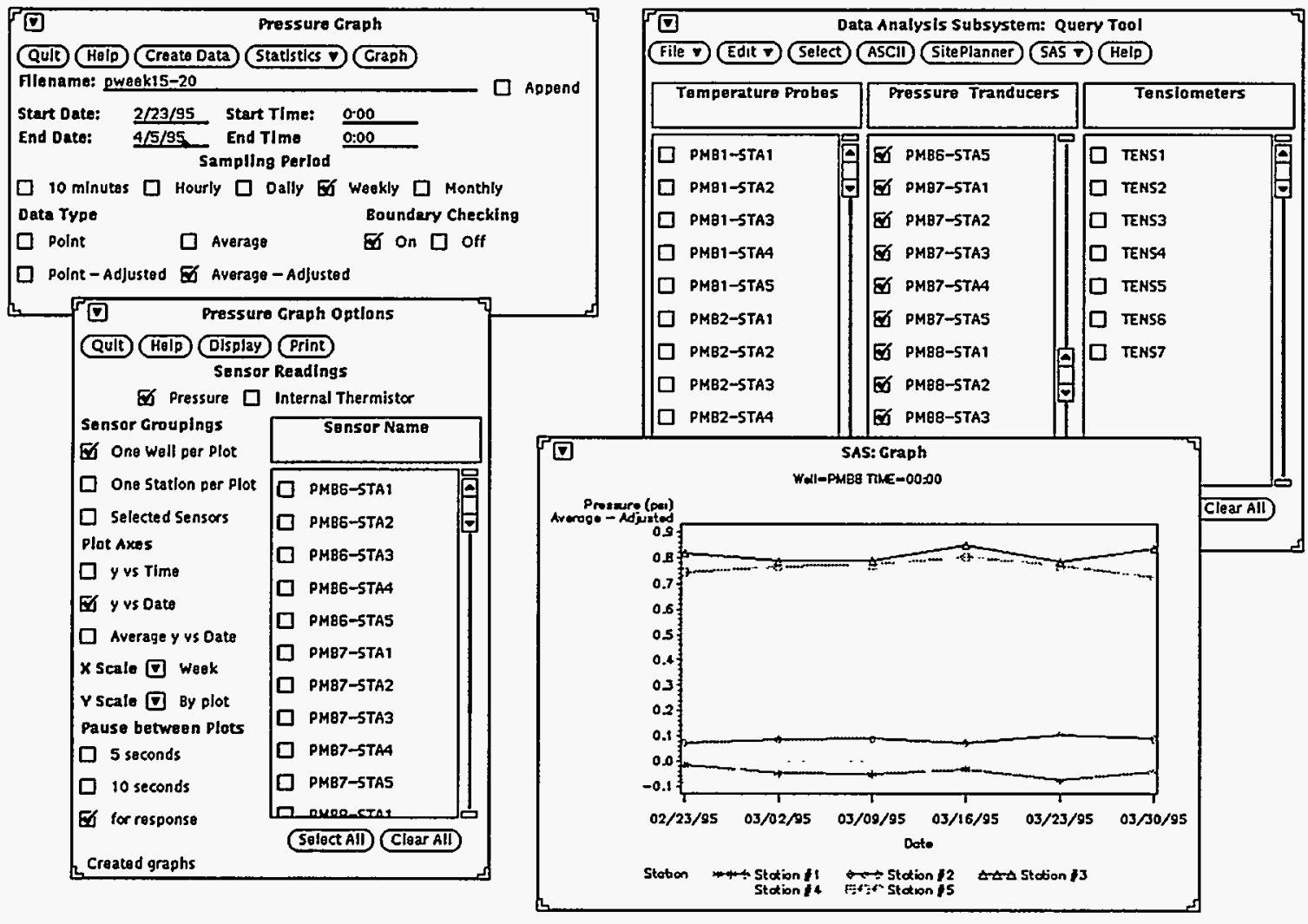

\section{FIGURE B.9 Weekly Sampled Data}


The next figure shows data that was sampled monthly. Figure B.10 shows a graph with an X Scale choice of Month and a Y Scale choice of By Plot.

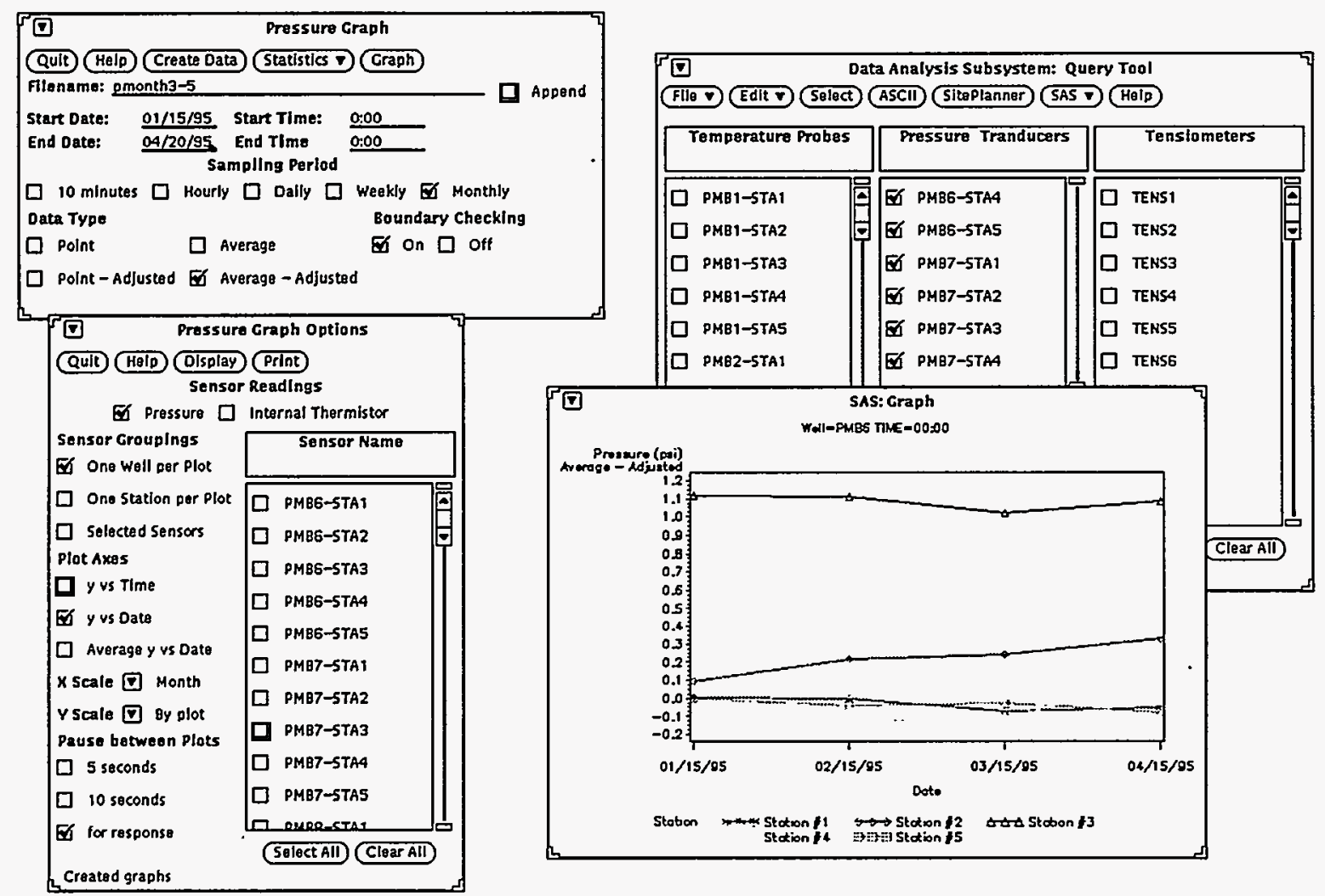

\section{FIGURE B.10 Monthly Sampled Data}


Figure B.11 shows a graph created with data sampled every 10 minutes. This option is appropriate for time periods in which the datalogger is sampling every 10 minutes. The program will not interpolate values if the time period is larger than 10 minutes.

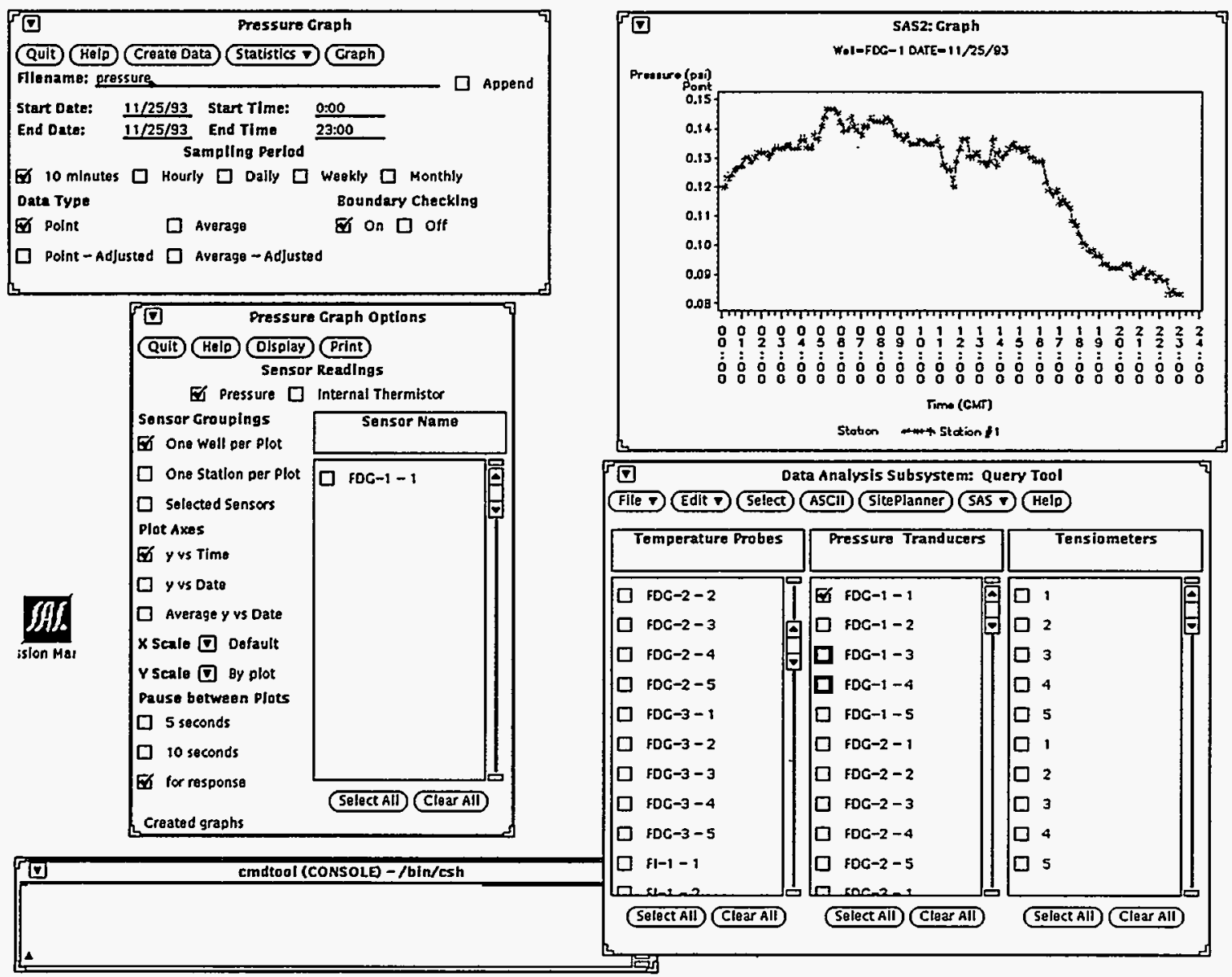

FIGURE B.11 10 Minute Sampled Data 
Figure B.12 shows a graph created with data sampled every hour. The data are averaged for each day using the statistics package in SAS. The average daily values are then plotted on the output graphs.

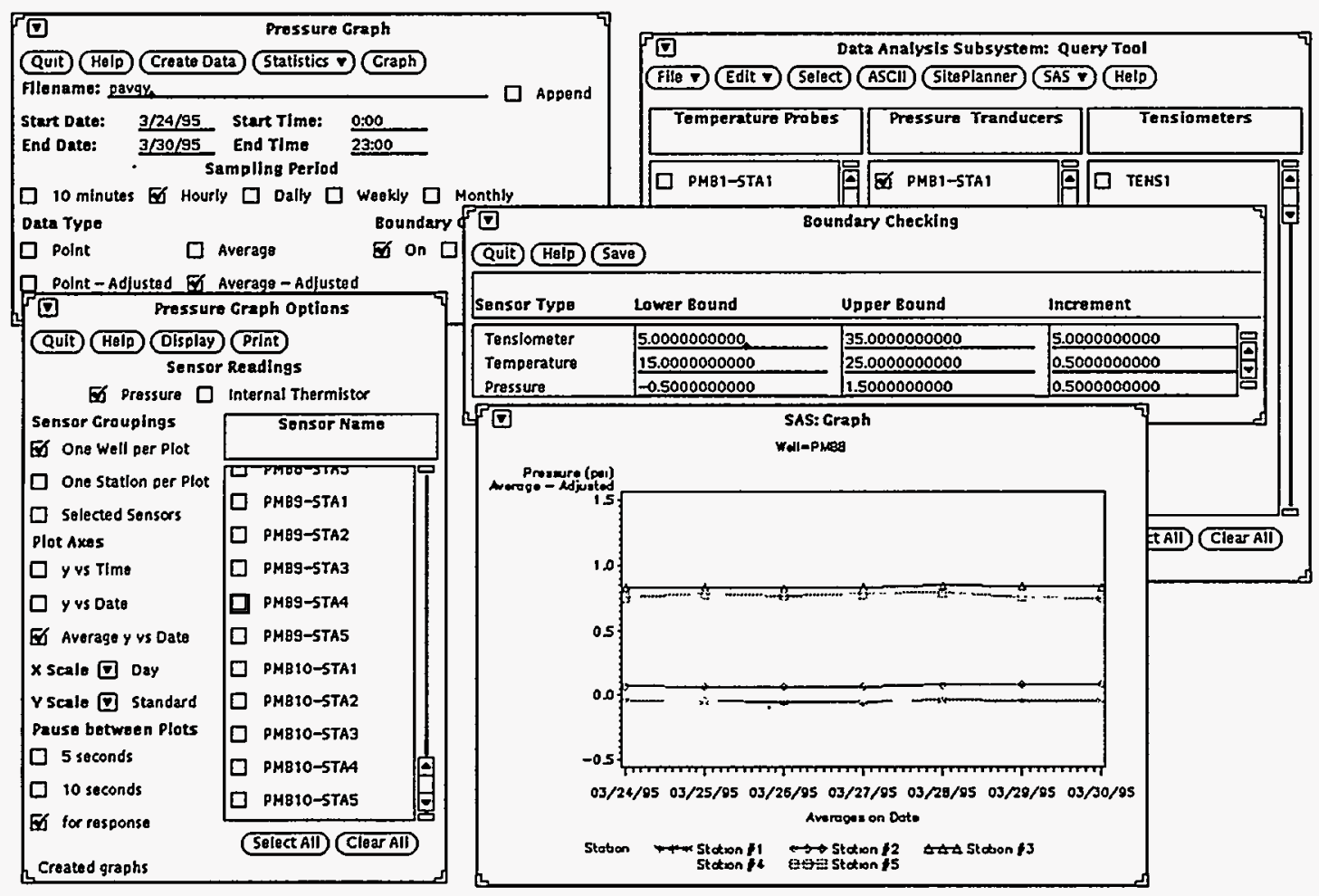

FIGURE B.12 Average y vs. Date 